\title{
Nitric oxide-releasing selective estrogen receptor modulators (NO-SERMs): a bifunctional approach to improve the therapeutic index
}

Nicole Bechmann ${ }^{1, \#}$, Torsten Kniess ${ }^{1}$, Jens Pietzsch ${ }^{1,2, *}$

${ }^{1}$ Helmholtz-Zentrum Dresden-Rossendorf, Institute of Radiopharmaceutical Cancer

Research, Department of Radiopharmaceutical and Chemical Biology, 01328 Dresden, Germany

${ }^{2}$ Technische Universität Dresden, School of Science, Faculty of Chemistry and Food Chemistry, 01069 Dresden, Germany

\#Present address: Technische Universität Dresden, University Hospital Carl Gustav Carus, Institute for Clinical Chemistry and Laboratory Medicine, Fetscherstraße 74, 01307 Dresden, Germany

\section{Table of Contents}

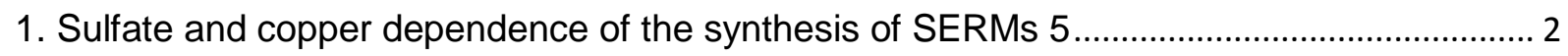

2. Synthesis of hydroxy-1-(4-(methylsulfonyl)phenyl)alkan-1-one ............................................. 3

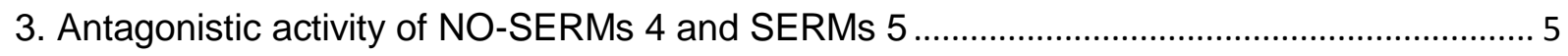

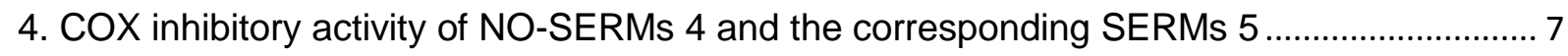

5. Characterization of the novel NO-SERMs 4 and corresponding SERMs 5 .......................... 8

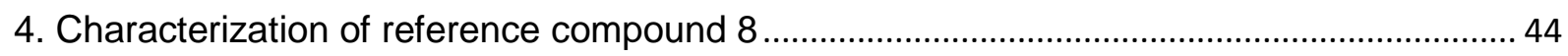




\section{Sulfate and copper dependence of the synthesis of SERMs 5}

The sulfate and cupper dependence of the reaction of the chlorinated derivatives $\mathbf{3 a - d}$ to SERMs $\mathbf{5 a - d}$ was analyzed by HPLC. As model the reaction of the chlorinated derivative 3a to SERM 5a was used. Therefore, the reaction was performed in presence of $\mathrm{CuSO}_{4} \times 5 \mathrm{H}_{2} \mathrm{O}, \mathrm{FeSO}_{4} \times 7 \mathrm{H}_{2} \mathrm{O}, \mathrm{MgSO}_{4} \times 7 \mathrm{H}_{2} \mathrm{O}$, $\mathrm{Na}_{2} \mathrm{SO}_{4}$ or in absence of cupper and sulfate in DMSO/water (Fig S1). Interestingly, after $24 \mathrm{~h}$ heating at $130^{\circ} \mathrm{C}$ the reaction in absence of copper and sulfate resulted in a nearly quantitative conversion of $3 \mathrm{a}$ to $5 \mathbf{a}$. In contrast, in presence of sulfates the reaction takes place with formation of an intermediate product, which might result in a lower yield also after $48 \mathrm{~h}$ heating. These findings suggest that the reaction follows a $\mathrm{S}_{\mathrm{N}} 2$ mechanism with the hydroxyl ions from water, whereby DMSO is necessary as aprotic-polar solvent and to enhance the solubility of the educt.

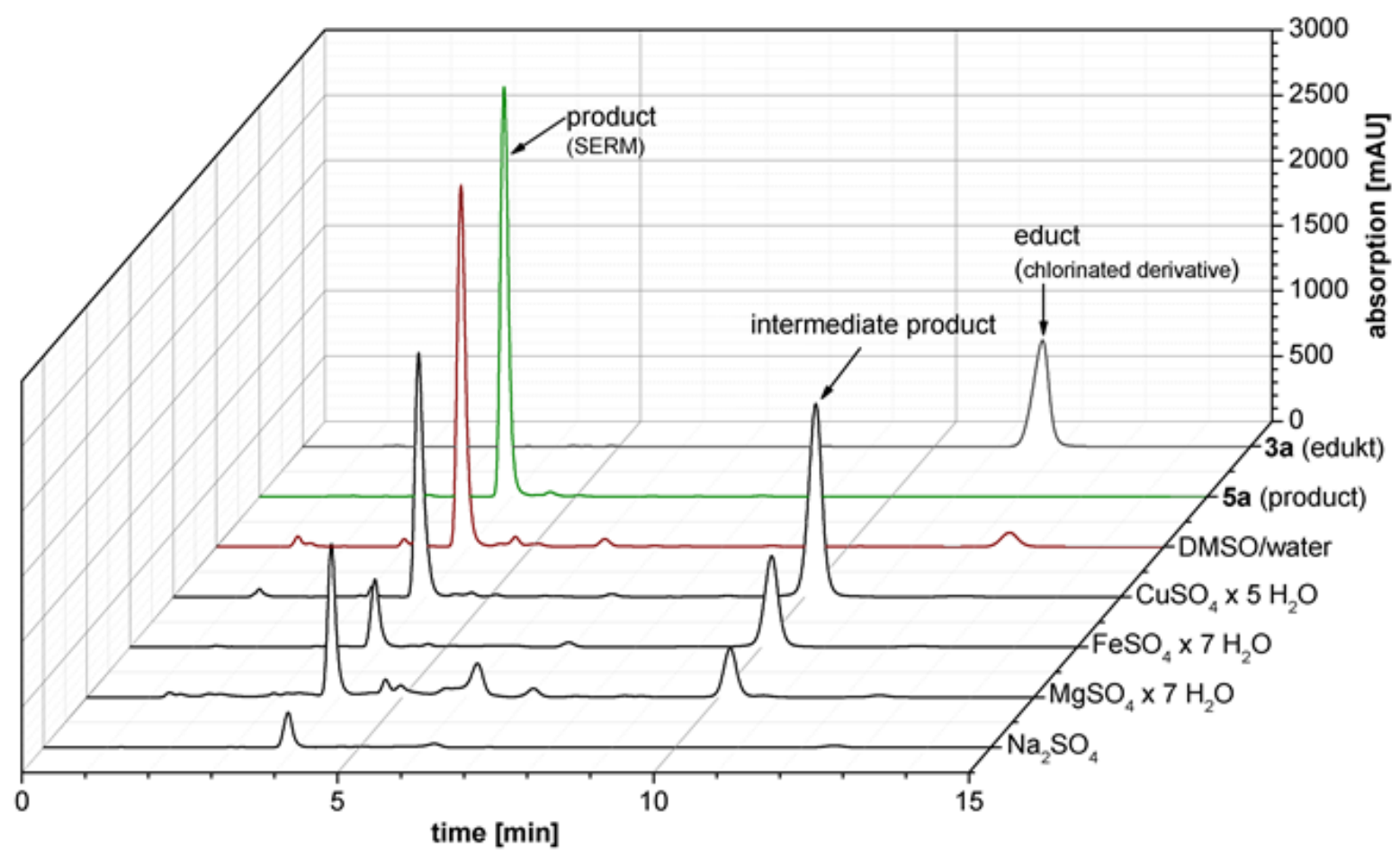

Figure S1: Analysis of sulfate and copper dependence of the reaction of chlorinated derivative 3a to SERM $5 a$.

The reaction mixtures were analyzed after $24 \mathrm{~h}$ heating at $130^{\circ} \mathrm{C}$ by HPLC. Conditions: Agilent 1100 series, PFP Kinetex C18 with precolumn (Phenomenex); isocratic: $50 / 50$, acetonitrile/water (v/v); flow rate $=1 \mathrm{~mL} / \mathrm{min} ; \mathrm{UV}=254$ $\mathrm{nm}$. 


\section{Synthesis of hydroxy-1-(4-(methylsulfonyl)phenyl)alkan-1-one}

First we tried the direct synthesis of 5-hydroxy-1-(4-(methylsulfonyl)phenyl)pentan-1-one (III) by the reaction of 1-bromo-4-(methylsulfonyl)benzene (I) and $\delta$-valerolactone (II) (Fig S2) following the reaction conditions previously described by Miao et al. ${ }^{1}$. They postulated a lithium-halogen-exchange on the aromatic ring (I) with $\mathrm{n}$-BuLi as first step of the reaction followed by a nucleophilic ring opening of the subsequently added lactone (II). Because of the electron-withdrawing character of the sulfonyl group and the resulting high $\mathrm{CH}$ acidity of the methyl sulfonyl group occurred the reaction in a lithium-halogenexchange on the methyl group. The ${ }^{1} \mathrm{H}$ NMR spectra of the resulting 1-((4-bromophenyl)sulfonyl)-6hydroxyhexan-2-one (IV) is shown in figure S3.<smiles>CS(=O)(=O)c1ccc(Br)cc1</smiles>

I<smiles>O=C1CCCCO1</smiles>

II

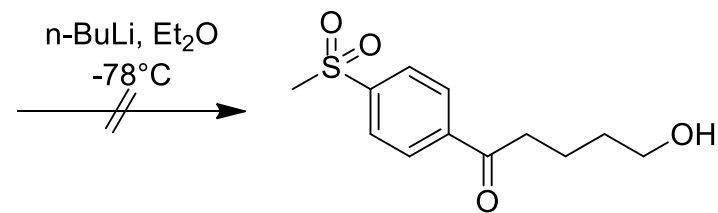

III<smiles>CCCCCCCC(=O)CS(=O)(=O)c1ccc(Br)cc1</smiles>

IV

Figure S2: Synthesis route 1 for the synthesis of 5-hydroxy-1-(4-(methylsulfonyl)phenyl)pentan-1-one (III)

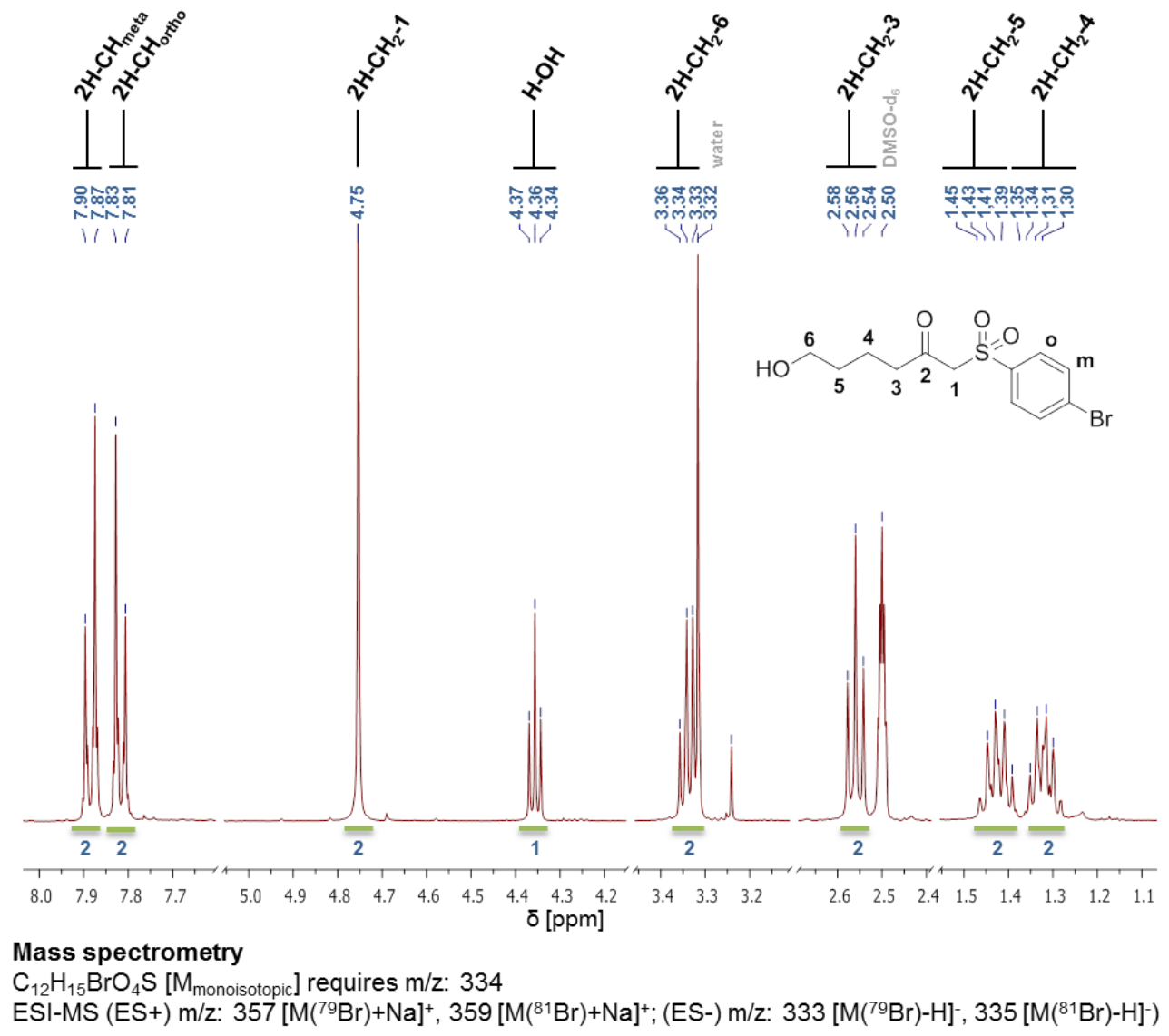

Figure S3: Characterization of 5-hydroxy-1-(4-(methylsulfonyl)phenyl)pentan-1-one (III) by ${ }^{1} \mathrm{H}$ NMR and mass spectrometry 
In the next step we tried to prefer the lithium-halogen-exchange at the aromatic ring by using 4bromothioanisole $(\mathbf{V})$ for the reaction (Fig S4). By using the methyl thio substituent $(-I$, but $+M)$ the nucleophilic ring opening was successfully, but 5-hydroxy-1-(4-(methylthio)phenyl)pentan-1-one (VI) exists in equilibrium with the hemiacetal derivative VII. The hemiacetal VII is not useful for the following McMurry olefination. Therefore, the reaction sequence illustrated in figure 1 (manuscript) was used for the synthesis of the triaryl olefin lead structure.

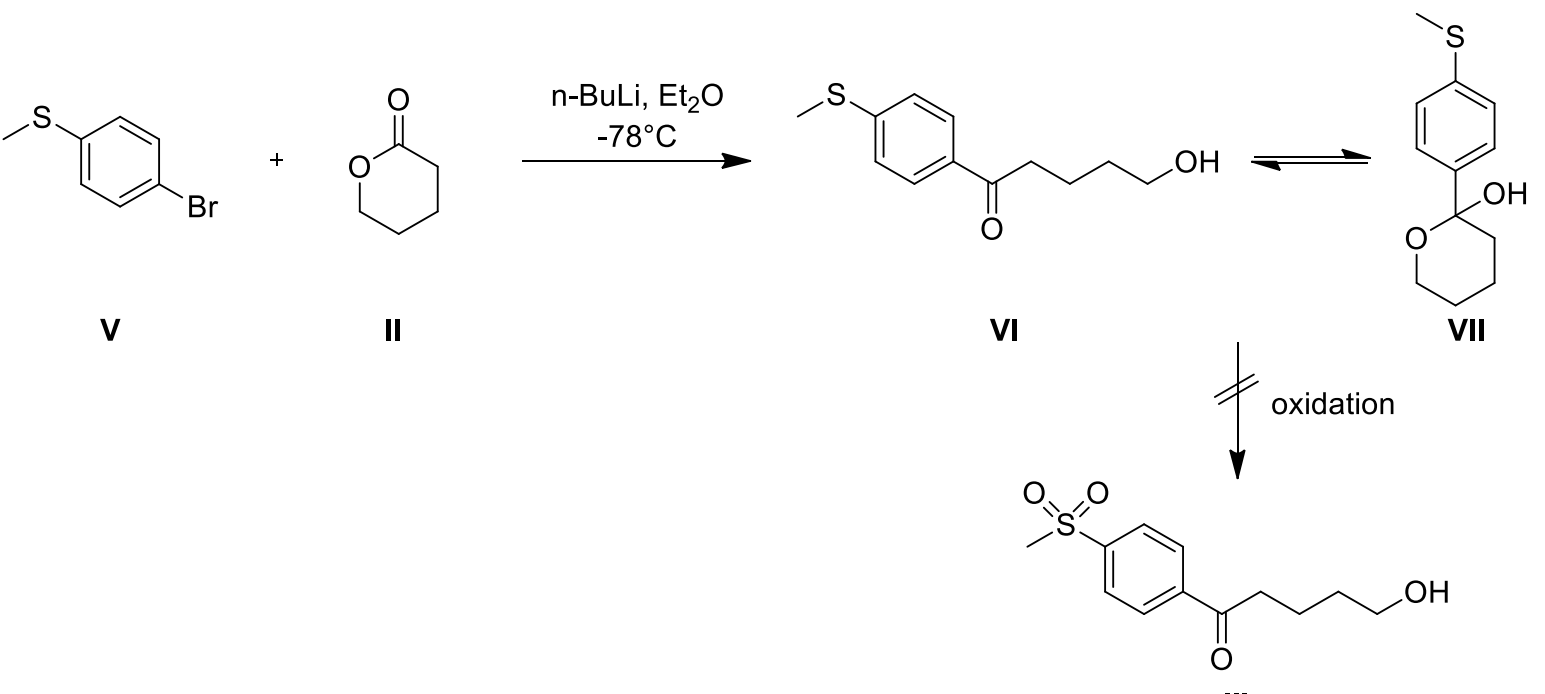

III

Figure S4: Synthesis route 2 for the synthesis of 5-hydroxy-1-(4-(methylsulfonyl)phenyl)pentan-1-one (III) 


\section{Antagonistic activity of NO-SERMs 4 and SERMs 5}
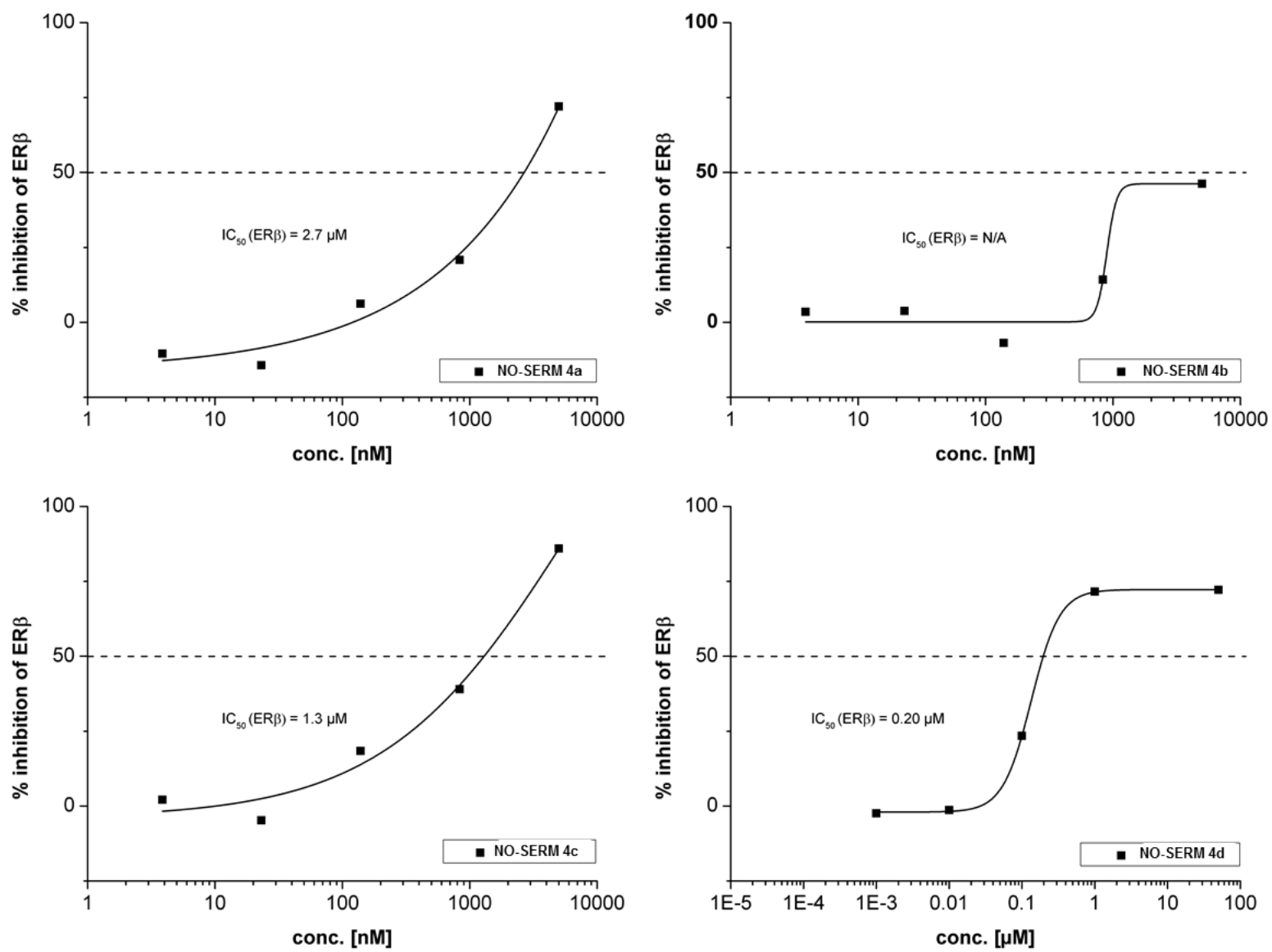

Figure S5: Dose-response curves of the ERß inhibition by NO-SERMs 4.

The dose-dependent antagonistic activity of NO-SERMs 4 on ERß was analyzed by using the human estrogen receptor beta reporter assay. Mean $(n=2)$. The $I_{50}$ values were calculated by non-linear fitting (Software: Origin, logistic fit). $\mathbf{4 d}$ was analyzed in a higher concentration range. 

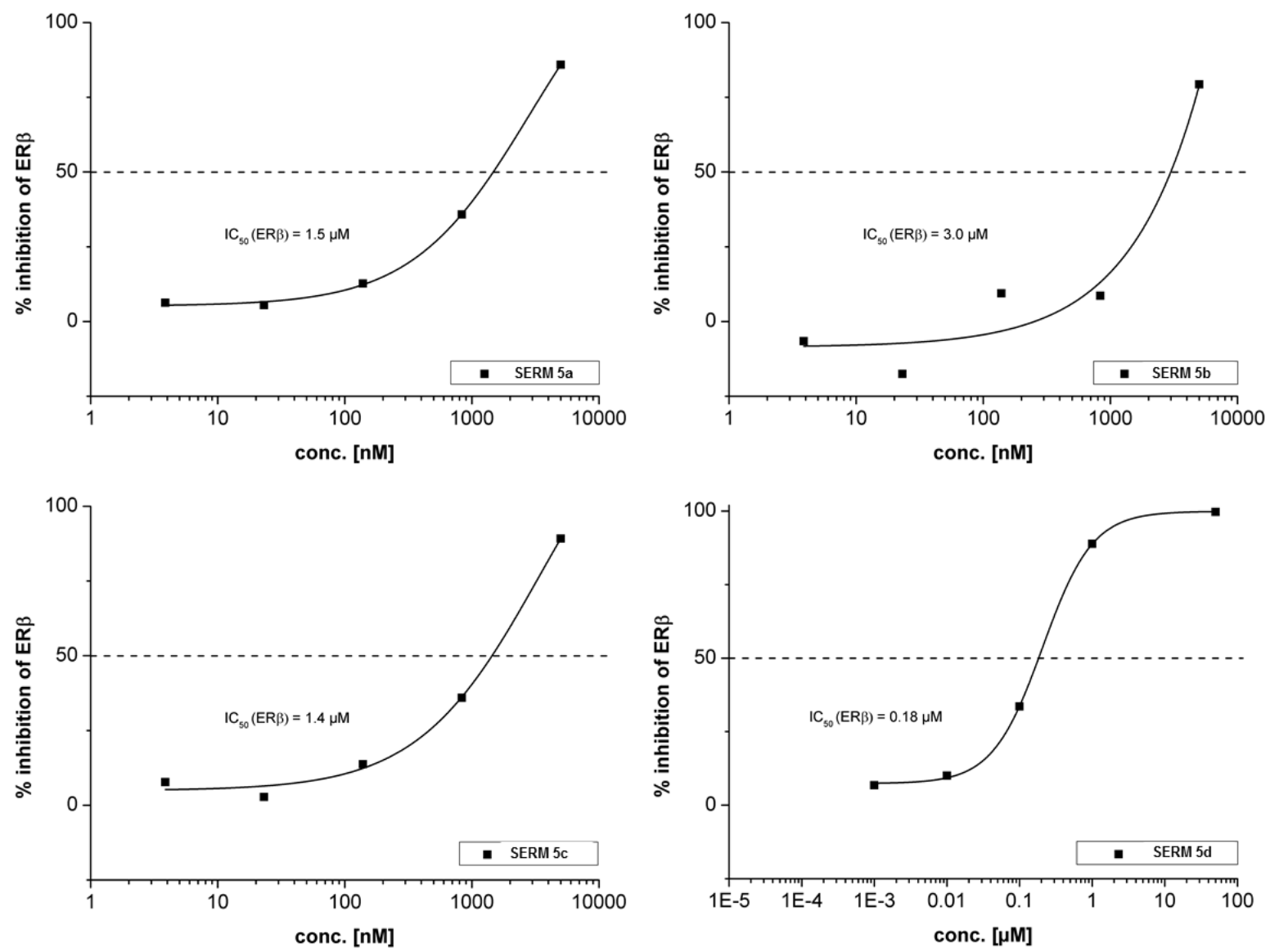

Figure S6: Dose-response curves of the ER $\beta$ inhibition by SERMs 5.

The dose-dependent antagonistic activity of SERMs 5 on ERß was analyzed by using the human estrogen receptor beta reporter assay. Mean $(n=2)$. The IC 50 values were calculated by non-linear fitting (Software: Origin, logistic fit). $\mathbf{5 d}$ was analyzed in a higher concentration range. 


\section{COX inhibitory activity of NO-SERMs 4 and the corresponding SERMs 5}

Acyclic triaryl olefins with a methansulfonyl group were previously described as excellent and selective COX-2 inhibitors. ${ }^{2-6}$ Particularly, (2-(4-(methylsulfonyl)phenyl)hex-1-ene-1,1diyl)dibenzene was described with a high COX-2 affinity and selectivity $\left(\mathrm{IC}_{50}(\mathrm{COX}-1)>100 \mu \mathrm{M}\right.$, $\left.\mathrm{IC}_{50}(\mathrm{COX}-2)=0.014 \mu \mathrm{M}\right){ }^{6}$ Therefore, the COX affinity of the novel compounds was determined by using a "COX Fluorescent Inhibitor Screening Assay Kit" (Cayman Chemical, Ann Arbor, MI, USA, cat. No. 700100) as described previously by us. ${ }^{8}$ Interestingly, the modification of the alkyl substituent resulted in a totally loss of the affinity for COX-2 and COX-1 (Tab S1). Both the hydroxyl derivatives 5 and the nitroester derivatives $\mathbf{4}$ showed no inhibition of COX. Surprisingly, also the introduction of the fluorine substituents on the unsubstituted phenyl rings (compound 8 ) resulted in a complete loss of the COX affinity. The COX-2 inhibitory activity of the novel compounds was confirmed by using a second assay ("COX-2 Inhibitor Screening Assay Kit", Cayman Chemical, Item No. 701080, Data not shown), which allows the quantification of PGF $2 a$ that arise by the oxidation with $\mathrm{SnCl}_{2}$ of the COX-2 derived $\mathrm{PGH}_{2}$. The second assay was used to make sure that the novel compounds are not interacting with the reagents of the first assay and thereby affected the results. The assay was performed according to manufacturer's instructions. In brief, two different concentrations of the novel compounds ( 100 and $10 \mu \mathrm{M})$ were used. All reagents and materials, expect the enzyme solution, were tempered at $37^{\circ} \mathrm{C}$. To allow enzyme-inhibitor-interactions the reaction mixture was incubated for $10 \mathrm{~min}$ at $37^{\circ} \mathrm{C}$ under permanent shaking. After the completed enzyme-immuno-reaction the absorption was measured by using Synergy HT plate reader (BioTek Instruments, Bad Friedrichshall, Germany) at $410 \mathrm{~nm}$. In complementation to the data from Chen results the modification of (2-(4(methylsulfonyl)phenyl)hex-1-ene-1,1-diyl)dibenzene on the methyl sulfonyl group ${ }^{7}$, the alkyl chain as well as on the benzene substituents in a total loss of the COX affinity of the triaryl olefin derivatives. All three groups used different COX-1/COX-2 assays. ${ }^{6-8}$ The $\mathrm{IC}_{50}$ values of (2-(4(methylsulfonyl)phenyl)hex-1-ene-1,1-diyl)dibenzene and the other triaryl olefins should be evaluated in the same assay for a better comparability.

Table S1: In vitro COX-1 and COX-2 inhibition data from the triaryl olefins 4, 5 and 6.

\begin{tabular}{|c|c|c|c|c|c|c|c|c|c|}
\hline \multicolumn{5}{|c|}{ nitroester compounds } & \multicolumn{5}{|c|}{ hydroxy reference compounds } \\
\hline compound & \multirow[t]{2}{*}{$\log P^{1}$} & \multicolumn{2}{|c|}{$\mathrm{IC}_{50}[\mu \mathrm{M}]$} & \multirow[t]{2}{*}{$\mathrm{COX}-2 \mathrm{SI}^{2}$} & \multirow[t]{2}{*}{ compound } & \multirow[t]{2}{*}{$\log P^{1}$} & \multicolumn{2}{|c|}{$\mathrm{IC}_{50}[\mu \mathrm{M}]$} & \multirow[t]{2}{*}{$\mathrm{COX}-2 \mathrm{SI}^{2}$} \\
\hline & & $\operatorname{cox}-1$ & $\operatorname{cox}-2$ & & & & $\operatorname{cox}-1$ & $\operatorname{cox}-2$ & \\
\hline $4 a$ & 5.48 & $>100$ & $>100$ & 1 & $5 a$ & 4.12 & $>100$ & $>100$ & 1 \\
\hline $4 b$ & 5.75 & $>100$ & $>100$ & 1 & $5 b$ & 4.44 & $>100$ & $>100$ & 1 \\
\hline 4c & 5.94 & $>100$ & $>100$ & 1 & $5 c$ & 4.54 & $>100$ & $>100$ & 1 \\
\hline $4 d$ & 6.21 & $>100$ & $>100$ & 1 & $5 d$ & 4.85 & $>100$ & $>100$ & 1 \\
\hline \multicolumn{10}{|c|}{ reference compounds } \\
\hline 6 & 6.05 & $>100$ & $>100$ & 1 & celecoxib & 4.34 & $>100$ & 0.13 & $>769.2$ \\
\hline \multicolumn{10}{|c|}{$\begin{array}{l}1 \text { calculated by ChemBioDraw Ultra } \\
2 \text { values are means of two determinations using a fluorescence based COX inhibitory assay (“COX Fluorescent } \\
\text { Inhibitor Screening Assay Kit”, Cayman Chemicals Inc. Ann Arbor, MI, USA, cat. No. 700100). The test } \\
\text { compounds were used in a concentration range of } 0.01 \mu \mathrm{M} \text { to } 100 \mu \mathrm{M} \text { and was limited by the solubility of the } \\
\text { compounds. The IC50 value was received using a non-linear fitting (Software: Origin } \circledast \text {, logistic fit). }\end{array}$} \\
\hline $2 \quad$ coX-2s & electivity & hdex (SI) & $n$ vitro $(\mathrm{IC}$ & ${ }_{50}(\mathrm{COX}-1) / \mathrm{I}$ & $\left.{ }_{50}(\mathrm{COX}-2)\right)$ & & & & \\
\hline
\end{tabular}


5. Characterization of the novel NO-SERMs 4 and corresponding SERMs 5

4-chloro-1-(4-(methylthio)phenyl)butan-1-one (1a)

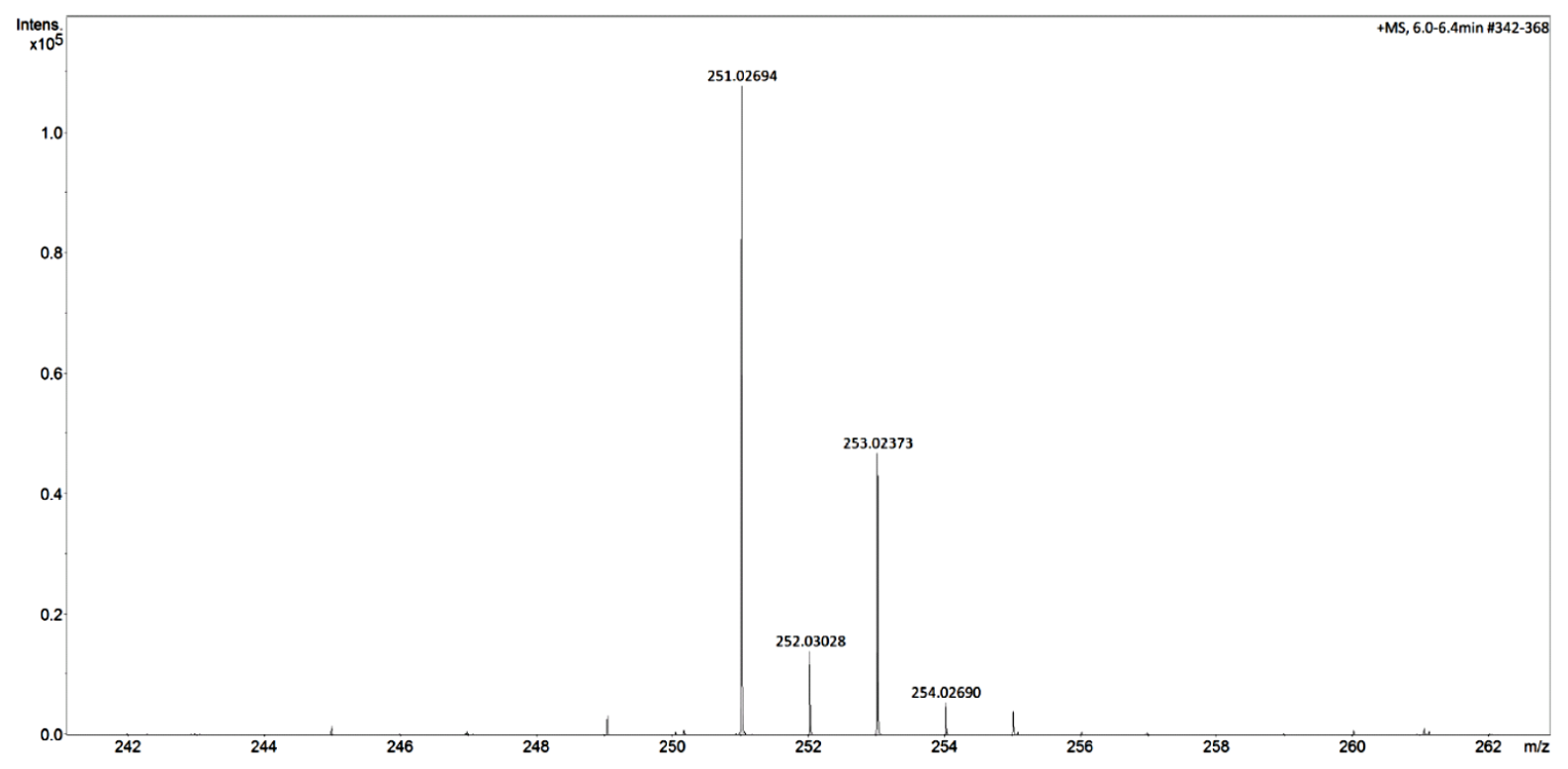

Figure S7: Section of the HRMS spectra of 4-chloro-1-(4-(methylthio)phenyl)butan-1-one (1a) 

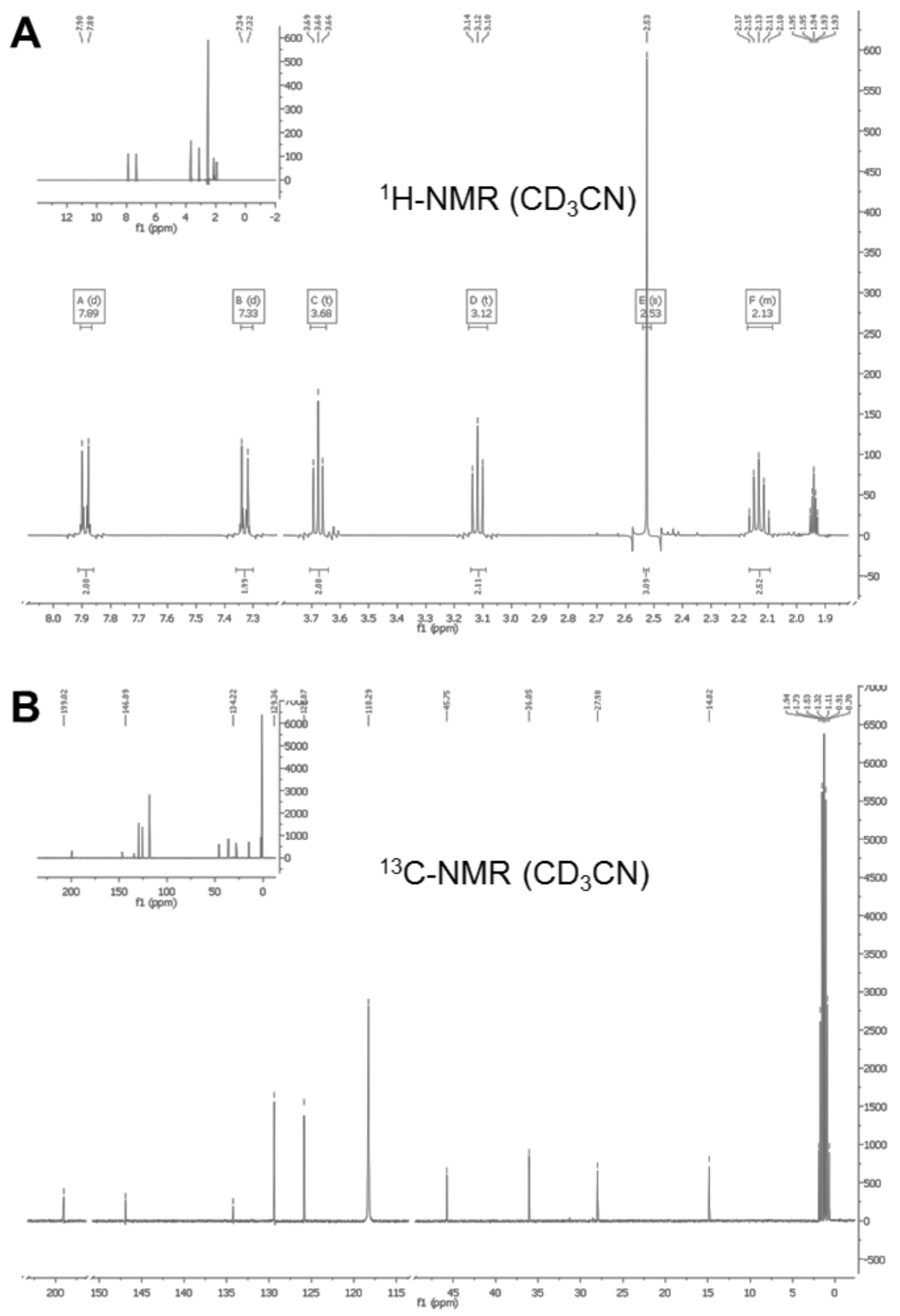

Figure S8: (A) ${ }^{1} \mathrm{H}$ - and (B) ${ }^{13} \mathrm{C}$-NMR-spectra of 4-chloro-1-(4-(methylthio)phenyl)butan-1-one (1a) 
5-chloro-1-(4-(methylthio)phenyl)pentan-1-one (1b)

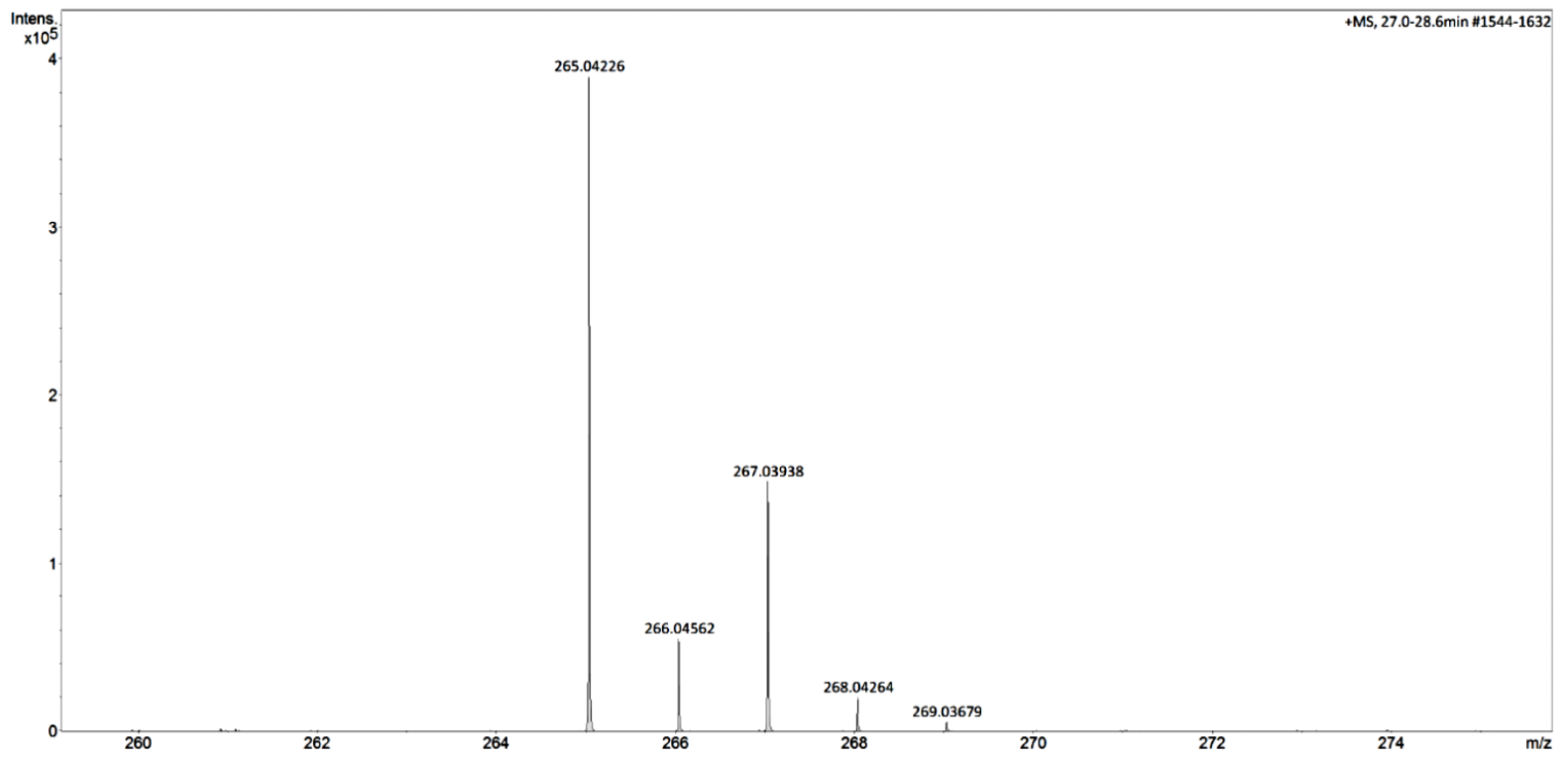

Figure S9: Section of the HSMR spectra of 5-chloro-1-(4-(methylthio)phenyl)pentan-1-one (1b) 

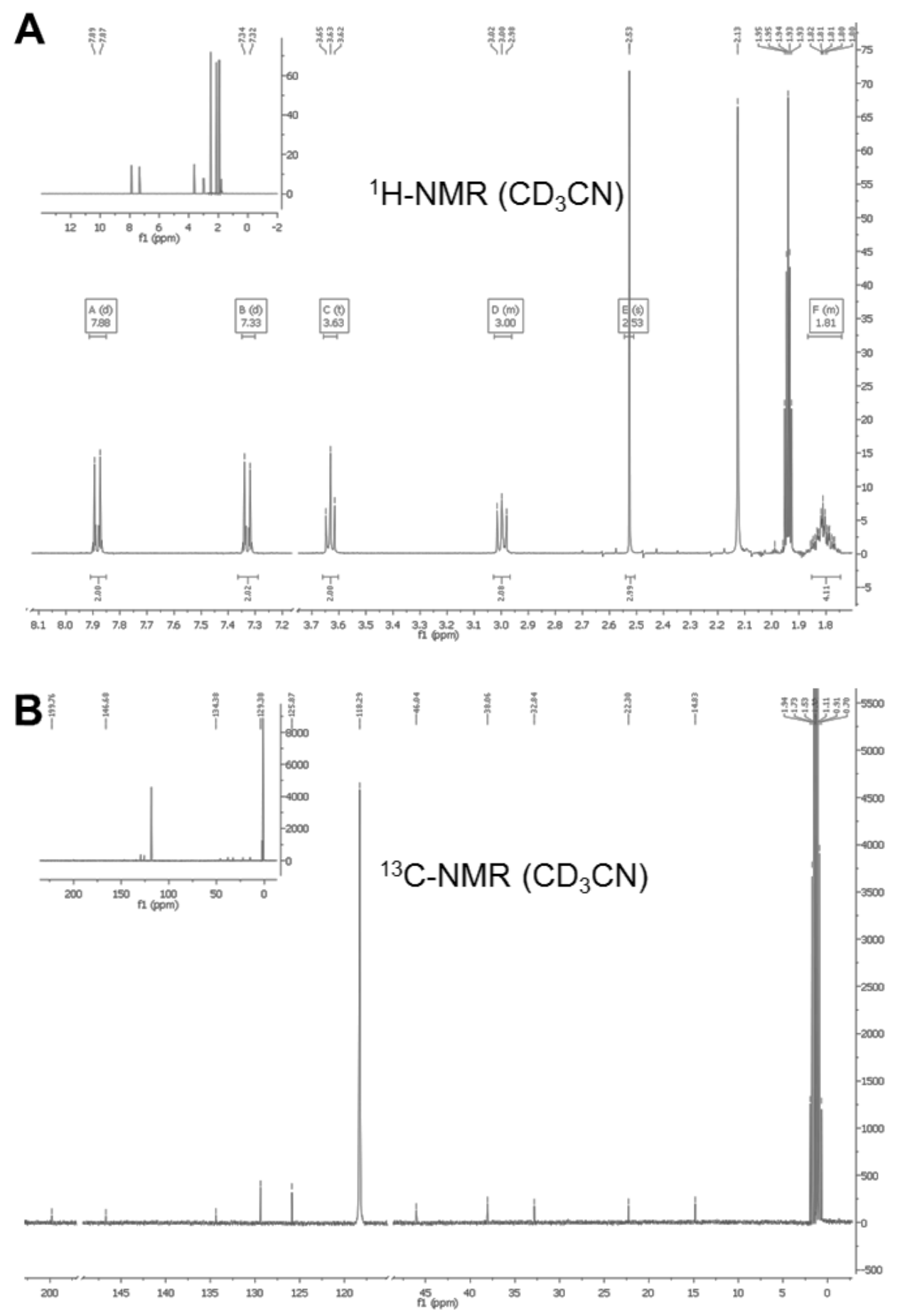

Figure S10: (A) ${ }^{1} \mathrm{H}$ - and (B) ${ }^{13} \mathrm{C}$-NMR-spectra of 5-chloro-1-(4-(methylthio)phenyl)pentan-1-one (1b) 
4-chloro-1-(4-(methylsulfonyl)phenyl)butan-1-one (2a)

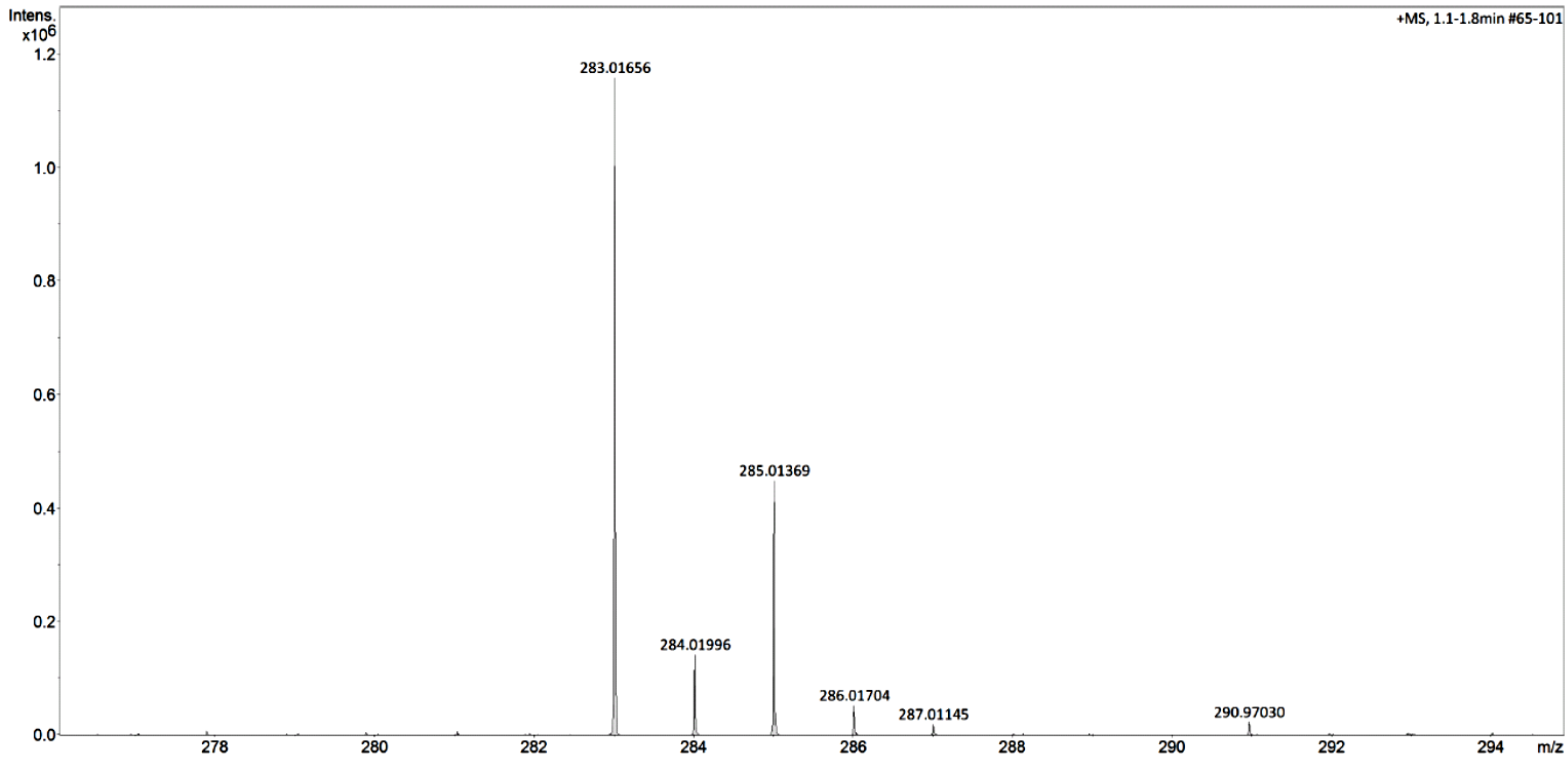

Figure S11: Section of the HSMS spectra of 4-chloro-1-(4-(methylsulfonyl)phenyl)butan-1-one (2a) 

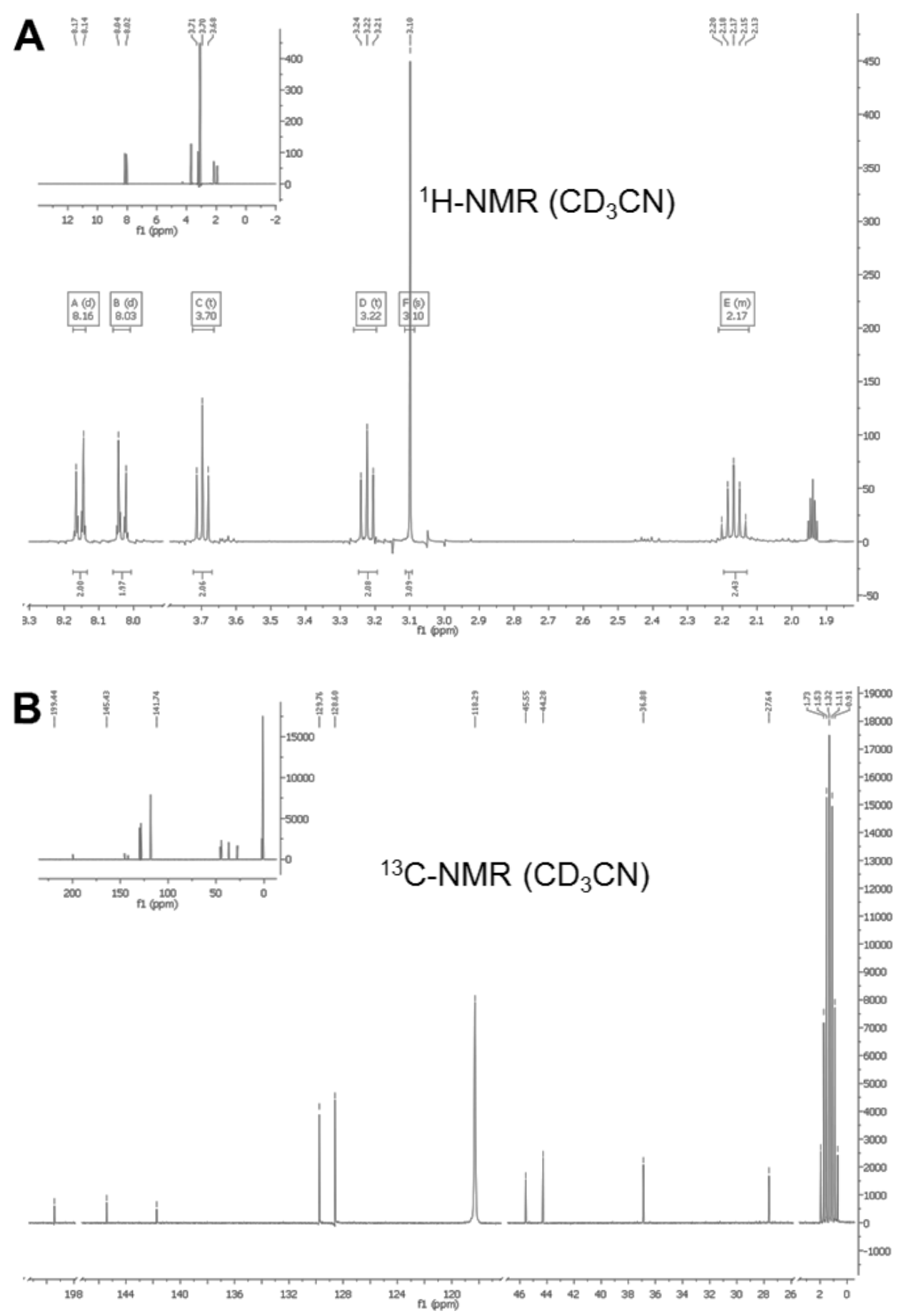

Figure S12: (A) ${ }^{1} \mathrm{H}$ - and (B) ${ }^{13} \mathrm{C}-\mathrm{NMR}$-spectra of 4-chloro-1-(4-(methylsulfonyl)phenyl)butan-1-one (2a) 
5-chloro-1-(4-(methylsulfonyl)phenyl)pentan-1-one (2b)

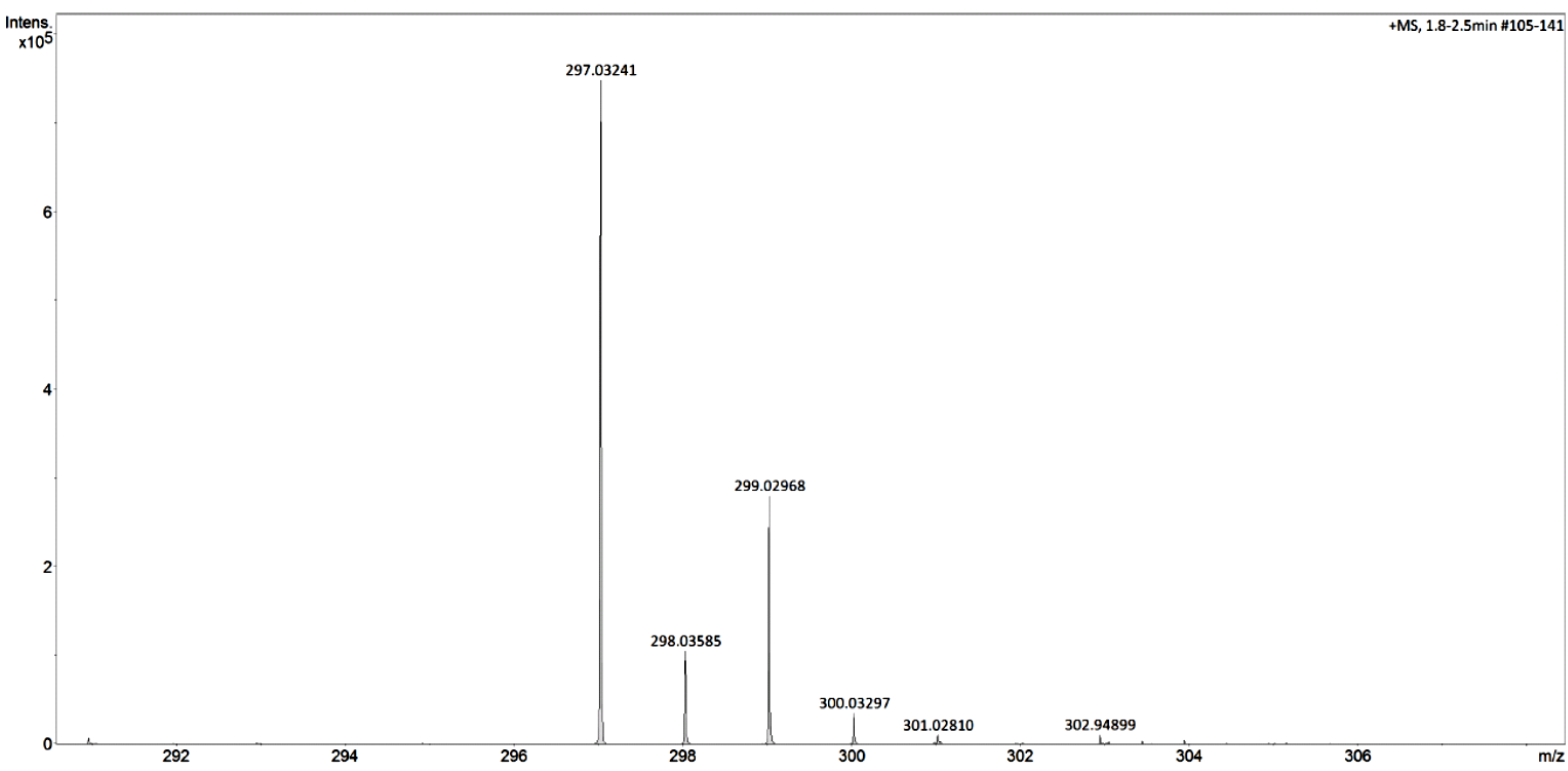

Figure S13: Section of the HSMR spectra of 5-chloro-1-(4-(methylsulfonyl)phenyl)pentan-1-one (2b) 

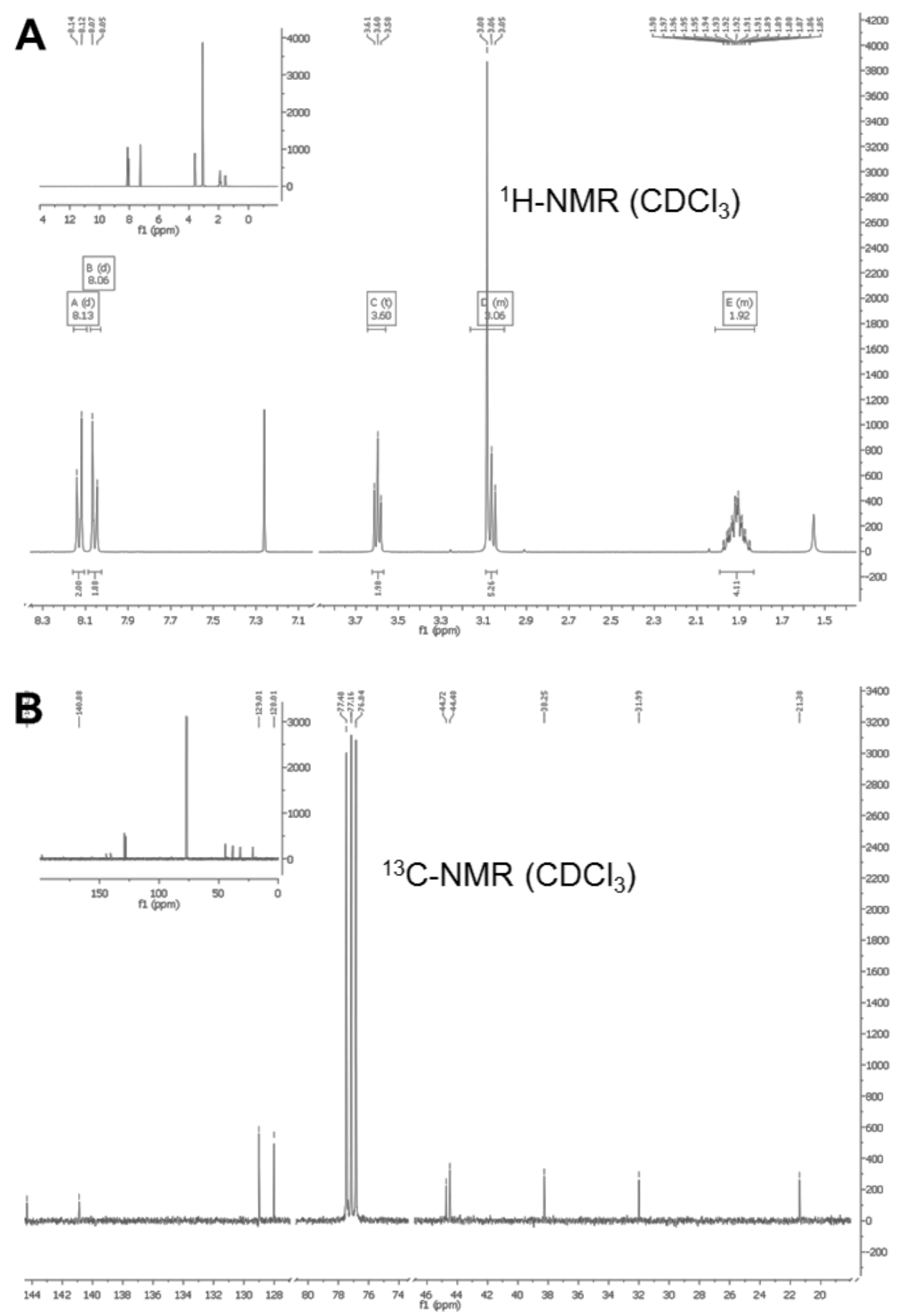

Figure S14: (A) ${ }^{1} \mathrm{H}$ - and (B) ${ }^{13} \mathrm{C}-\mathrm{NMR}$-spectra of 5-chloro-1-(4-(methylsulfonyl)phenyl)pentan-1-one (2b) 
5-chloro-2-(4-(methylsulfonyl)phenyl)pent-1-en-1,1-diyl)dibenzene (3a)

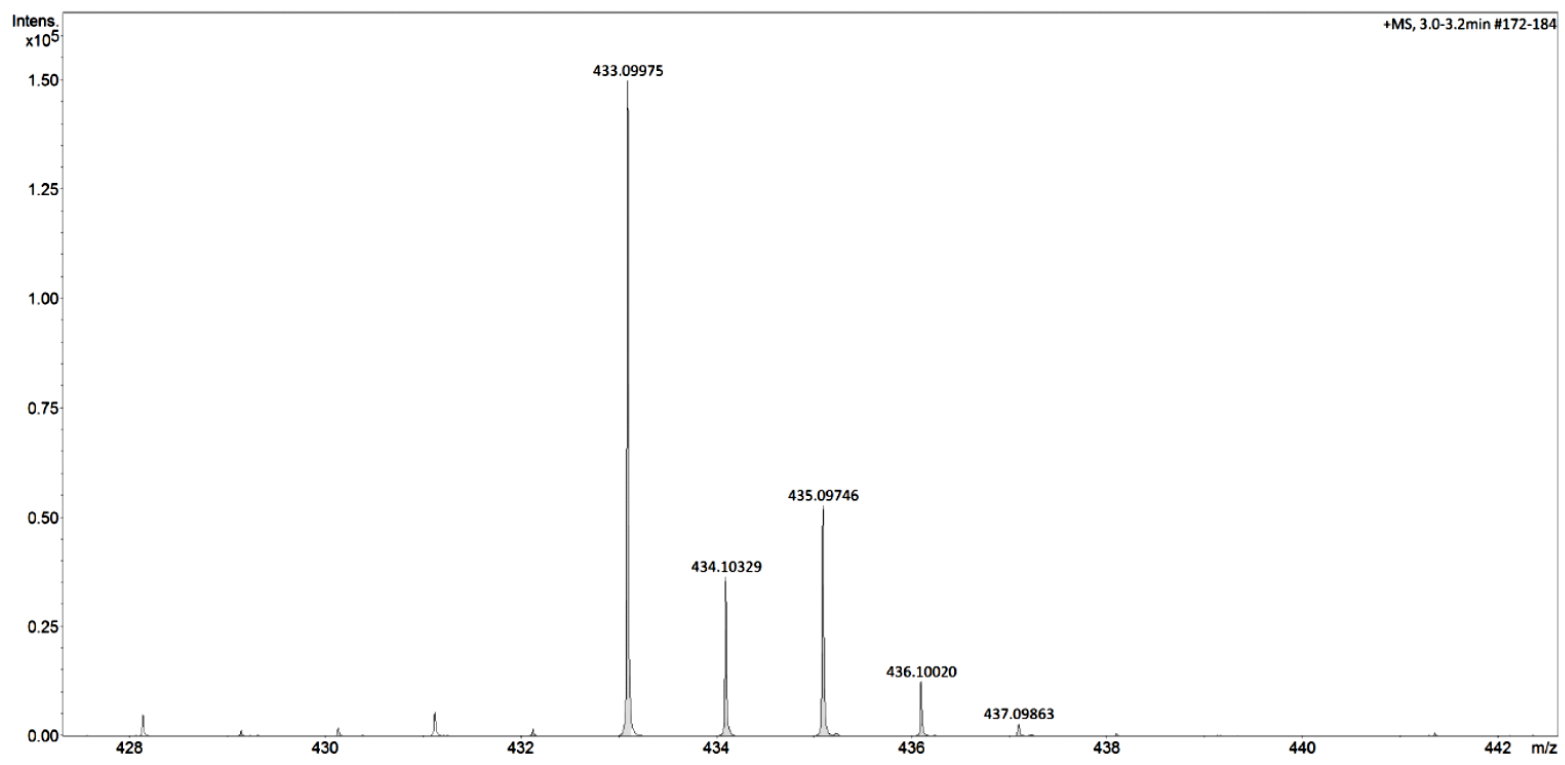

Figure S15: Section of the HSMR spectra of 5-chloro-2-(4-(methylsulfonyl)phenyl)pent-1-en-1,1diyl)bibenzene (3a) 

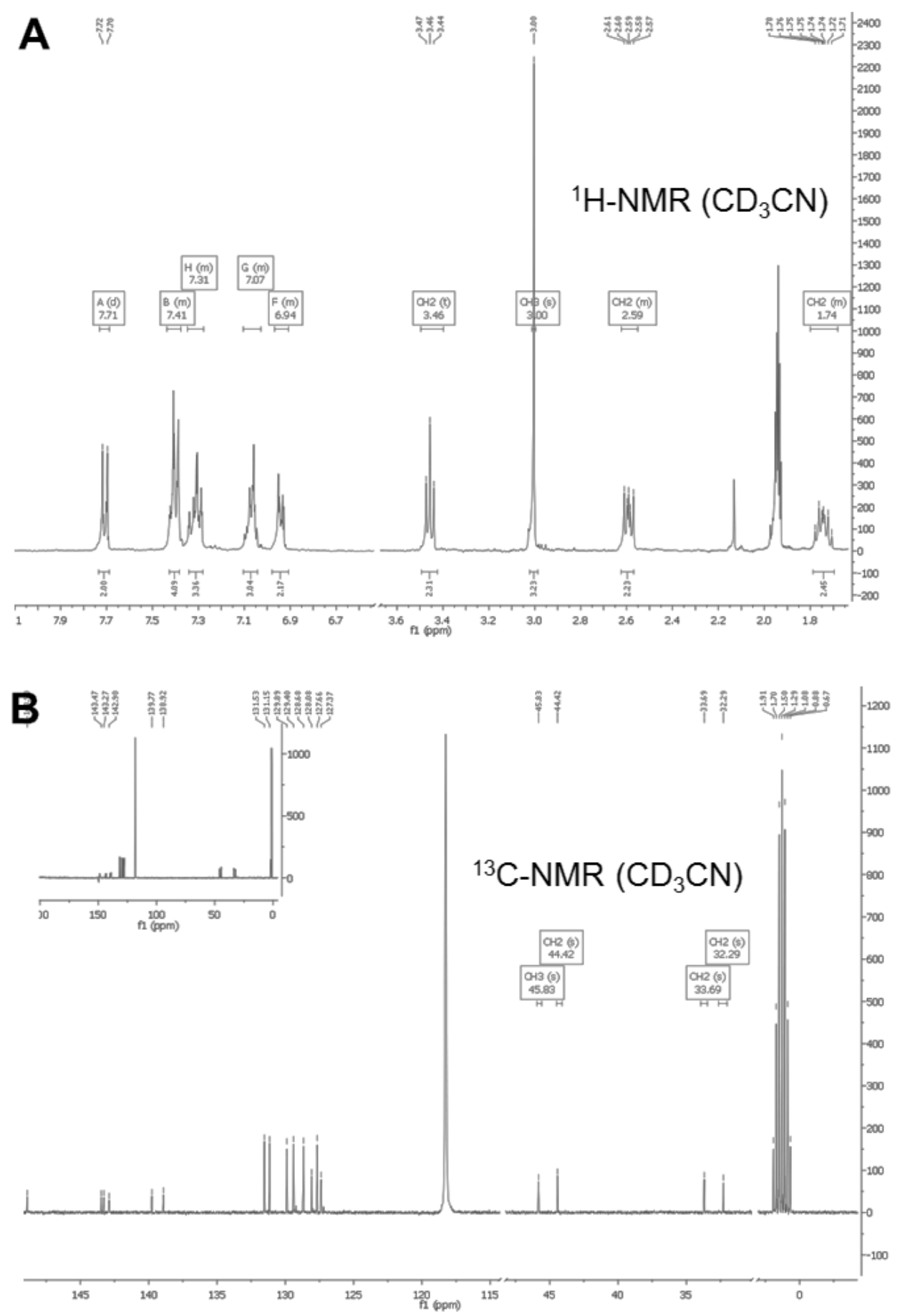

Figure S16: (A) ${ }^{1} \mathrm{H}$-, and (B) ${ }^{13} \mathrm{C}-\mathrm{NMR}$-spectra of 5 -chloro-2-(4-(methylsulfonyl)phenyl)pent-1-en-1,1diyl)bibenzene (3a) 


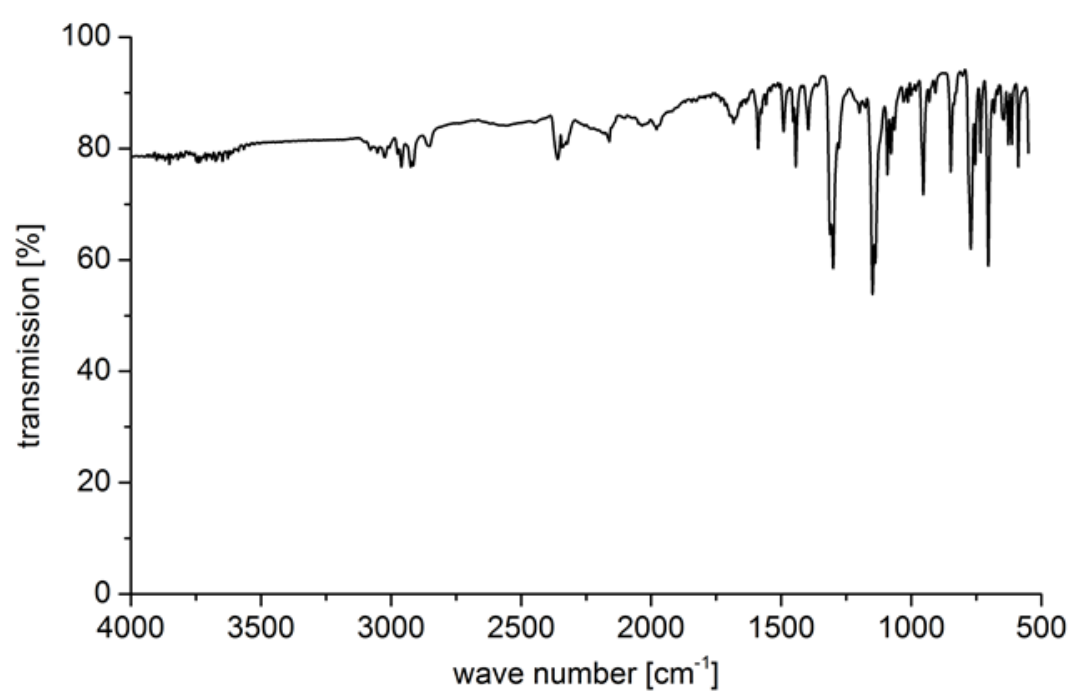

Figure S17: IR-spectra of 5-chloro-2-(4-(methylsulfonyl)phenyl)pent-1-en-1,1-diyl)bibenzene (3a)

4,4'-(5-chloro-2-(4-(methylsulfonyl)phenyl)pent-1-en-1,1-diyl)bis(fluorobenzene) (3b)

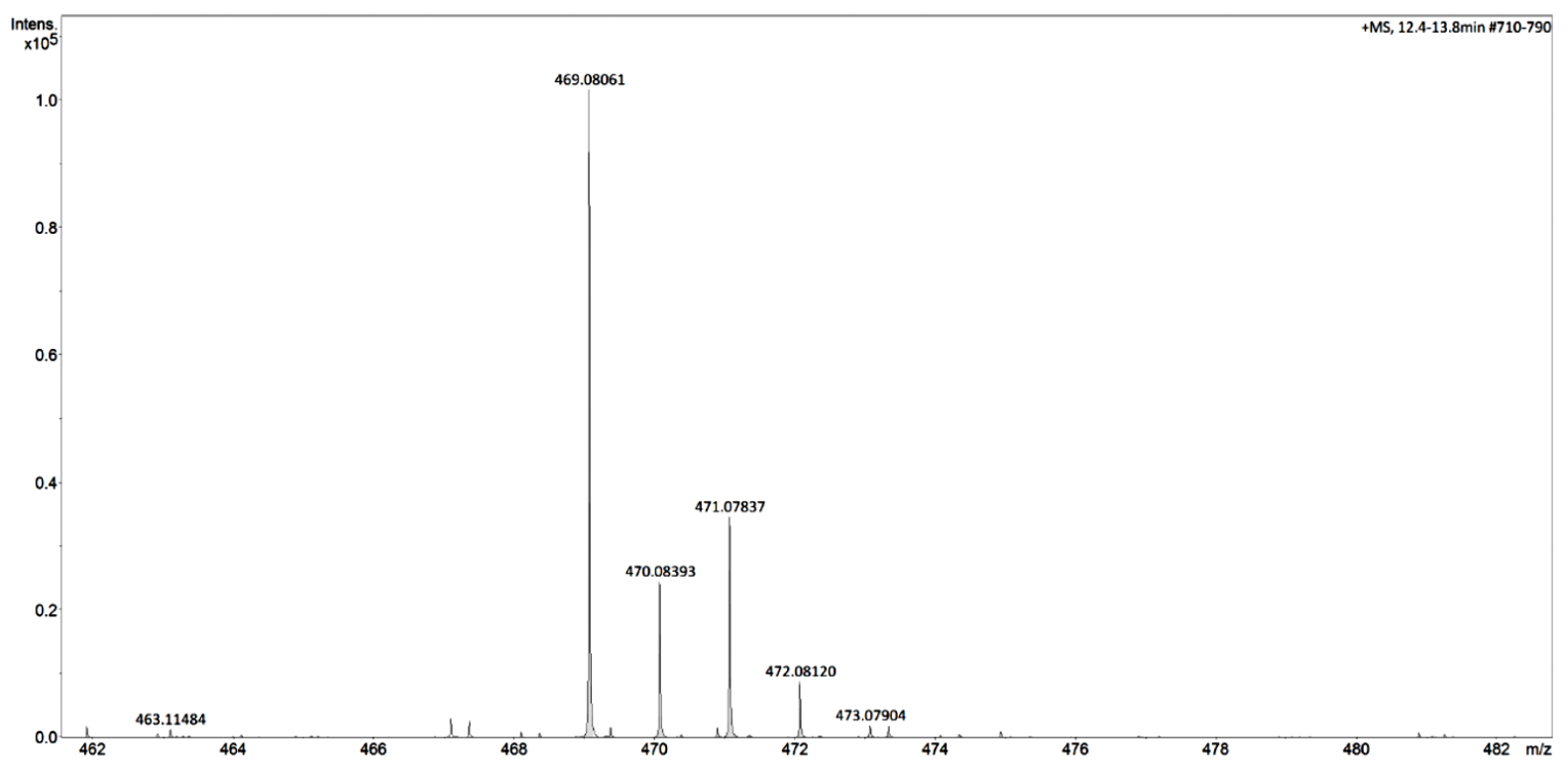

Figure S18: Section of the HSMR spectra of 4,4'-(5-chloro-2-(4-(methylsulfonyl)phenyl)pent-1-en-1,1diyl)bis-(fluorobenzene) (3b) 

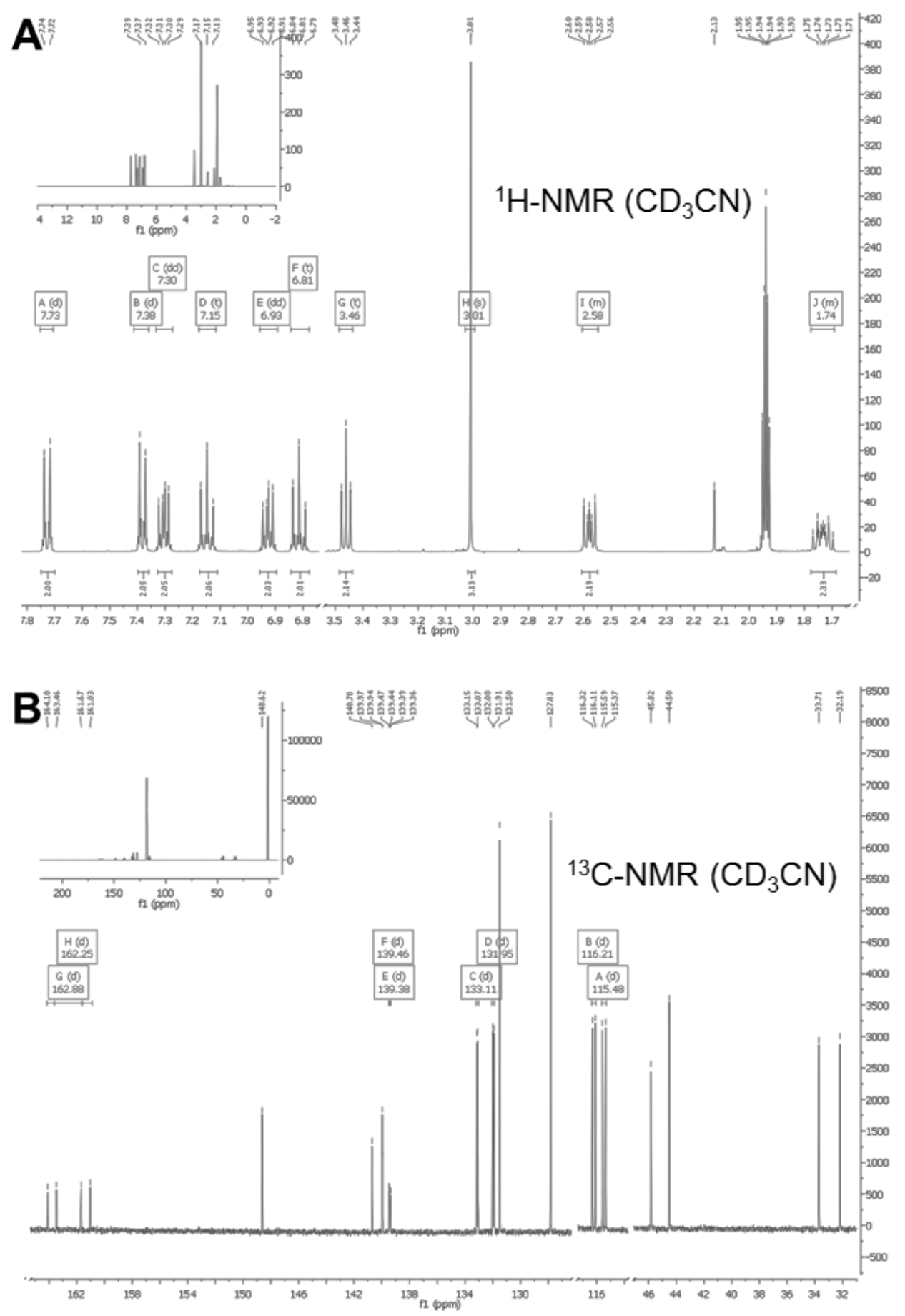

Figure S19: (A) ${ }^{1} \mathrm{H}$ - and (B) ${ }^{13} \mathrm{C}$-spectra of 4,4'-(5-chloro-2-(4-(methylsulfonyl)phenyl)pent-1-en-1,1diyl)bis(fluorobenzene) (3b) 


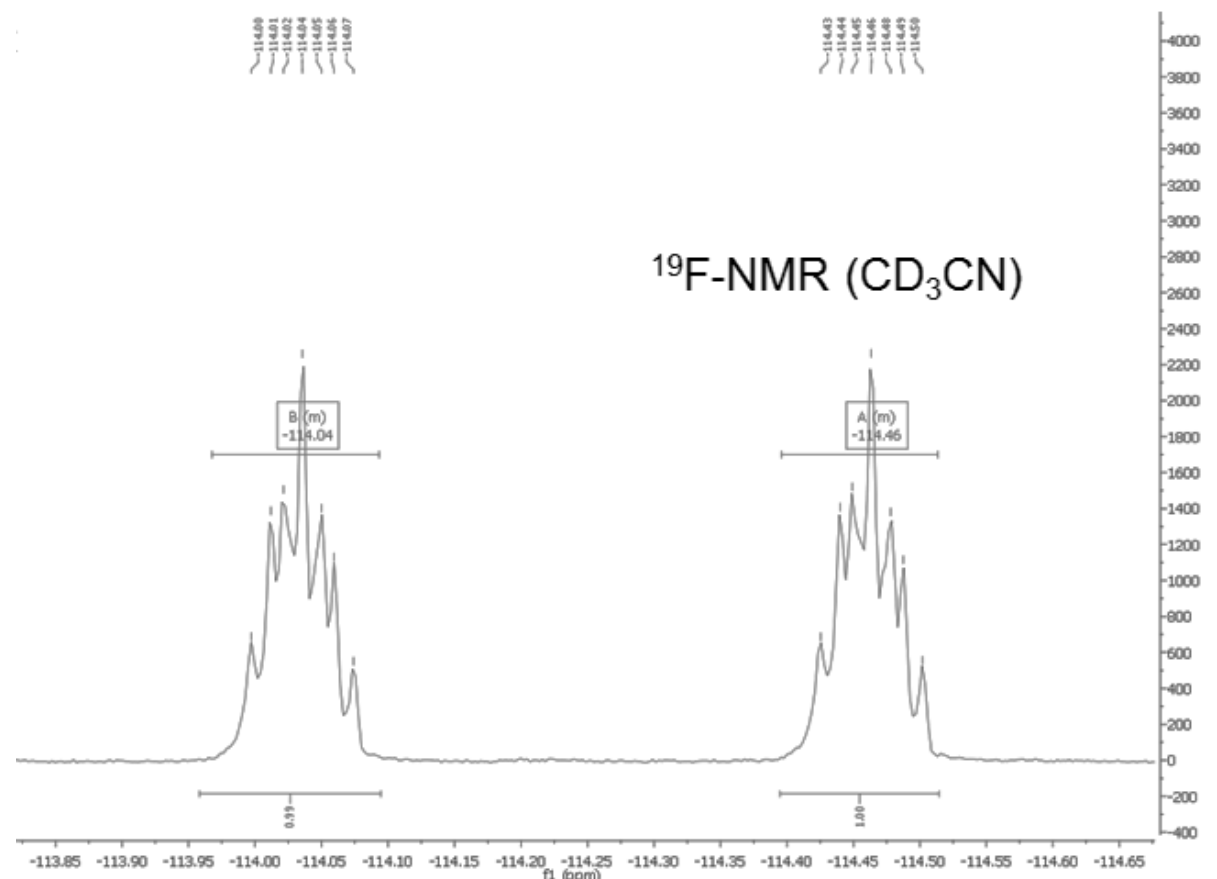

Figure S20: ${ }^{19} \mathrm{~F}$-spectra of 4,4'-(5-chloro-2-(4-(methylsulfonyl)phenyl)pent-1-en-1,1-diyl)bis(fluorobenzene) (3b)

6-chloro-2-(4-(methylsulfonyl)phenyl)hex-1-en-1,1-diyl)dibenzene (3c)

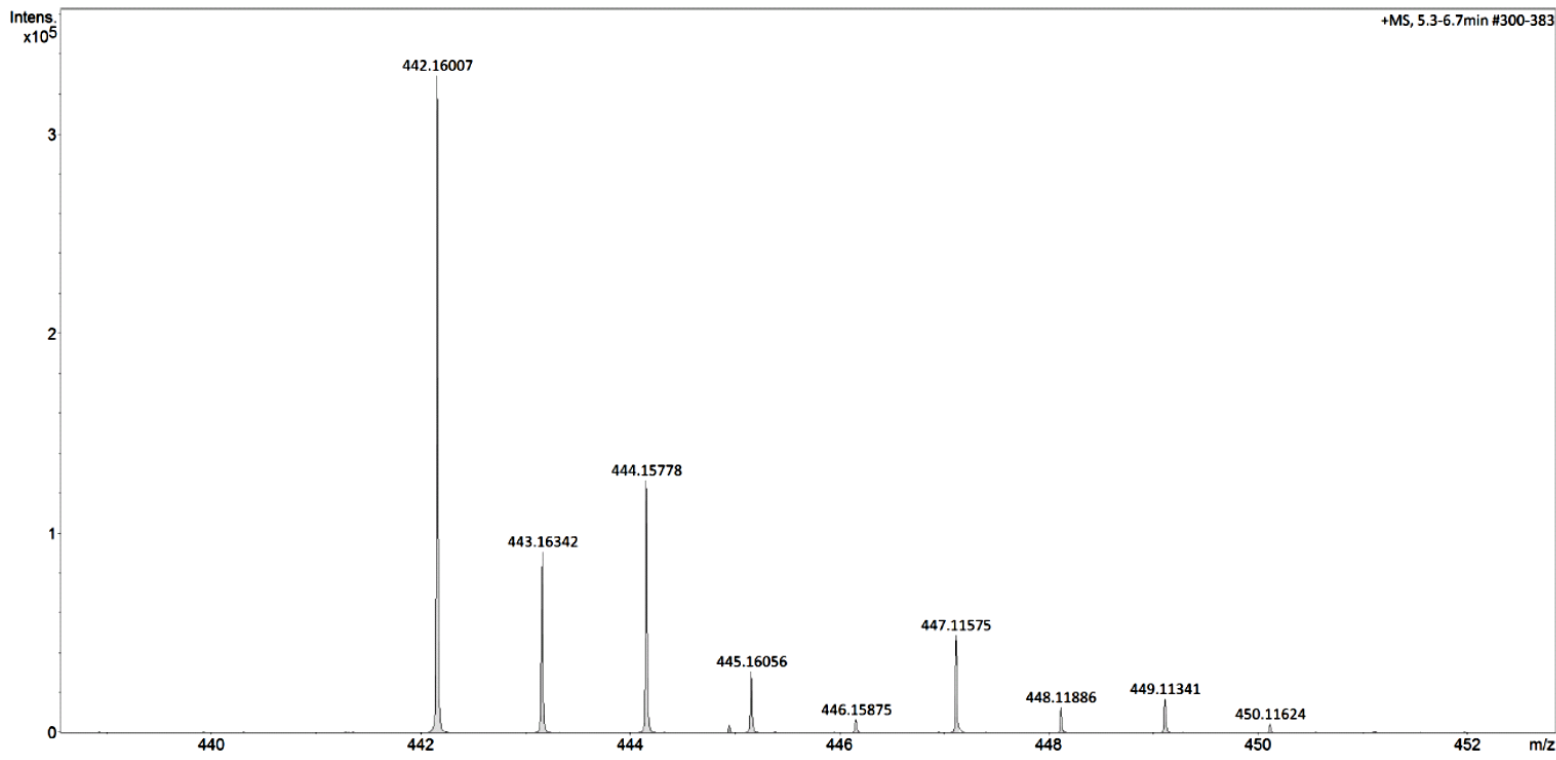

Figure S21: Section of the HRMS spectra of 6-chloro-2-(4-(methylsulfonyl)phenyl)hex-1-en-1,1diyl)dibenzene (3c) 


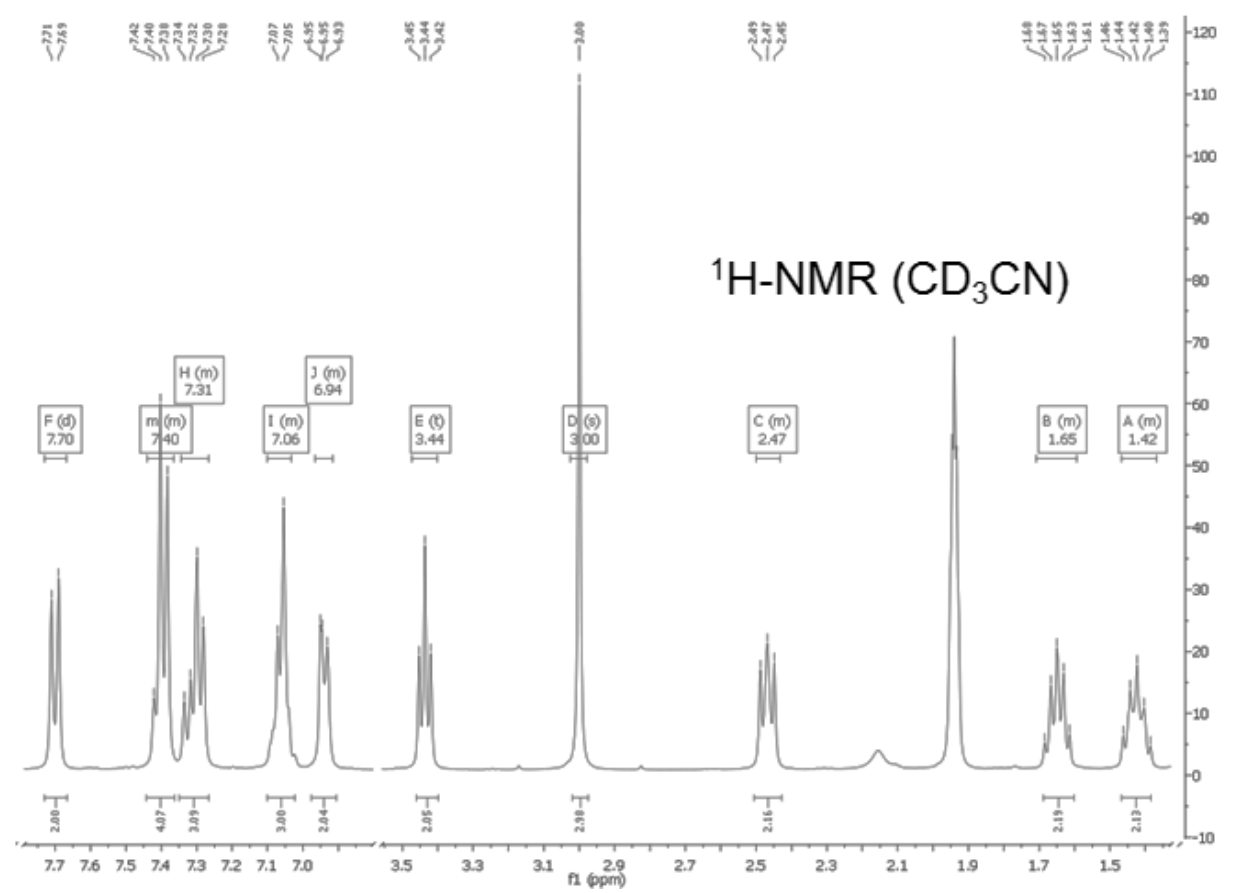

Figure S22: ${ }^{1} \mathrm{H}-\mathrm{NMR}$-spectra of 6-chloro-2-(4-(methylsulfonyl)phenyl)hex-1-en-1,1-diyl)dibenzene (3c)

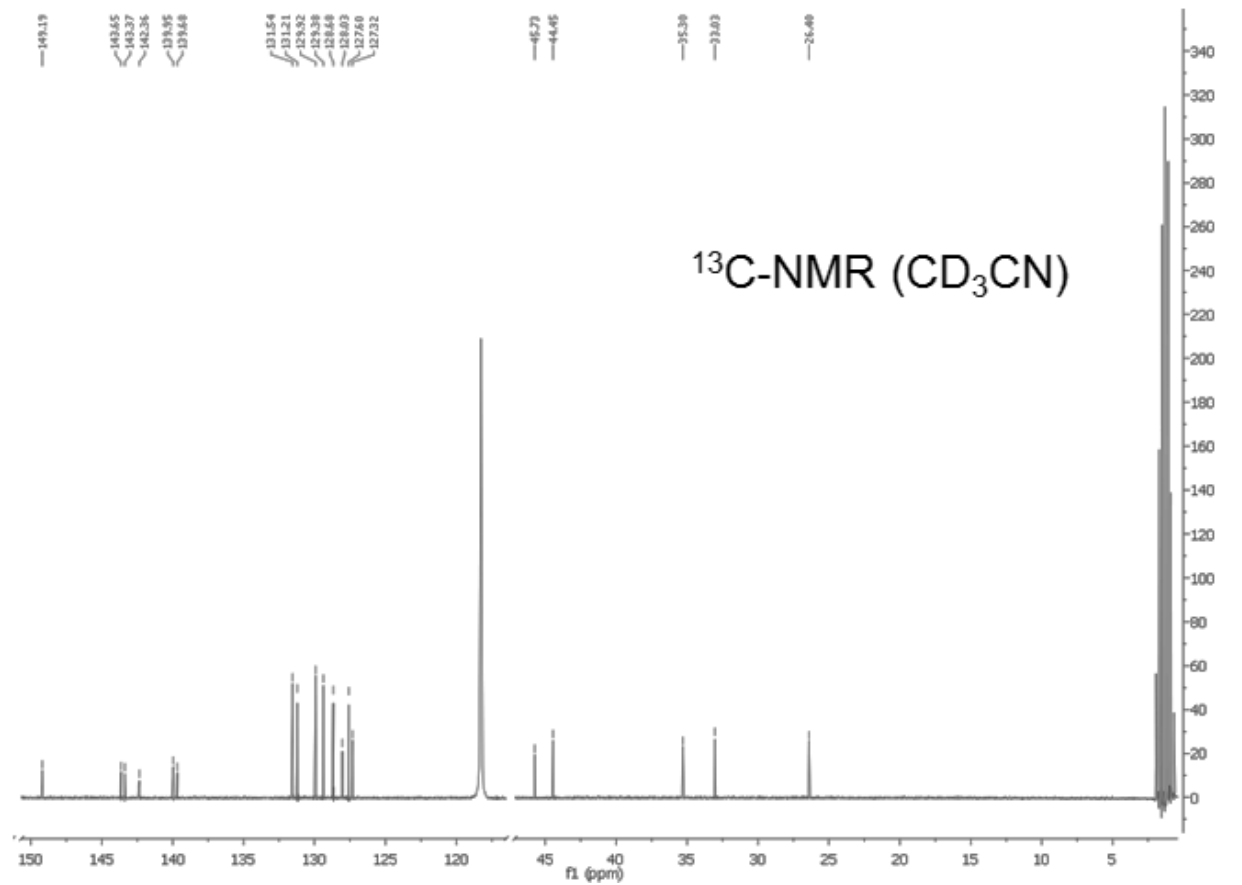

Figure S23: ${ }^{13}$ C-NMR-spectra of 6-chloro-2-(4-(methylsulfonyl)phenyl)hex-1-en-1,1-diyl)dibenzene (3c) 


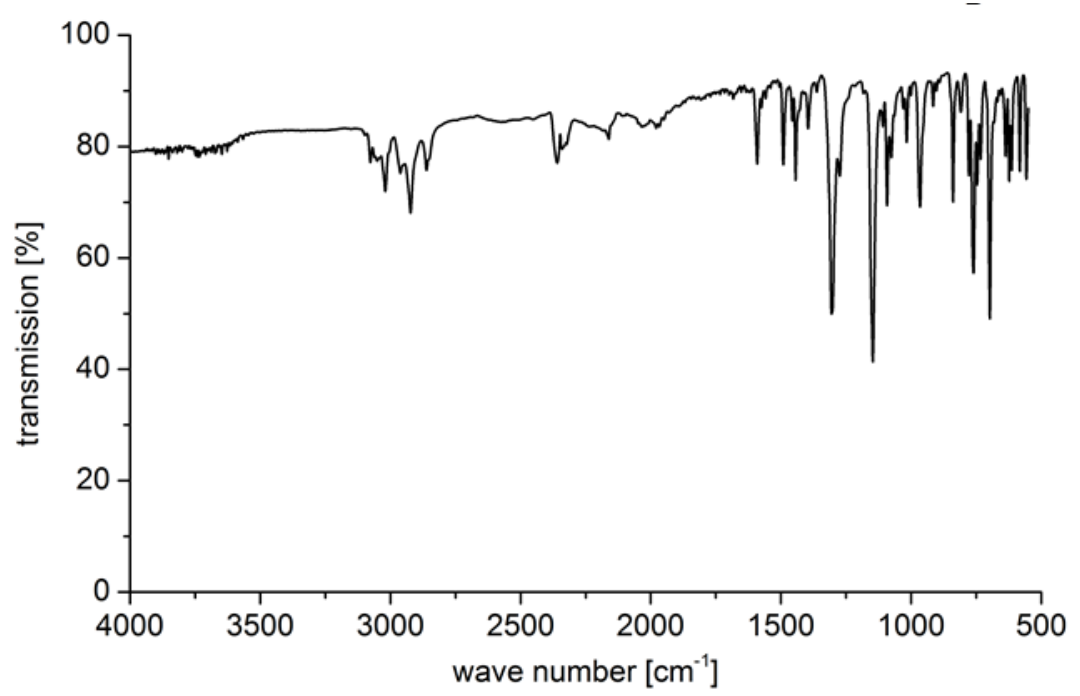

Figure S24: IR-spectra of 6-chloro-2-(4-(methylsulfonyl)phenyl)hex-1-en-1,1-diyl)dibenzene (3c) 
4,4'-(6-chloro-2-(4-(methylsulfonyl)phenyl)hex-1-en-1,1-diyl)bis(fluorobenzene) (3d)
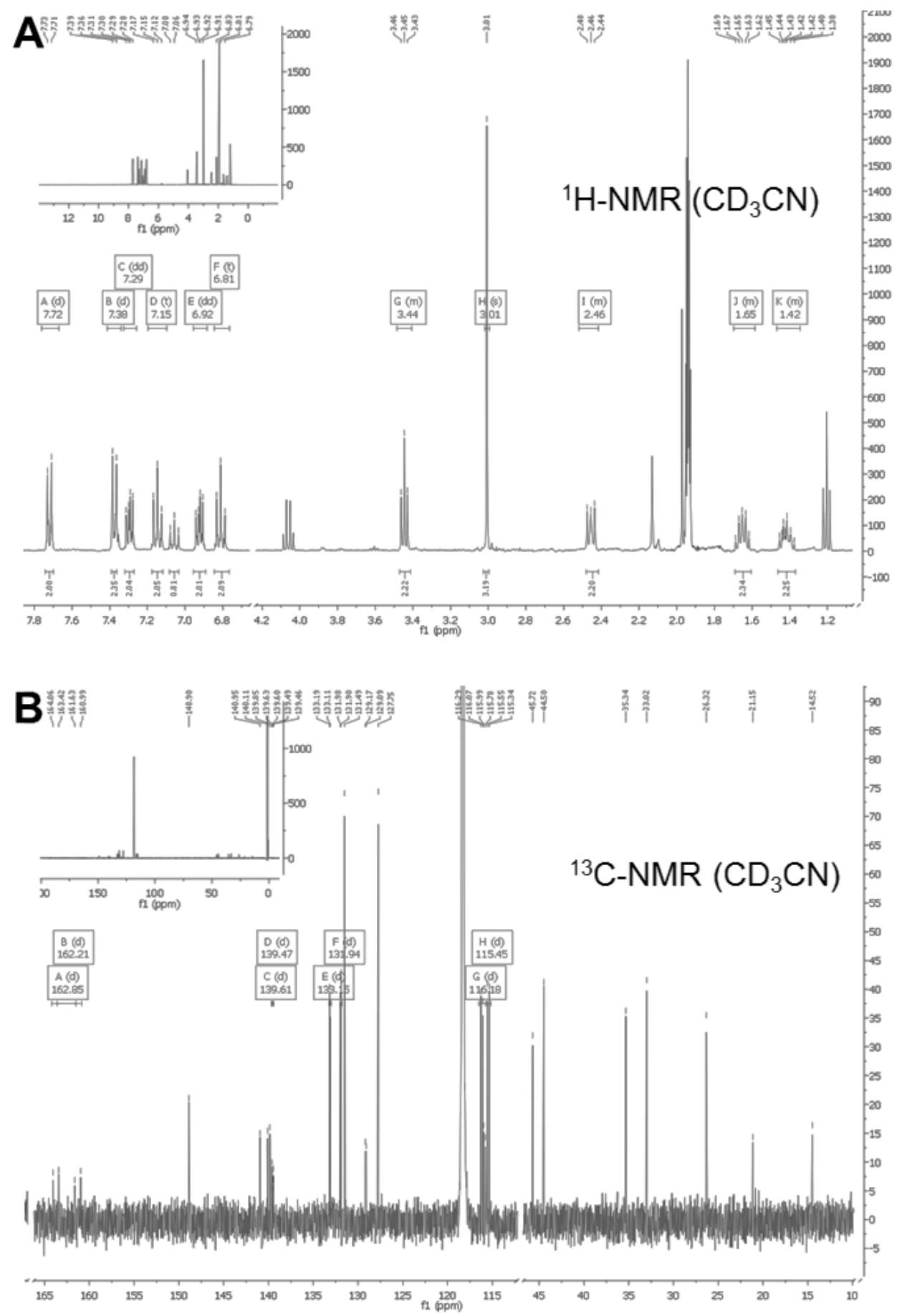

Figure S25: (A) ${ }^{1} \mathrm{H}$ - and (B) ${ }^{13} \mathrm{C}$-spectra of 4,4'-(6-chloro-2-(4-(methylsulfonyl)phenyl)hex-1-en-1,1diyl)bis(fluorobenzene) (3d) 
4-(4-(methylsulfonyl)phenyl)-5-5-diphenylpent-4-en-1-yl nitrate (4a)

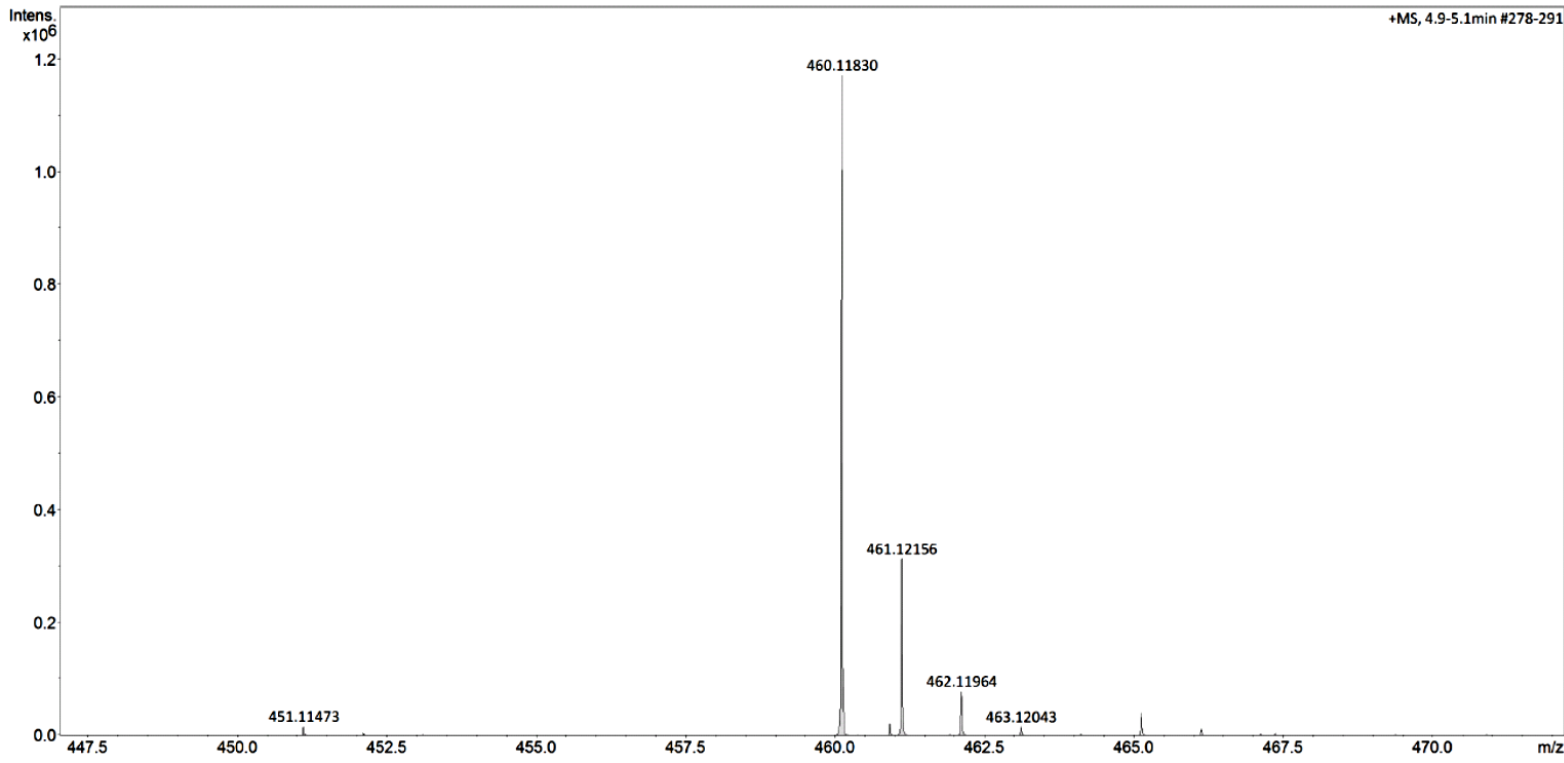

Figure S26: Section of the HRMS spectra of 4-(4-(methylsulfonyl)phenyl)-5-5-diphenylpent-4-en-1-yl nitrate (4a) 

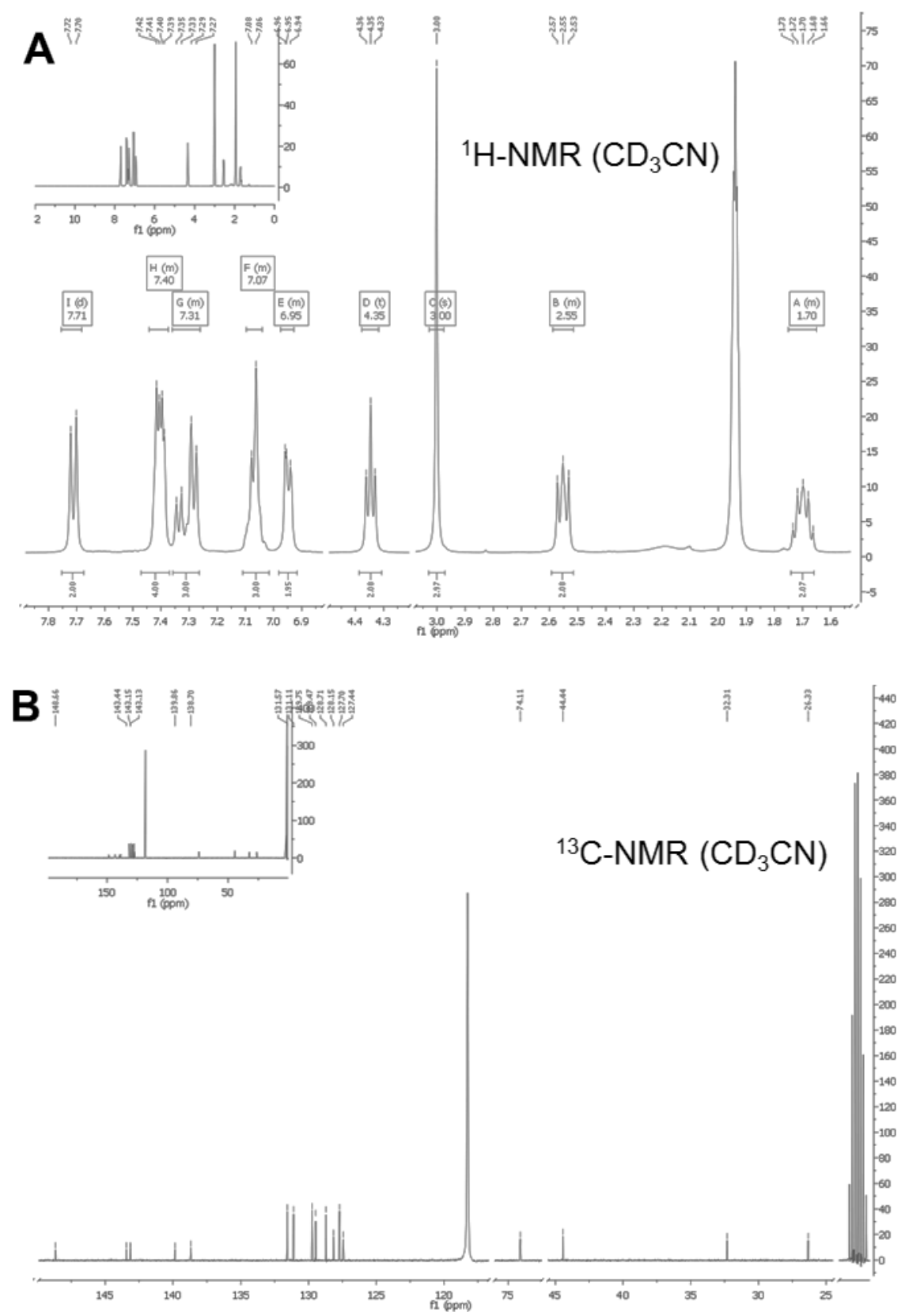

Figure S27: (A) ${ }^{1} \mathrm{H}$ - and (B) ${ }^{13} \mathrm{C}$-spectra of 4-(4-(methylsulfonyl)phenyl)-5-5-diphenylpent-4-en-1-yl nitrate (4a) 


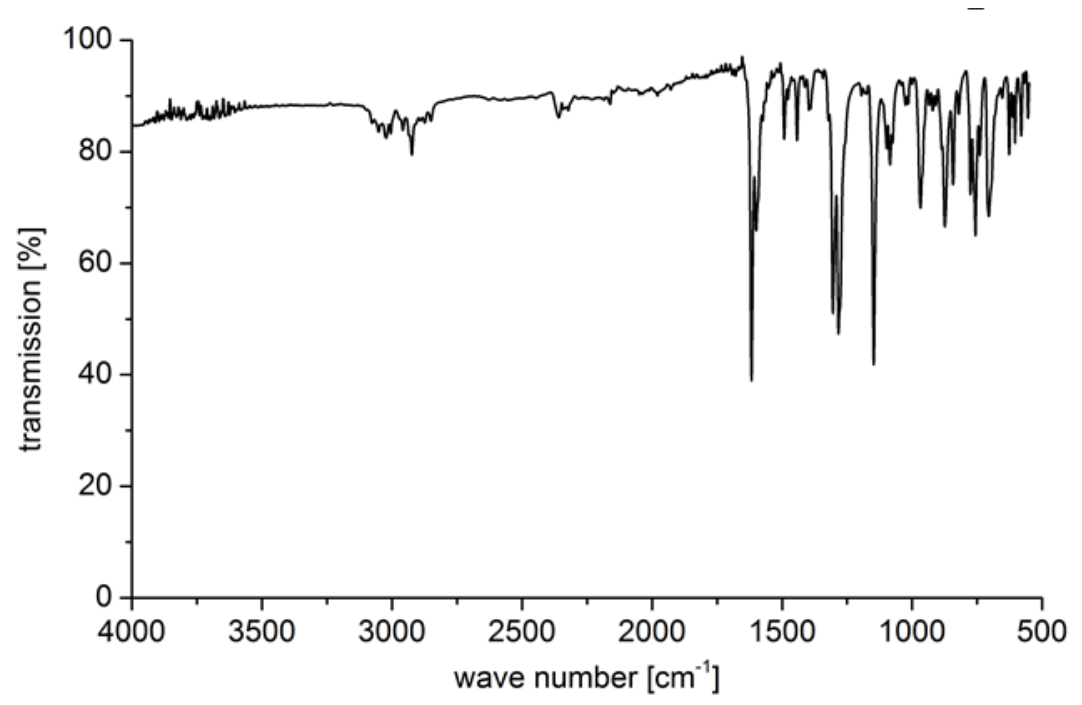

Figure S28: IR-spectra of 4-(4-(methylsulfonyl)phenyl)-5-5-diphenylpent-4-en-1-yl nitrate (4a)

\section{5,5'-bis-(4-fluorophenyl)-4-(4-methylsulfonyl)phenyl)pent-4-en-1-yl nitrate (4b)}

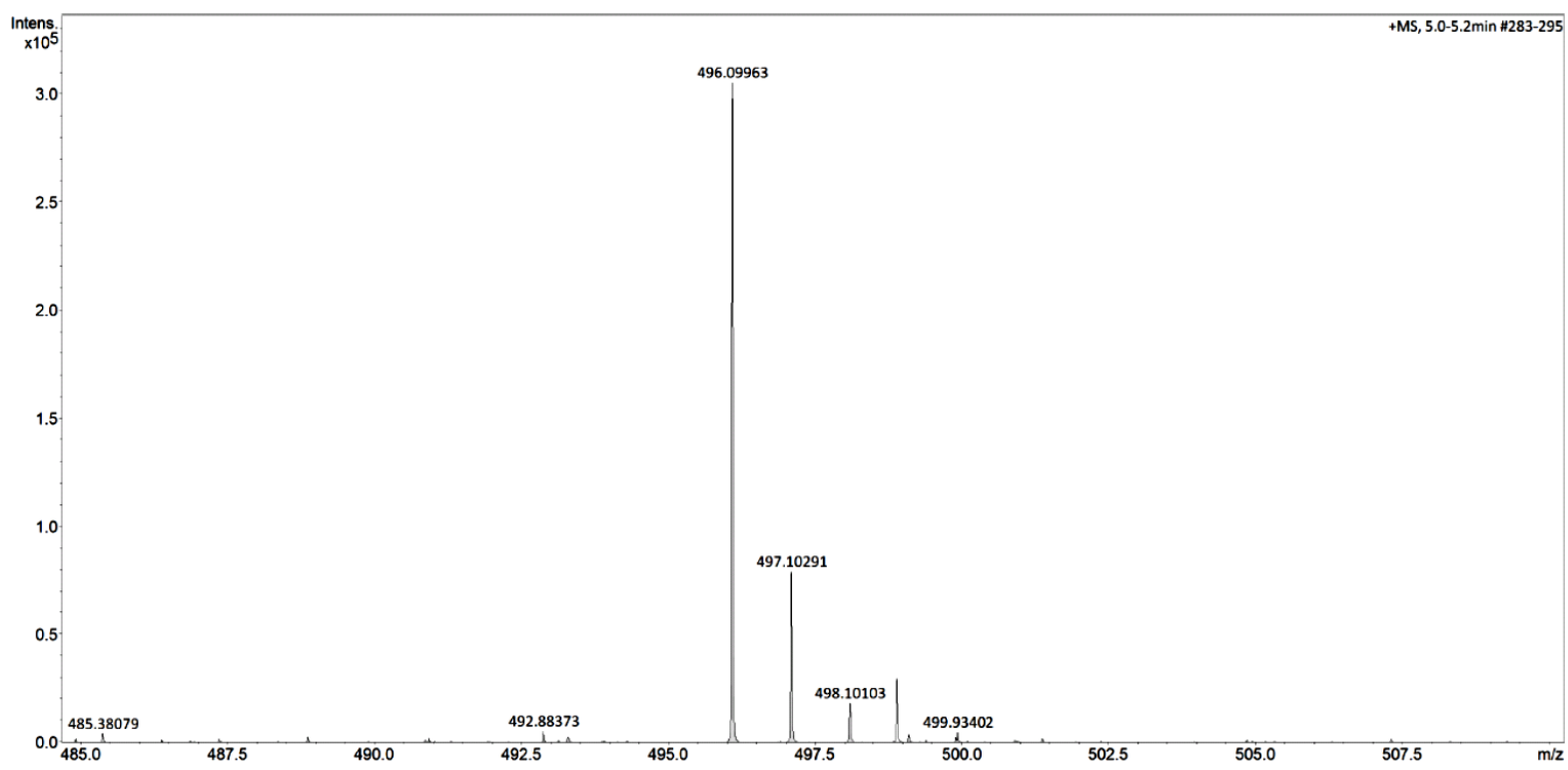

Figure S29: Section of the HRMS spectra of 5,5'-bis-(4-fluorophenyl)-4-(4-methylsulfonyl)phenyl)pent-4en-1-yl nitrate (4b) 

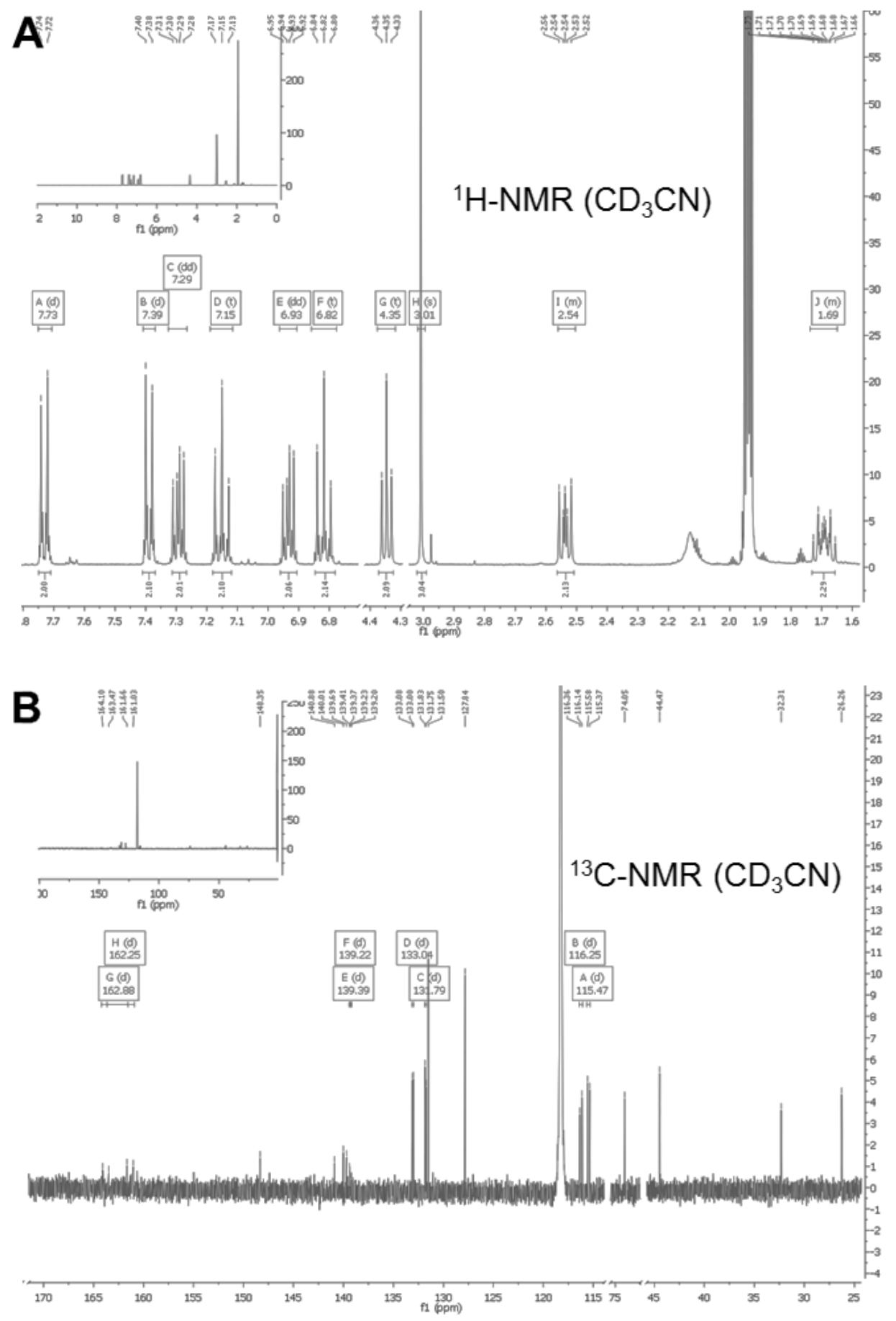

Figure S30: (A) ${ }^{1} \mathrm{H}$ - and (B) ${ }^{13} \mathrm{C}$-NMR -spectra of 5,5'-bis-(4-fluorophenyl)-4-(4-methylsulfonyl)phenyl)pent4-en-1-yl nitrate (4b) 


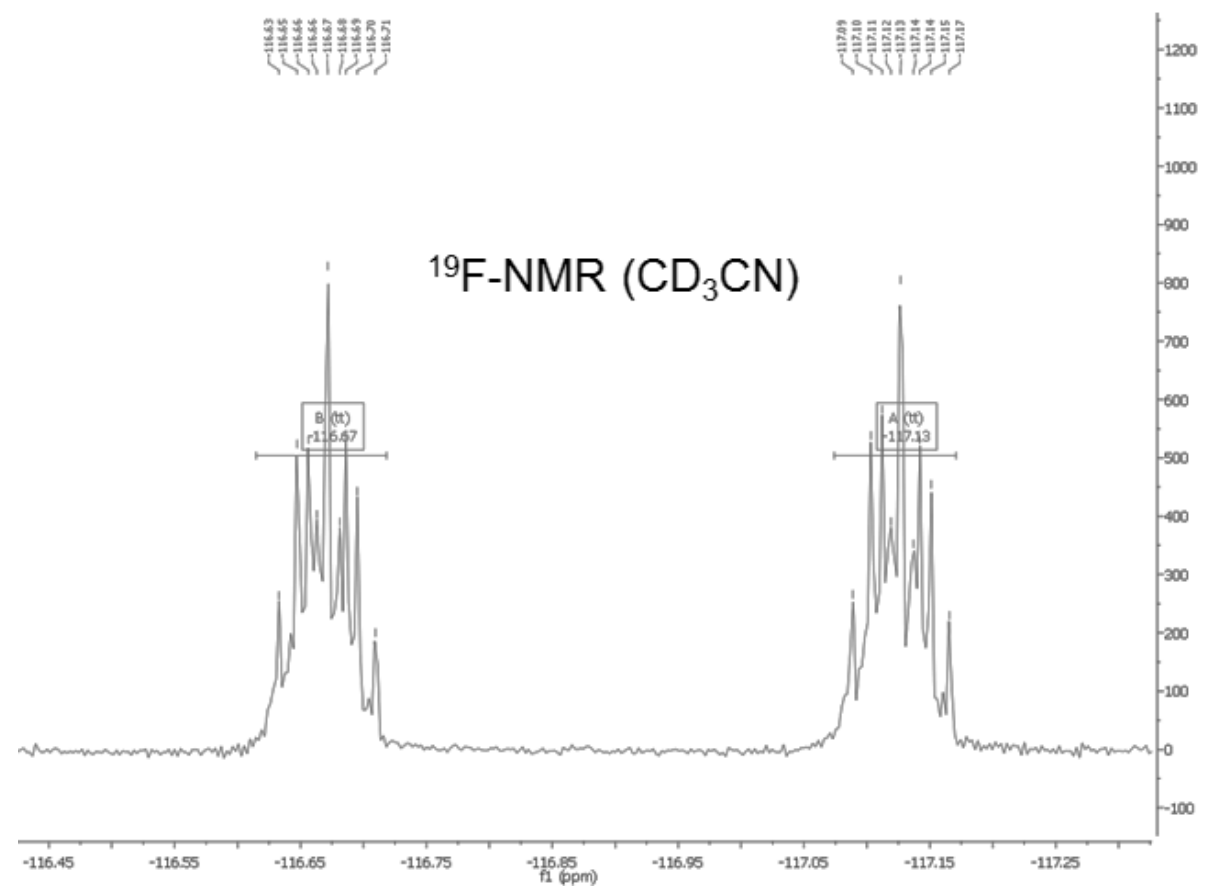

Figure S31: ${ }^{19} \mathrm{~F}-\mathrm{NMR}$-spectra of 5,5'-bis-(4-fluorophenyl)-4-(4-methylsulfonyl)phenyl)pent-4-en-1-yl nitrate (4b)

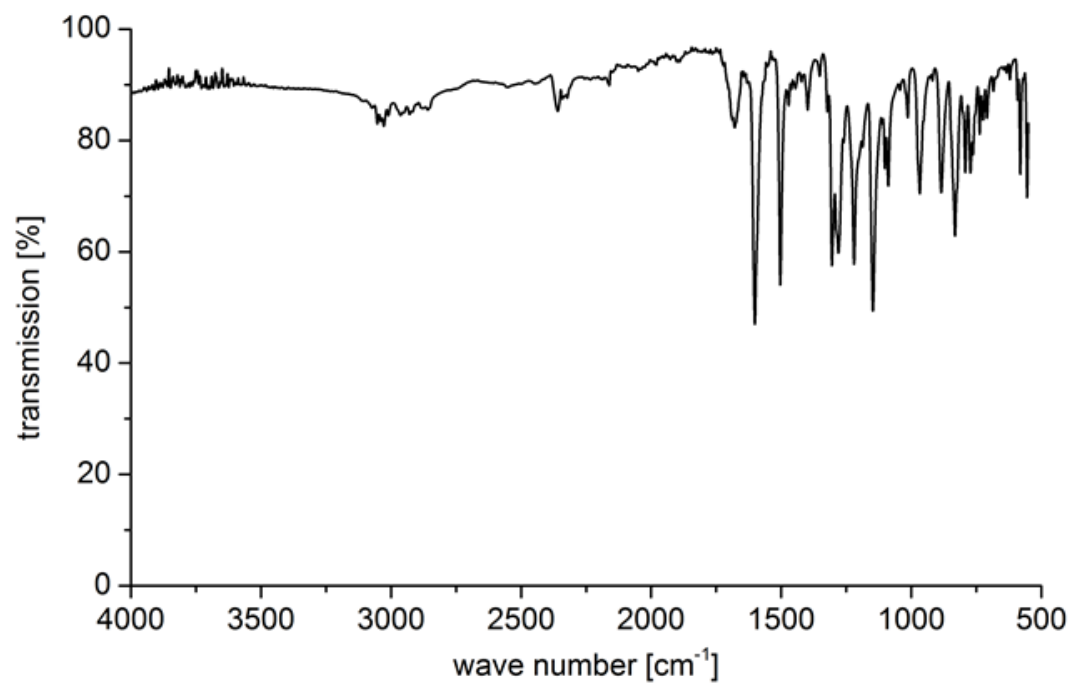

Figure S32: IR-spectra of 5,5'-bis-(4-fluorophenyl)-4-(4-methylsulfonyl)phenyl)pent-4-en-1-yl nitrate (4b) 
5-(4-(methylsulfonyl)phenyl)-6-6-diphenylhex-5-en-1-yl nitrate (4c)

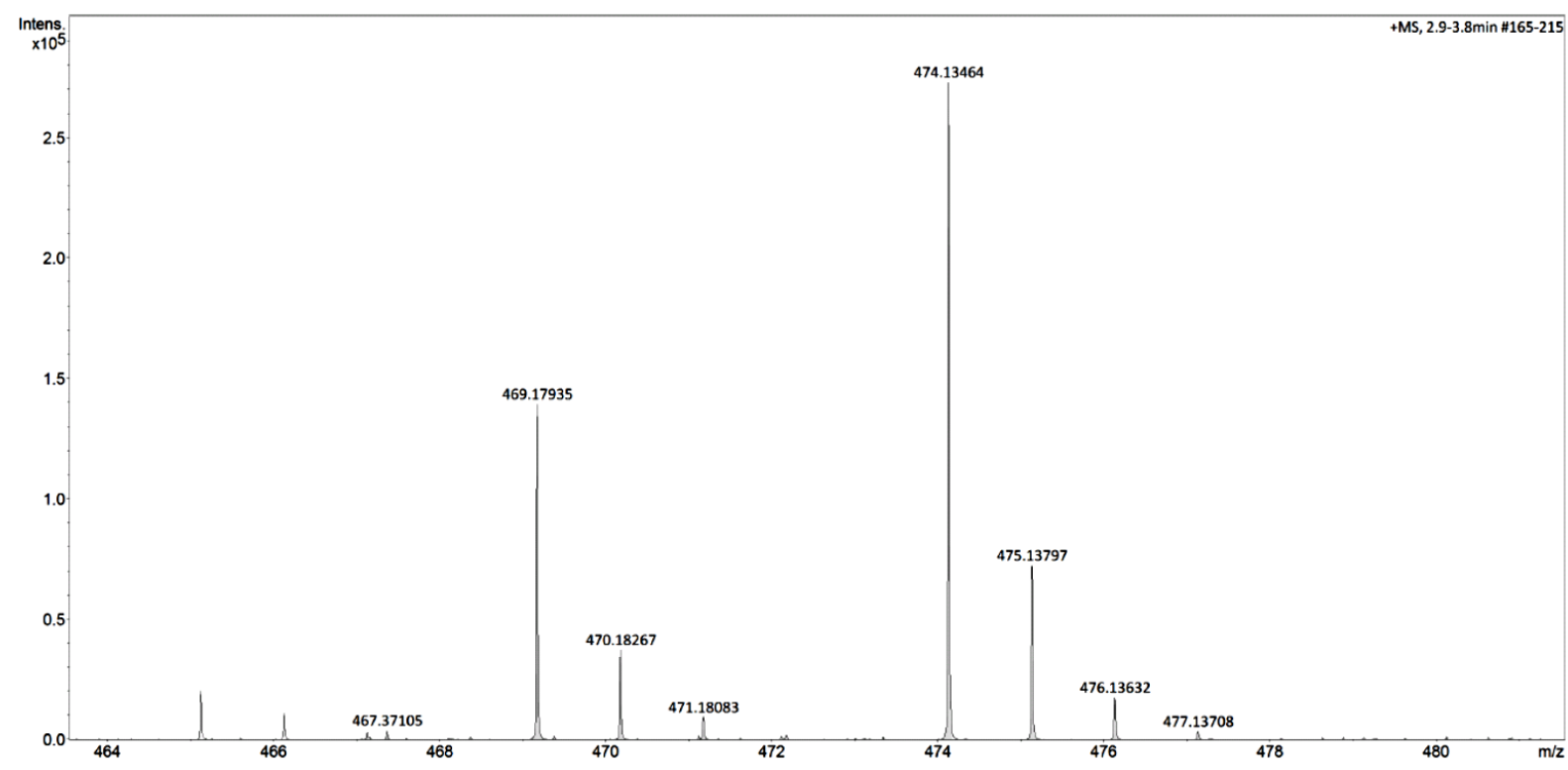

Figure S33: Section of the HRMS spectra of 5-(4-(methylsulfonyl)phenyl)-6-6-diphenylhex-5-en-1-yl nitrate (4c) 

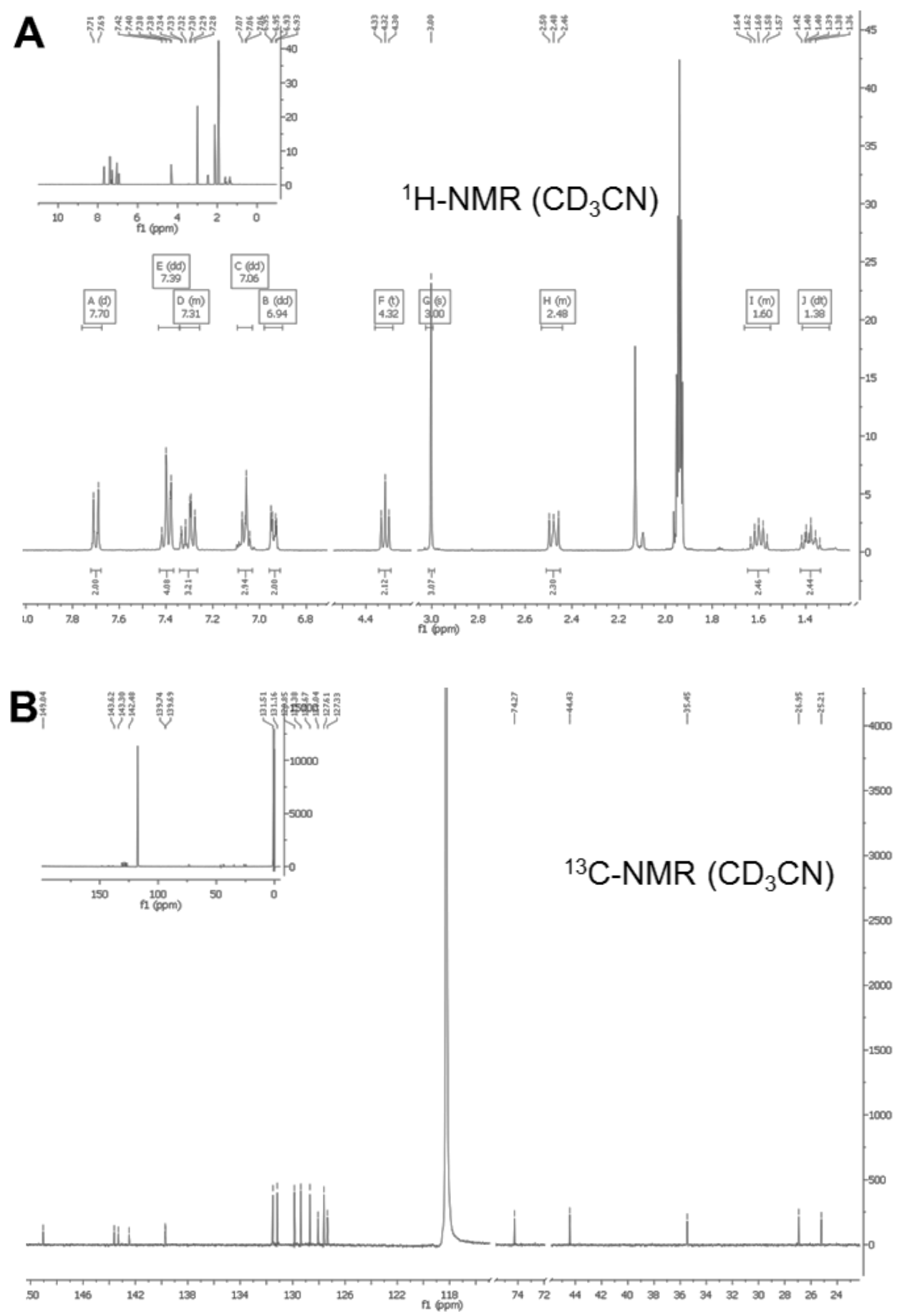

Figure S34: (A) ${ }^{1} \mathrm{H}$ - and (B) ${ }^{13} \mathrm{C}$-NMR-spectra of 5-(4-(methylsulfonyl)phenyl)-6-6-diphenylhex-5-en-1-yl nitrate (4c) 


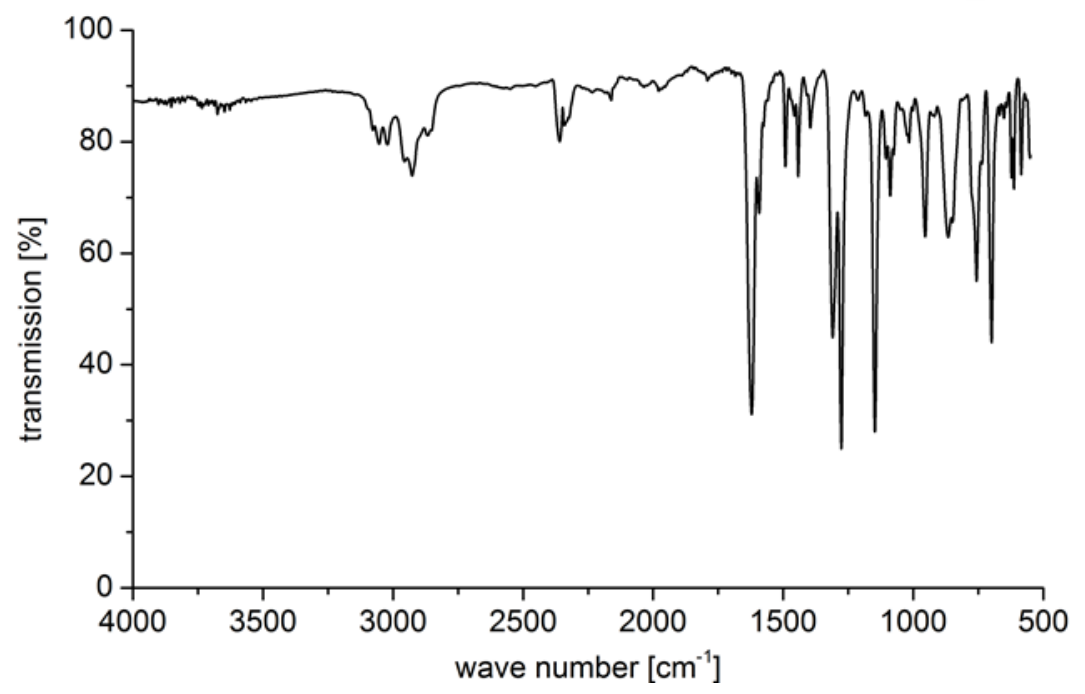

Figure S35: IR-spectra of 5-(4-(methylsulfonyl)phenyl)-6-6-diphenylhex-5-en-1-yl nitrate (4c)

6,6'-bis(4-fluorophenyl)-5-(4-(methylsulfonyl)phenyl)hex-5-en-1-yl nitrate (4d)

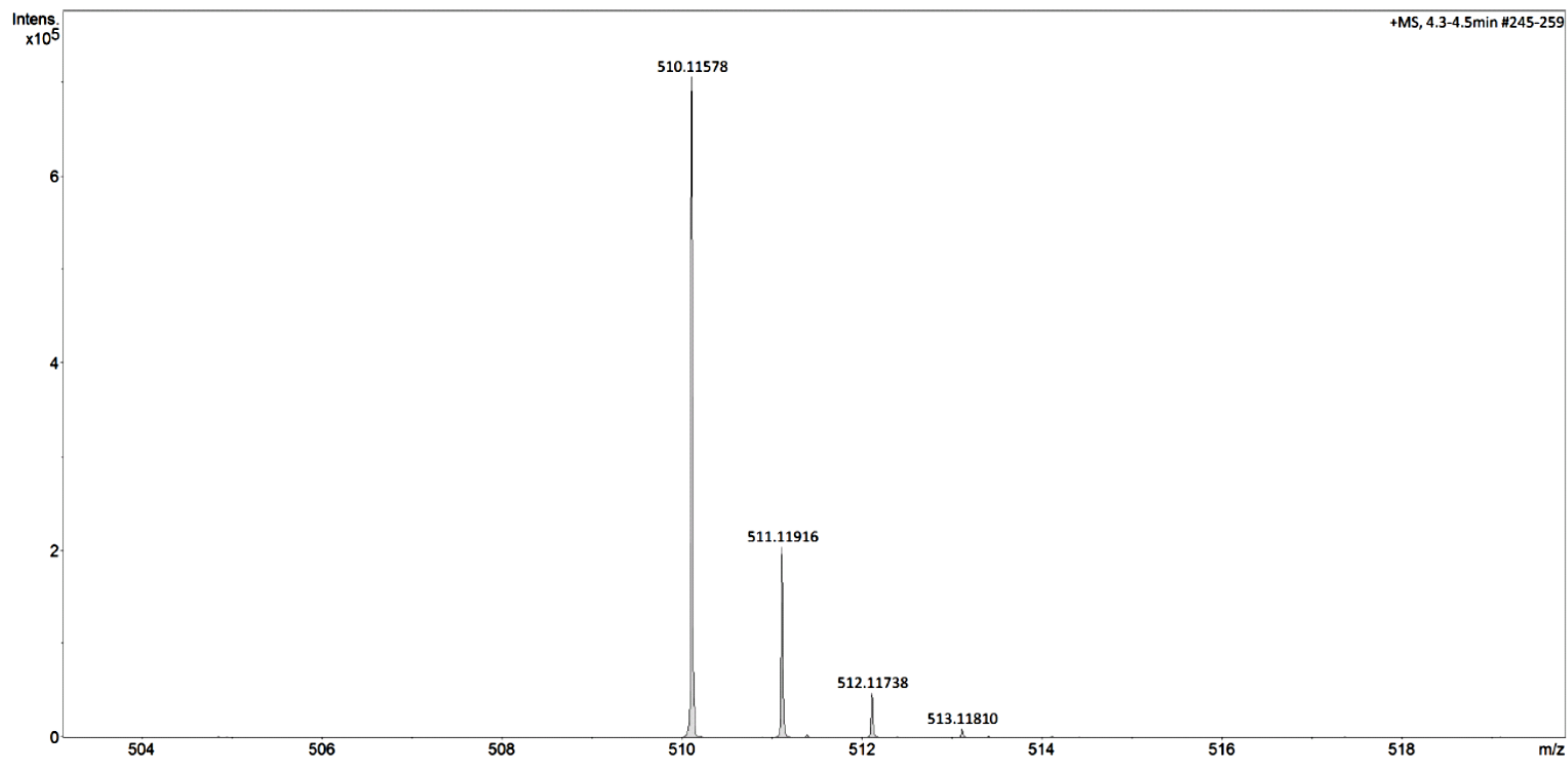

Figure S36: Section of the HRMS spectra of 6,6'-bis(4-fluorophenyl)-5-(4-(methylsulfonyl)phenyl)hex-5-en1-yl nitrate (4d) 


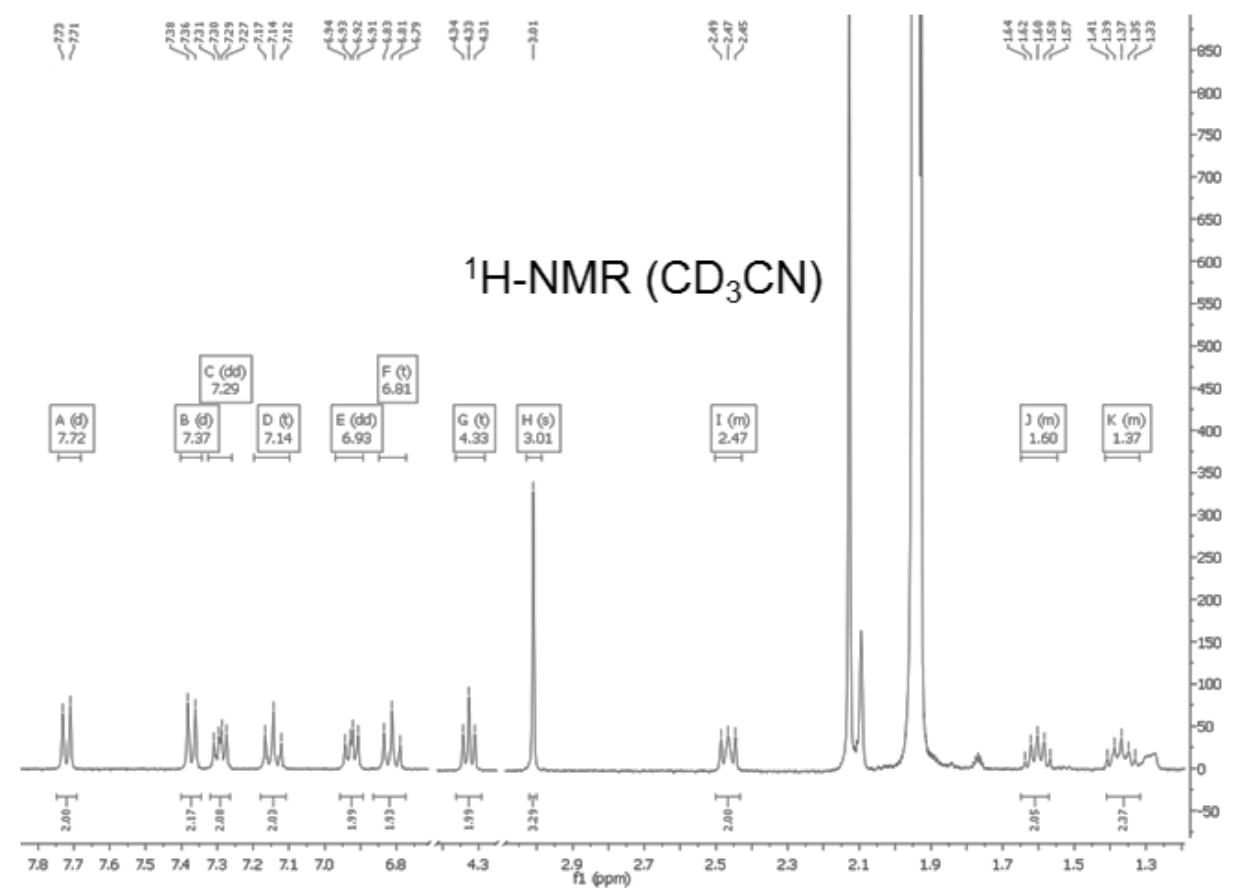

Figure S37: ${ }^{1} \mathrm{H}-\mathrm{NMR}$-spectra of 6,6'-bis(4-fluorophenyl)-5-(4-(methylsulfonyl)phenyl)hex-5-en-1-yl nitrate (4d) 

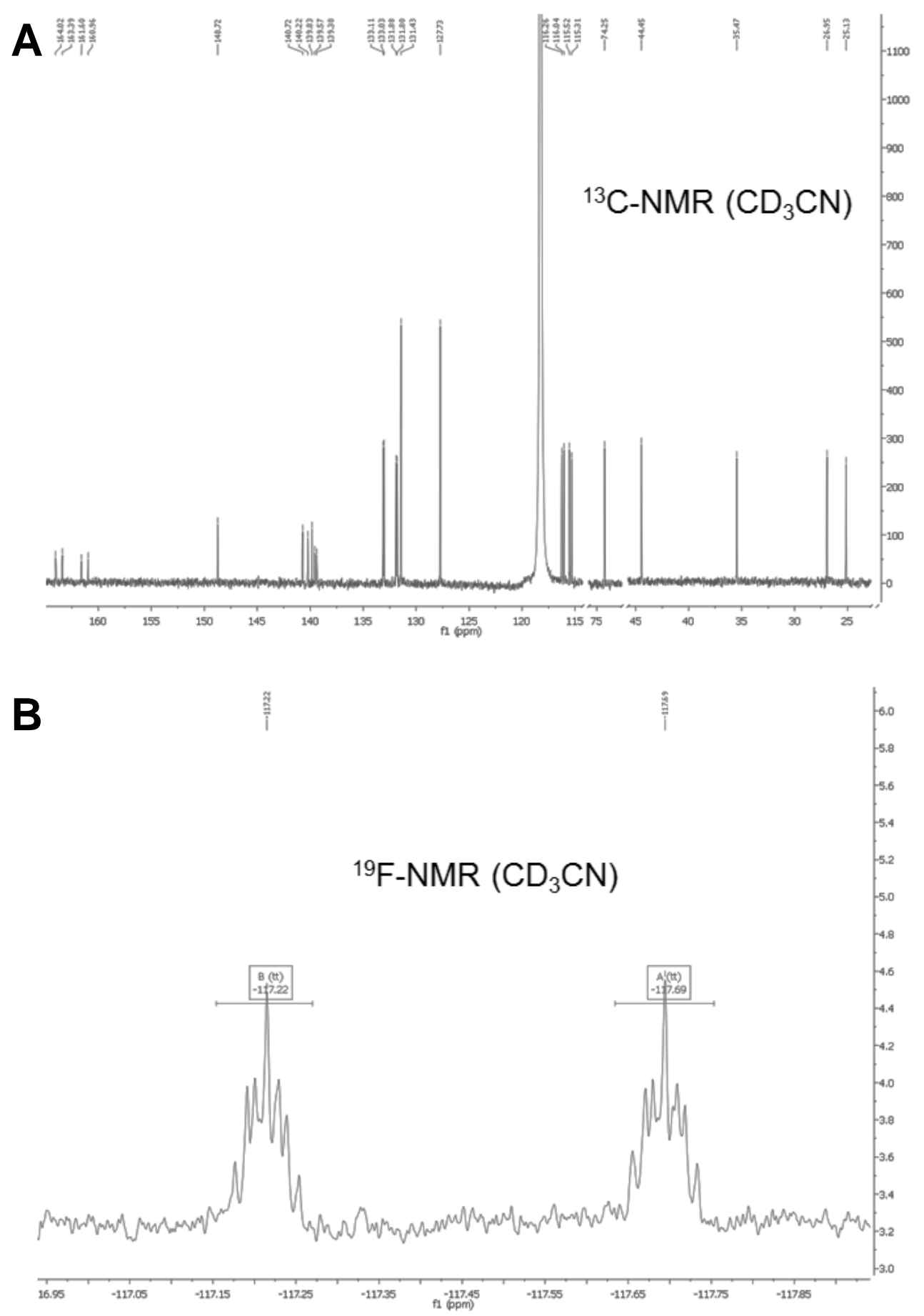

Figure S38: (A) ${ }^{13} \mathrm{C}$ - and (B) ${ }^{19} \mathrm{~F}$-NMR -spectra of 6,6'-bis(4-fluorophenyl)-5-(4-(methylsulfonyl)phenyl)hex5-en-1-yl nitrate (4d) 


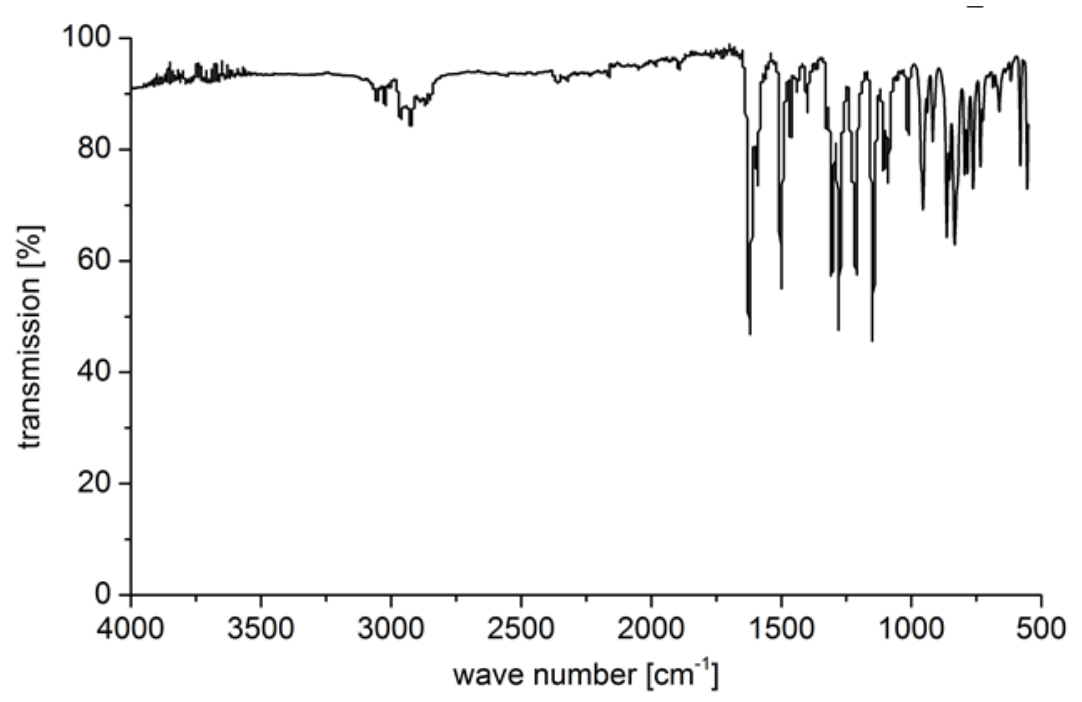

Figure S39: IR-spectra of 6,6'-bis(4-fluorophenyl)-5-(4-(methylsulfonyl)phenyl)hex-5-en-1-yl nitrate (4d)

\section{4-(4-(methylsulfonyl)phenyl)-5,5-diphenylpent-4-en-1-ol (5a)}

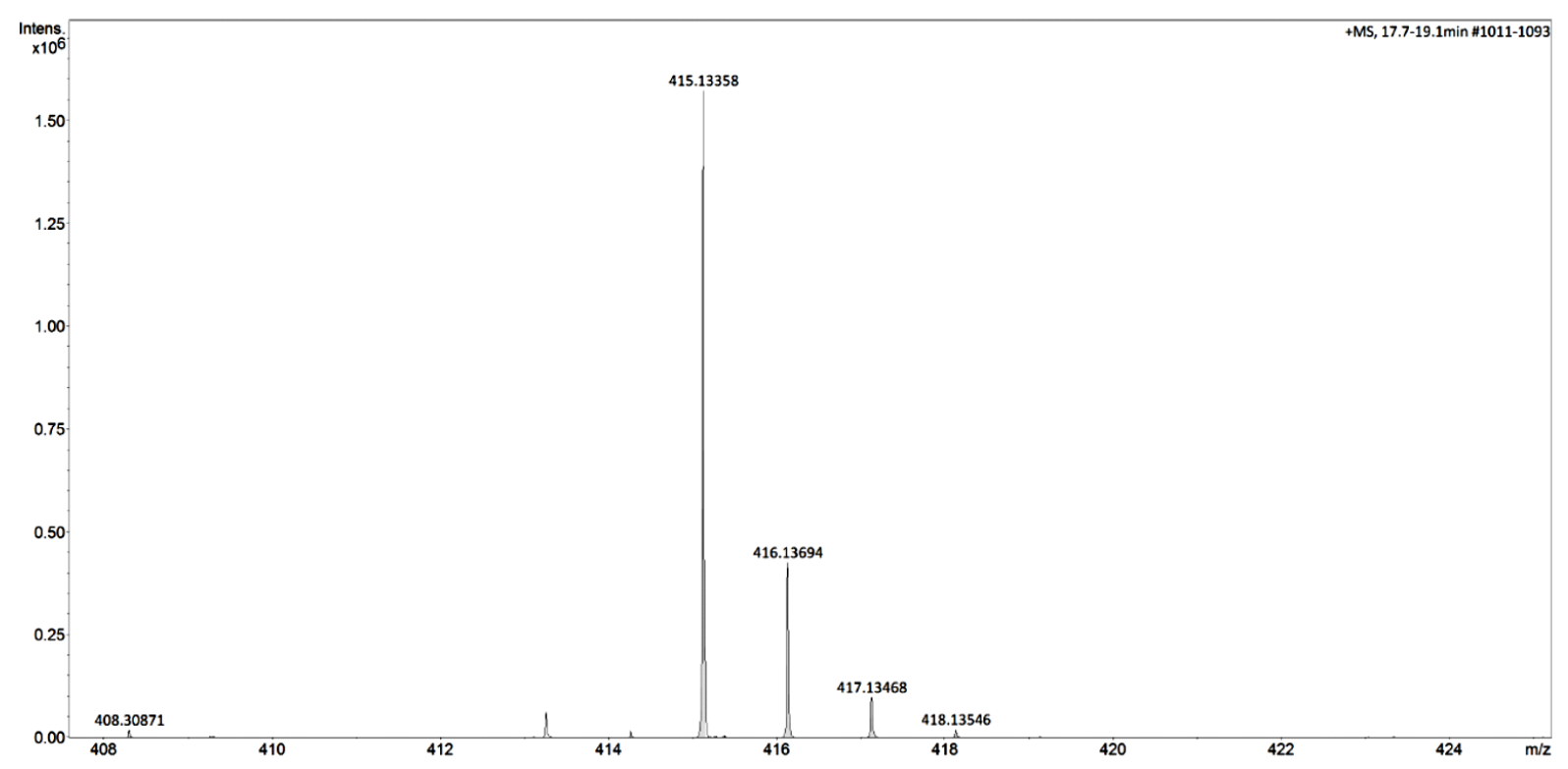

Figure S40: Section of the HRMS spectra of 4-(4-(methylsulfonyl)phenyl)-5,5-diphenylpent-4-en-1-ol (5a) 


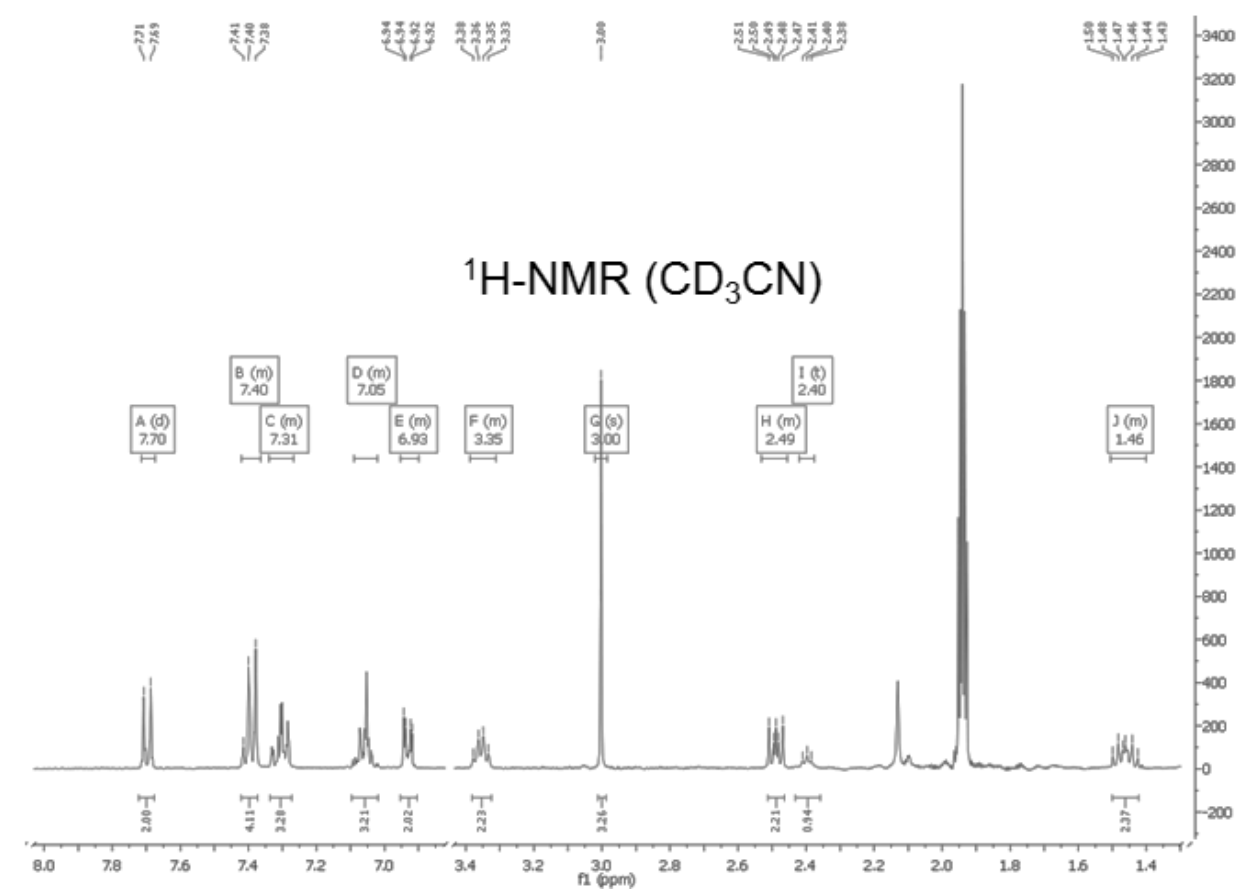

Figure S41: ${ }^{1} \mathrm{H}-\mathrm{NMR}$-spectra of 4-(4-(methylsulfonyl)phenyl)-5,5-diphenylpent-4-en-1-ol (5a)

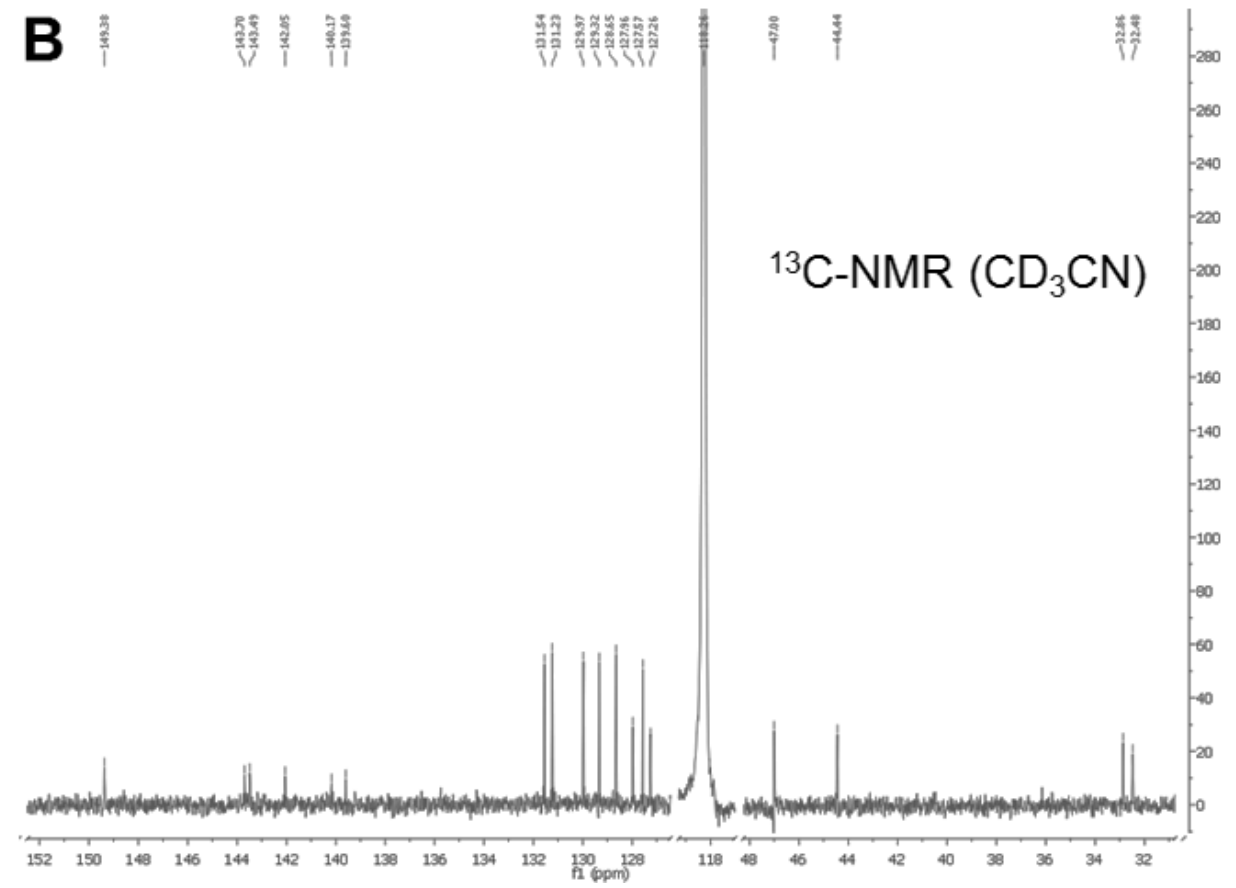

Figure S42: ${ }^{13}$ C-NMR-spectra of 4-(4-(methylsulfonyl)phenyl)-5,5-diphenylpent-4-en-1-ol (5a) 


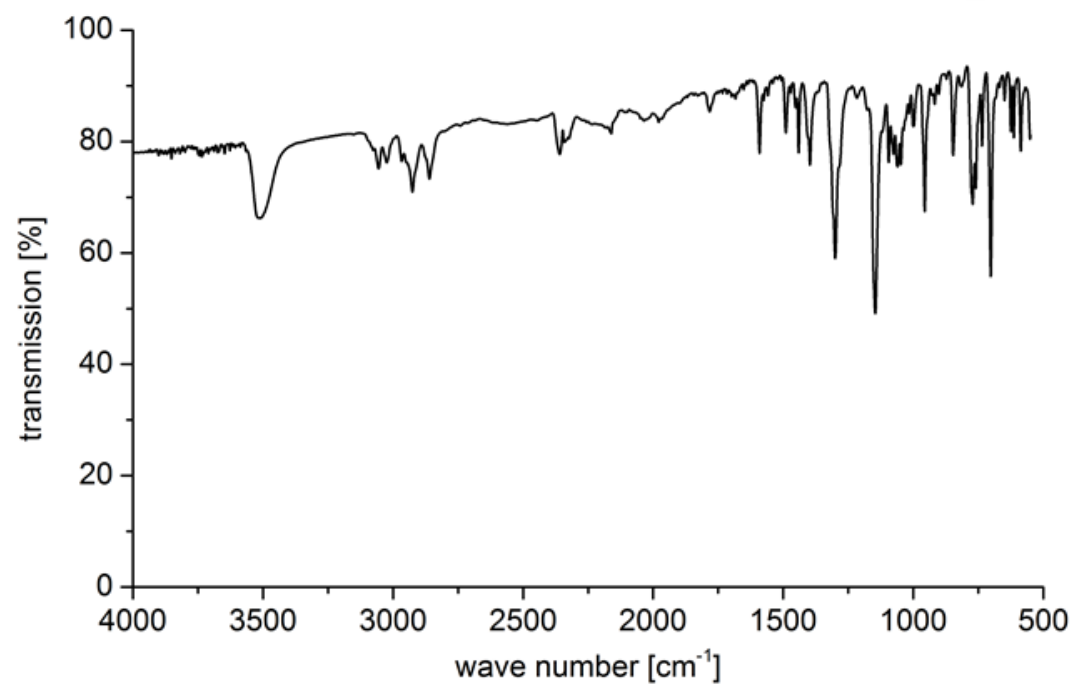

Figure S43: IR-spectra of 4-(4-(methylsulfonyl)phenyl)-5,5-diphenylpent-4-en-1-ol (5a)

\section{5,5'-bis(4-fluorophenyl)-4-(4-methylsulfonyl)phenyl)pent-4-en-1-ol (5b)}

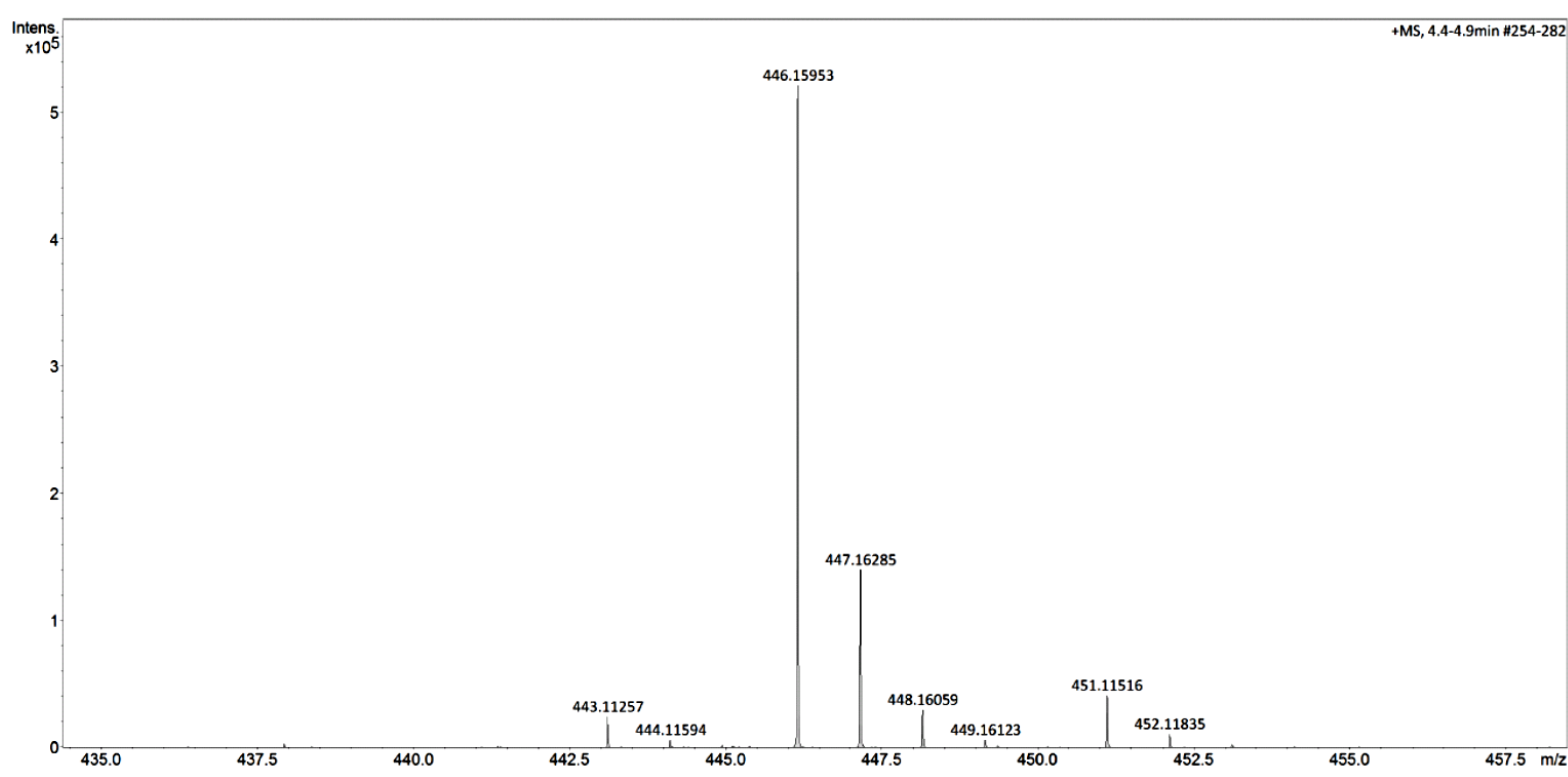

Figure S44: Section of the HRMS spectra of 5,5'-bis(4-fluorophenyl)-4-(4-methylsulfonyl)phenyl)pent-4-en1 -ol (5b) 

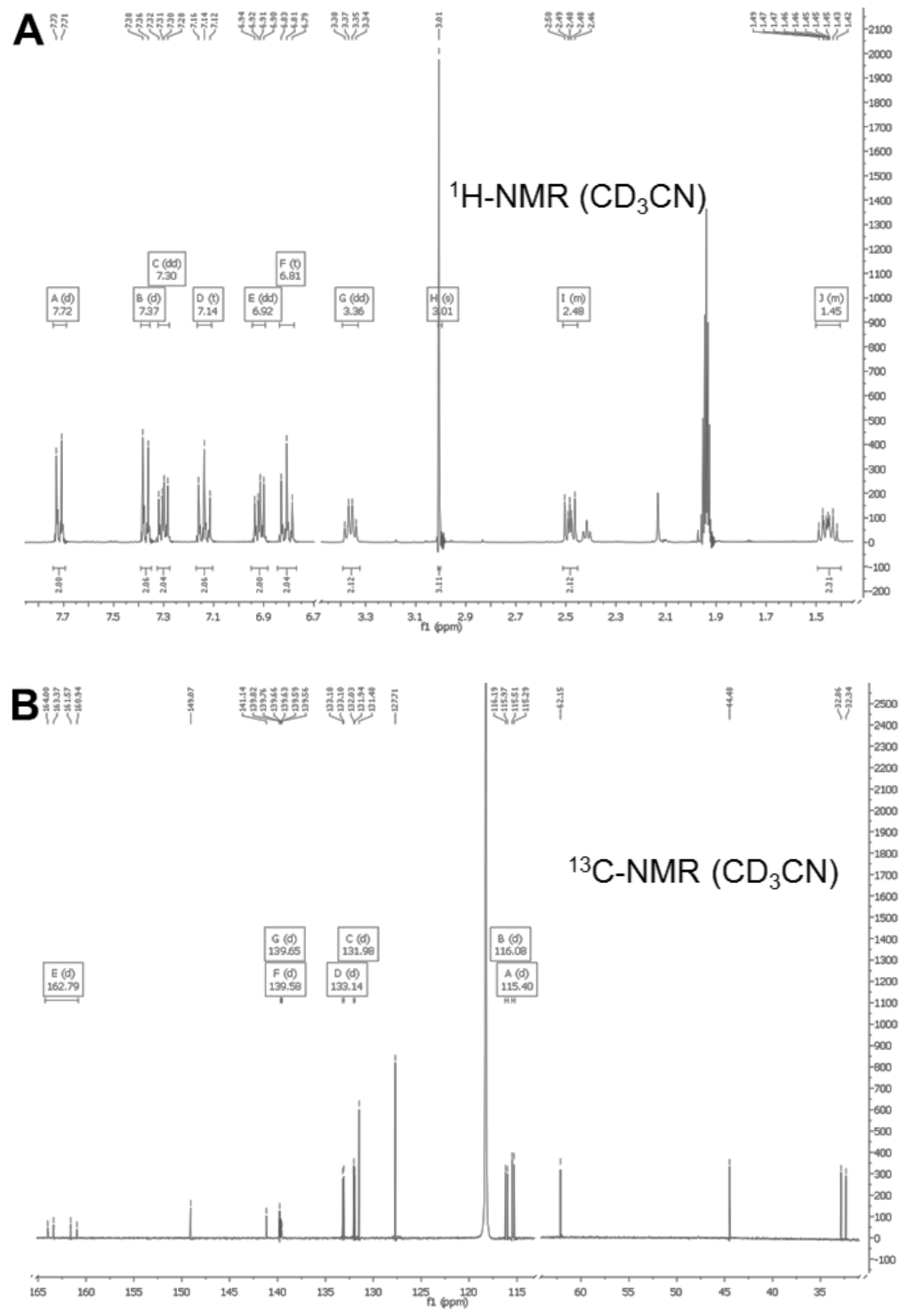

Figure S45: (A) ${ }^{1} \mathrm{H}$ - and (B) ${ }^{13} \mathrm{C}-\mathrm{NMR}$-spectra of 5,5'-bis(4-fluorophenyl)-4-(4-methylsulfonyl)phenyl)pent-4en-1-ol (5b) 


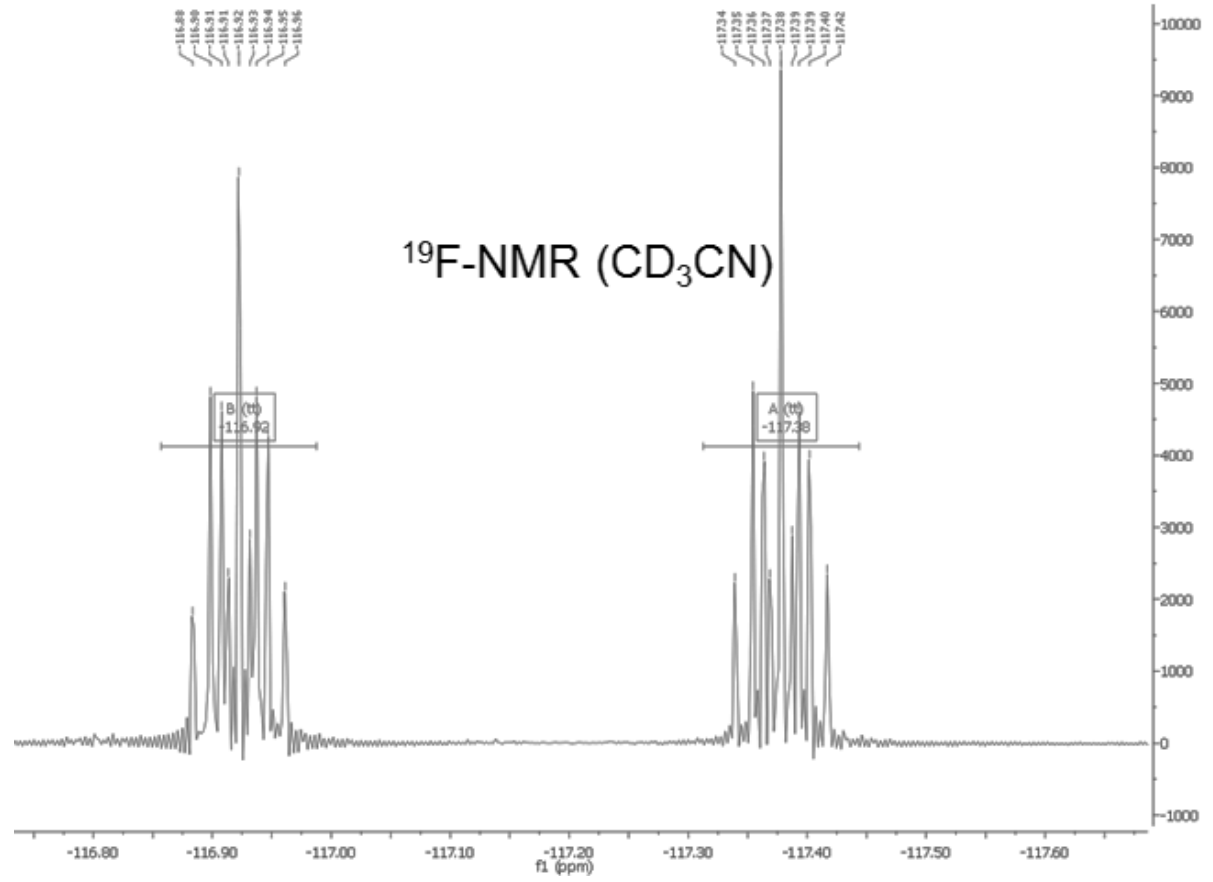

Figure S46: ${ }^{19} \mathrm{~F}-\mathrm{NMR}-\mathrm{spectra}$ of 5,5'-bis(4-fluorophenyl)-4-(4-methylsulfonyl)phenyl)pent-4-en-1-ol (5b)

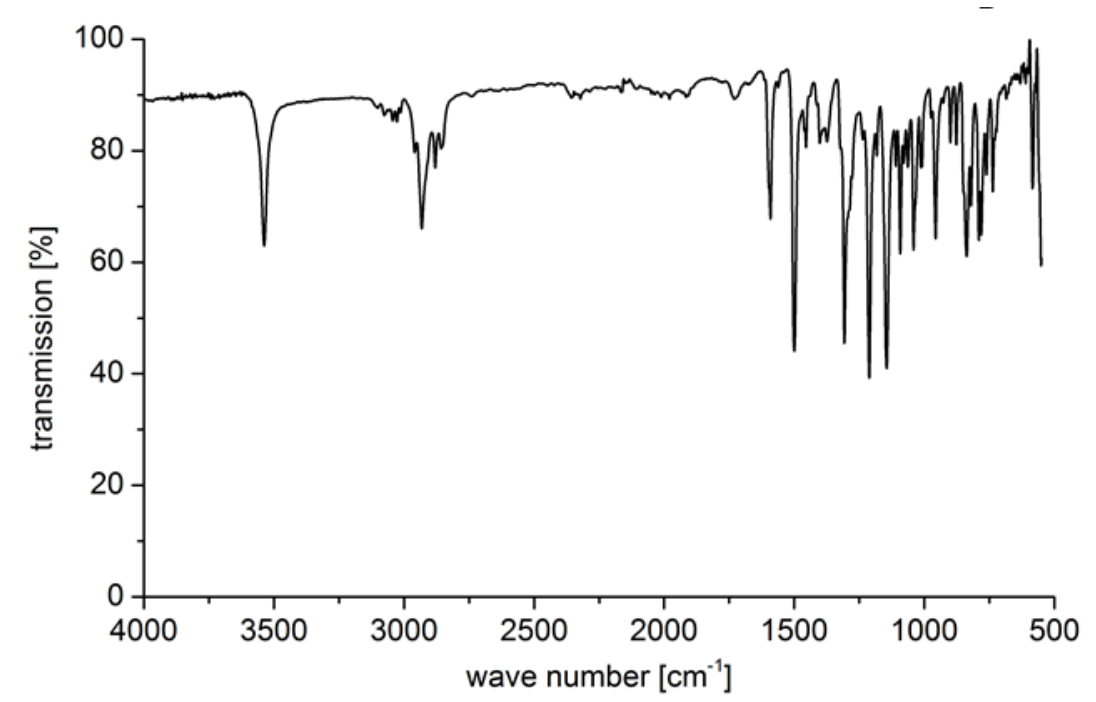

Figure S47: IR-spectra of 5,5'-bis(4-fluorophenyl)-4-(4-methylsulfonyl)phenyl)pent-4-en-1-ol (5b) 


\section{5-(4-(methylsulfonyl)phenyl)-6,6-diphenylhex-5-en-1-ol (5c)}

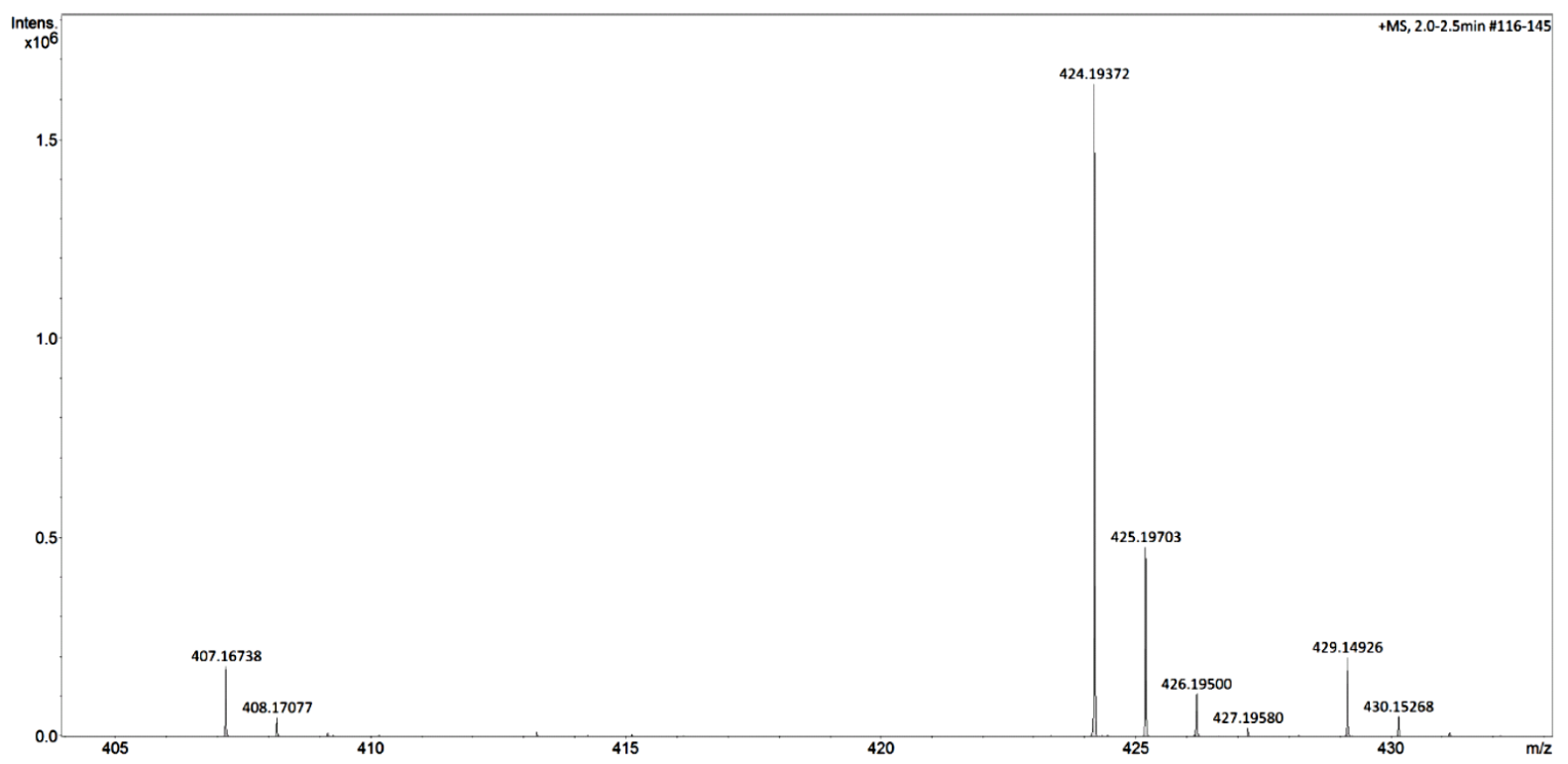

Figure S48: Section of the HRMS spectra of 5-(4-(methylsulfonyl)phenyl)-6,6-diphenylhex-5-en-1-ol (5c) 

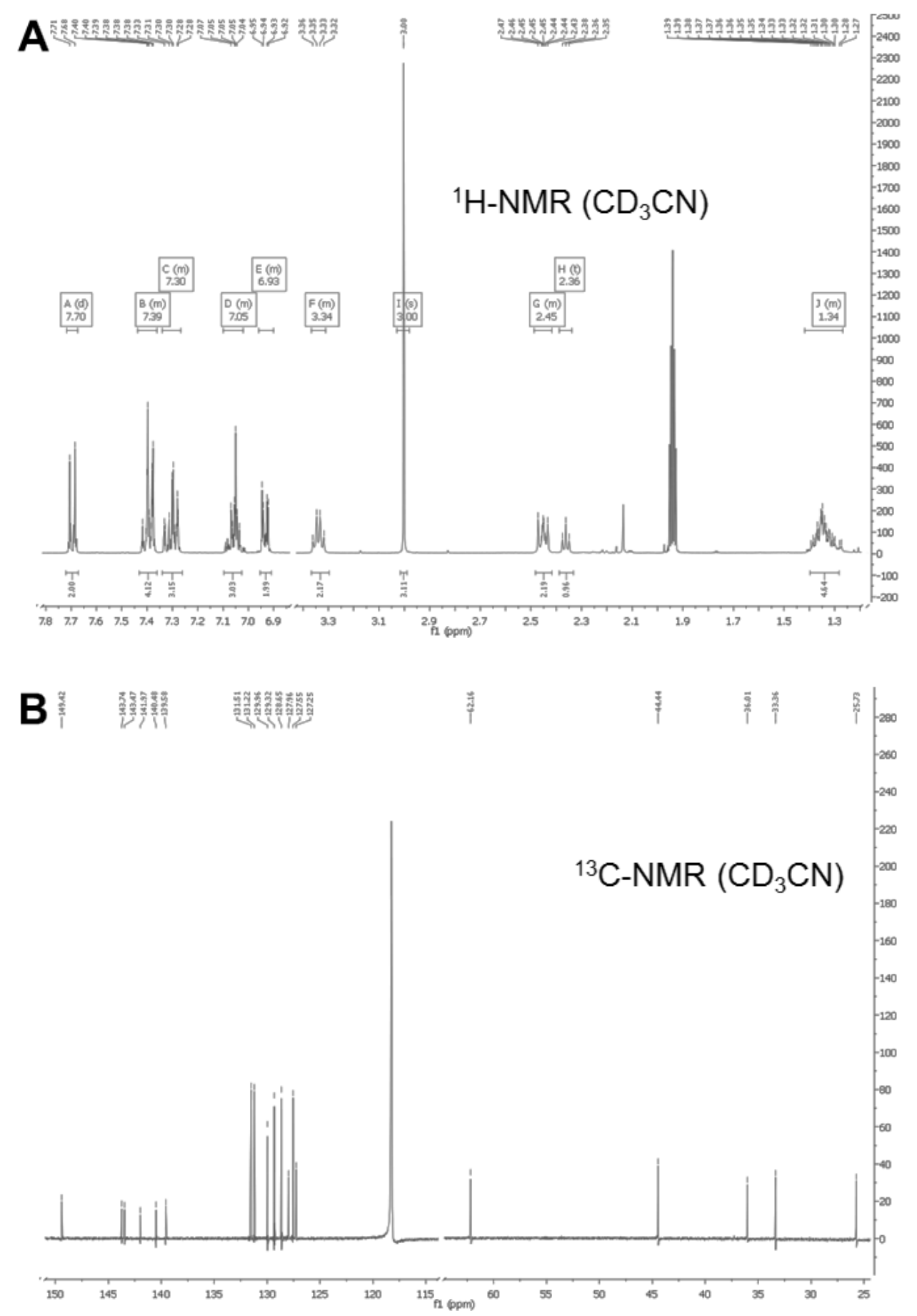

Figure S49: (A) ${ }^{1} \mathrm{H}$ - and (B) ${ }^{13} \mathrm{C}-\mathrm{NMR}$-spectra of 5-(4-(methylsulfonyl)phenyl)-6,6-diphenylhex-5-en-1-ol (5c) 


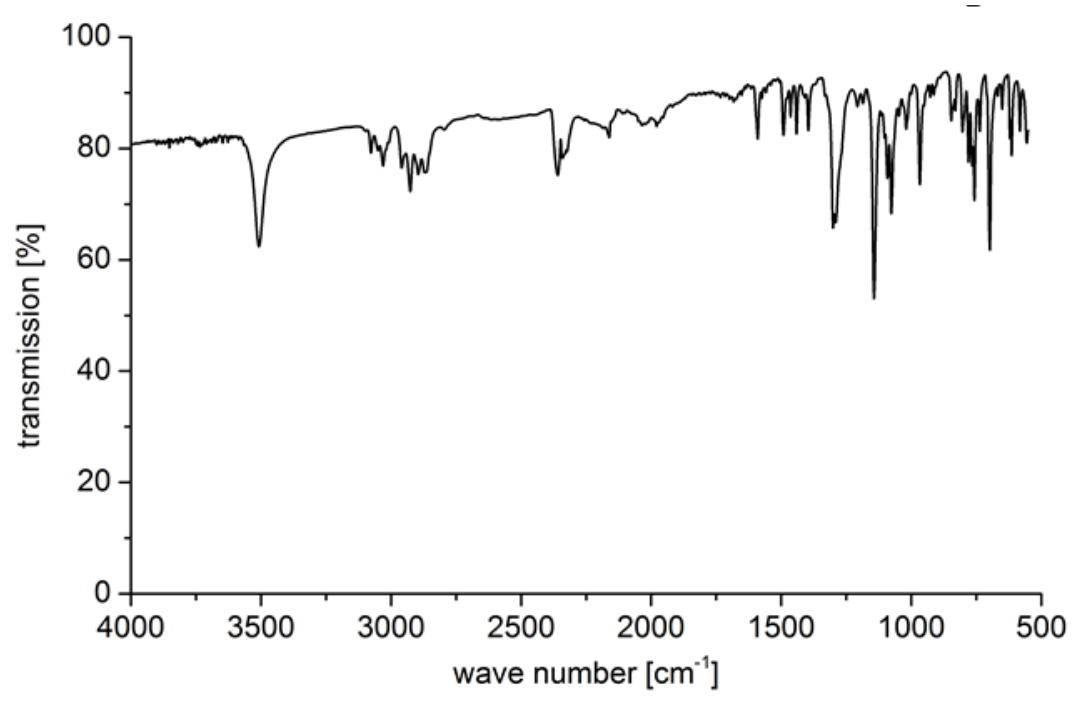

Figure S50: IR-spectra of 5-(4-(methylsulfonyl)phenyl)-6,6-diphenylhex-5-en-1-ol (5c)

\section{6,6'-bis(4-fluorophenyl)-5-(4-(methylsulfonyl)phenyl)hex-5-en-1-ol (5d)}

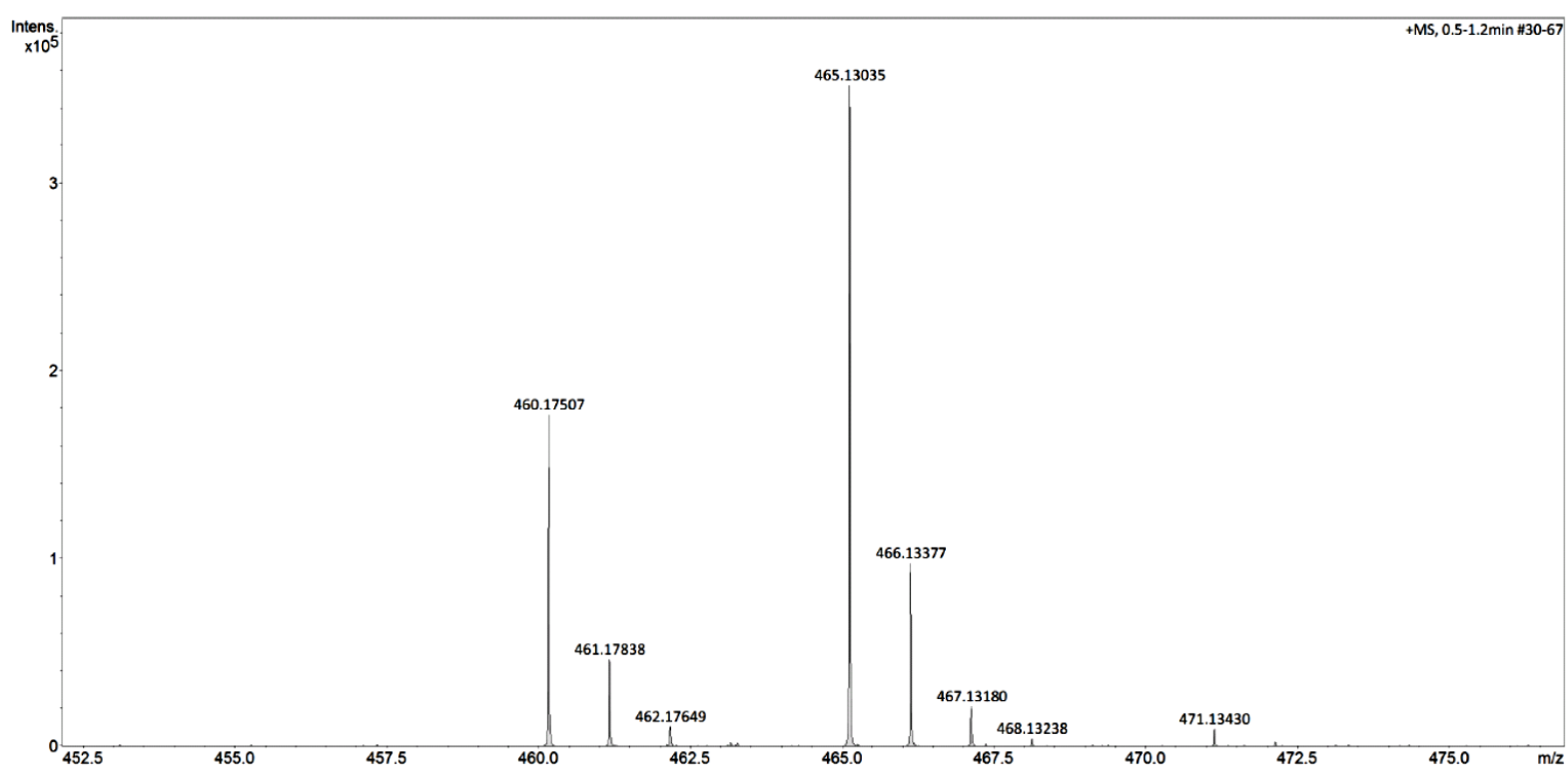

Figure S51: Section of the HRMS spectra of 6,6'-bis(4-fluorophenyl)-5-(4-(methylsulfonyl)phenyl)hex-5-en1-ol (5d) 


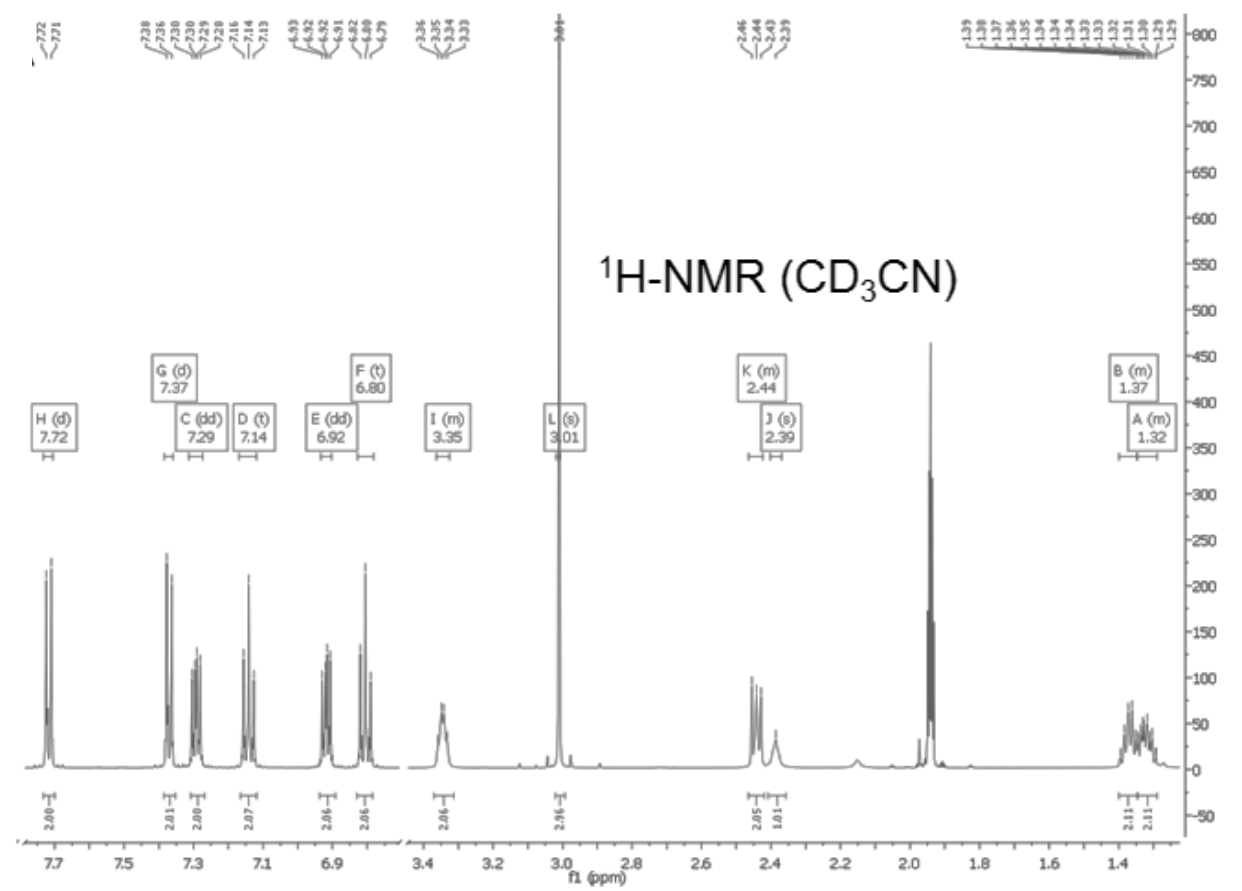

Figure S52: ${ }^{1} \mathrm{H}-\mathrm{NMR}$-spectra of 6,6'-bis(4-fluorophenyl)-5-(4-(methylsulfonyl)phenyl)hex-5-en-1-ol (5d) 

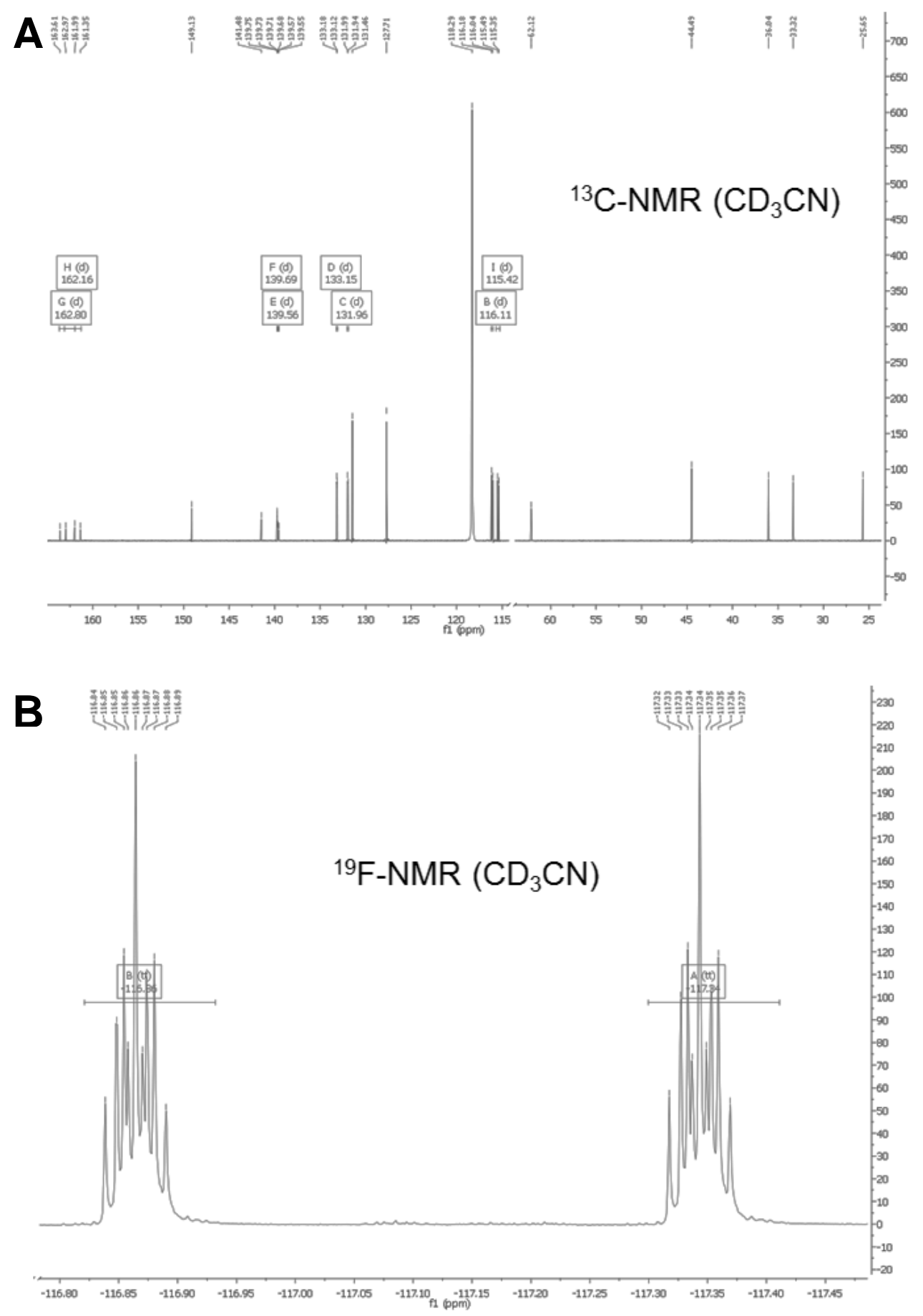

Figure S53: (A) ${ }^{13} \mathrm{C}$ - and (B) ${ }^{19} \mathrm{~F}-\mathrm{NMR}$-spectra of 6,6'-bis(4-fluorophenyl)-5-(4-(methylsulfonyl)phenyl)hex-5en-1-ol (5d) 


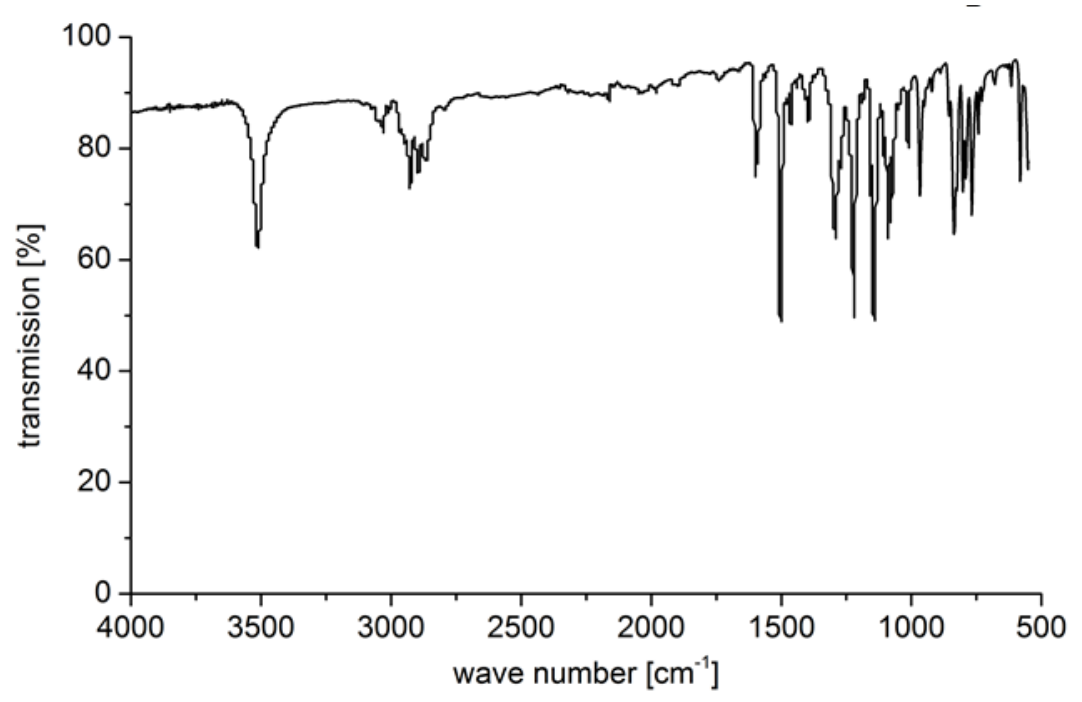

Figure S54: IR-spectra of 6,6'-bis(4-fluorophenyl)-5-(4-(methylsulfonyl)phenyl)hex-5-en-1-ol (5d)

\section{Characterization of reference compound 8}

\section{1-(4-(methylthio)phenyl)pentan-1-one (6)}

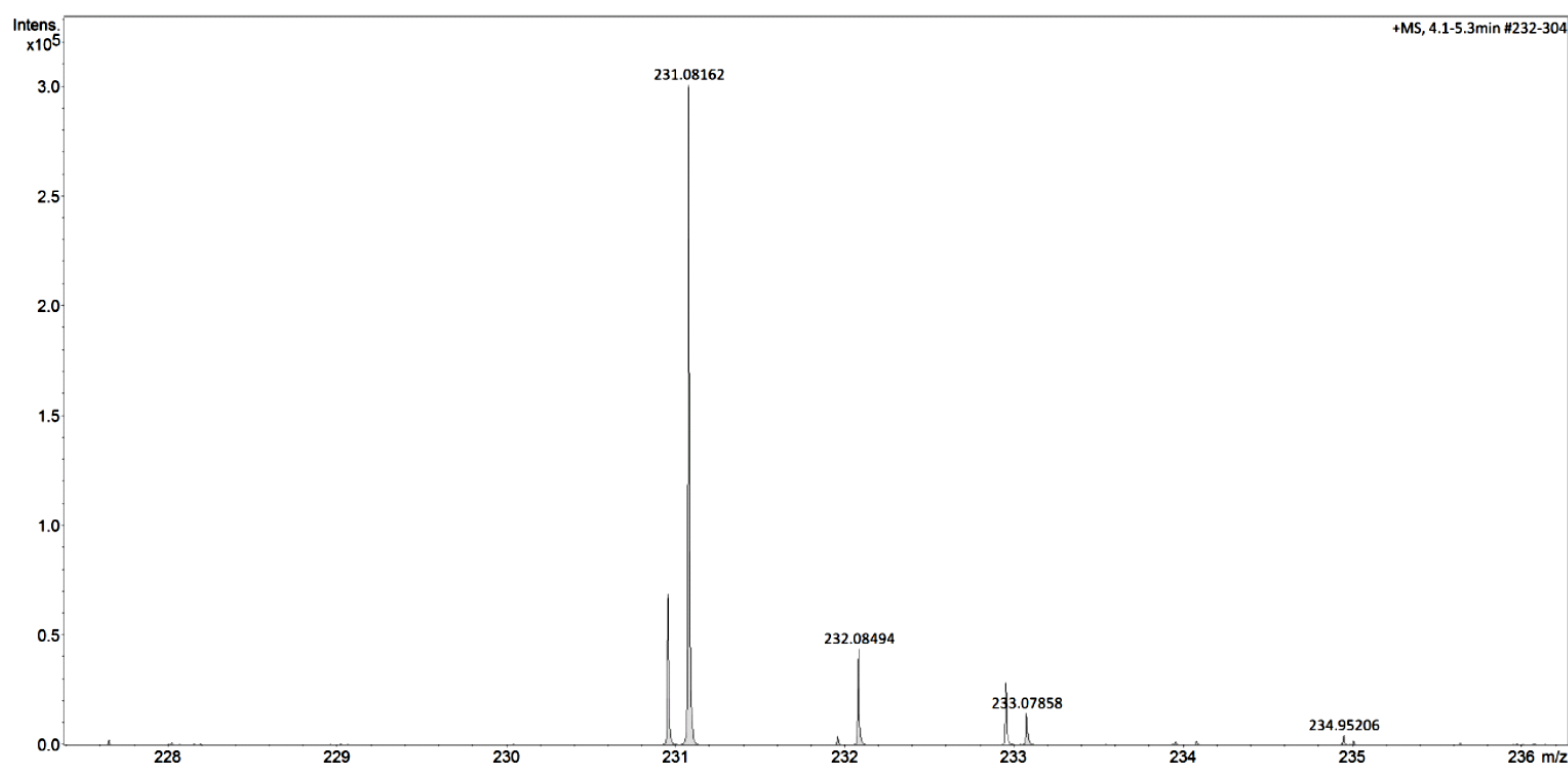

Figure S55: HRMS spectra of 1-(4-(methylthio)phenyl)pentan-1-one (6) 


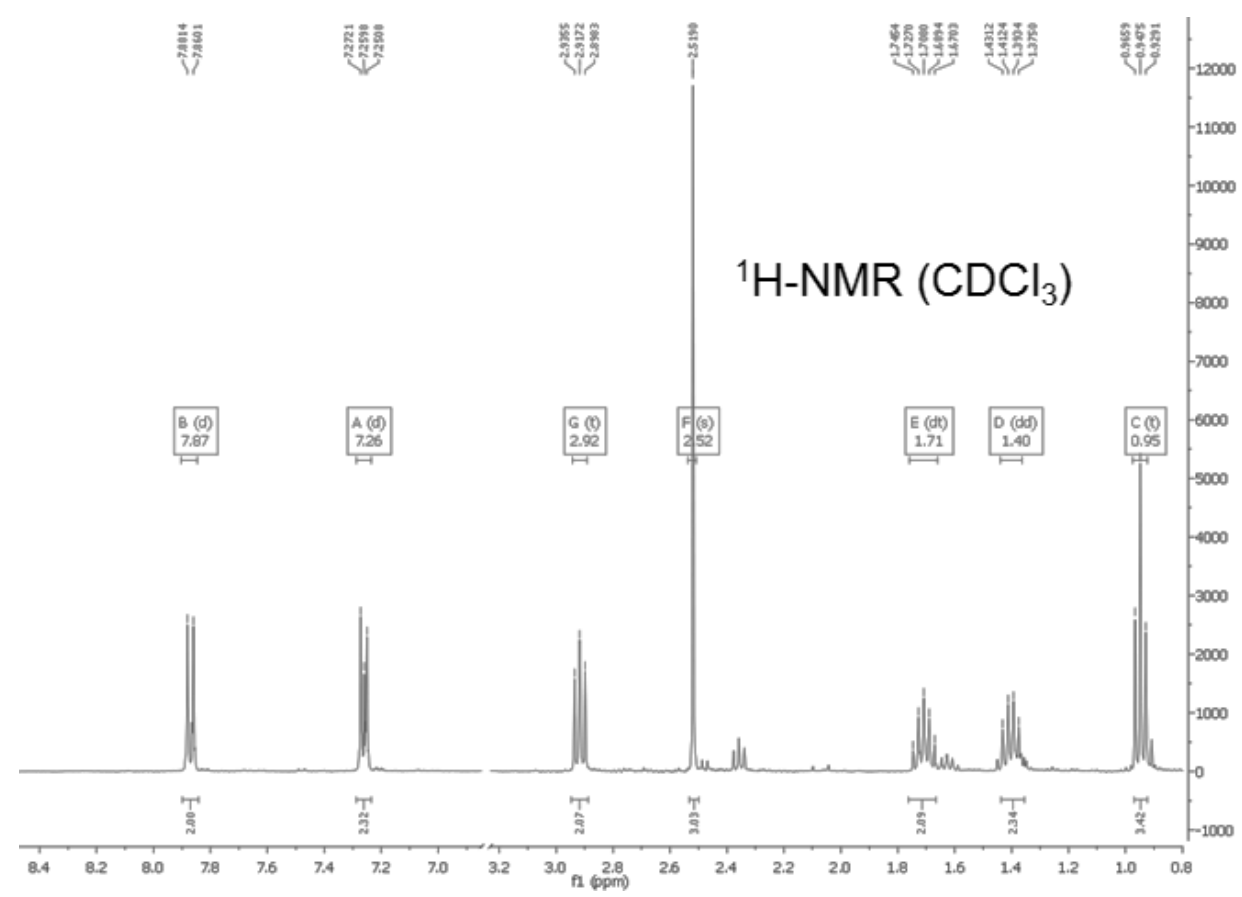

Figure S56: ${ }^{1} \mathrm{H}-$ spectra of 1-(4-(methylthio)phenyl)pentan-1-one (6)

\section{1-(4-(methylsulfonyl)phenyl)pentan-1-one (7)}

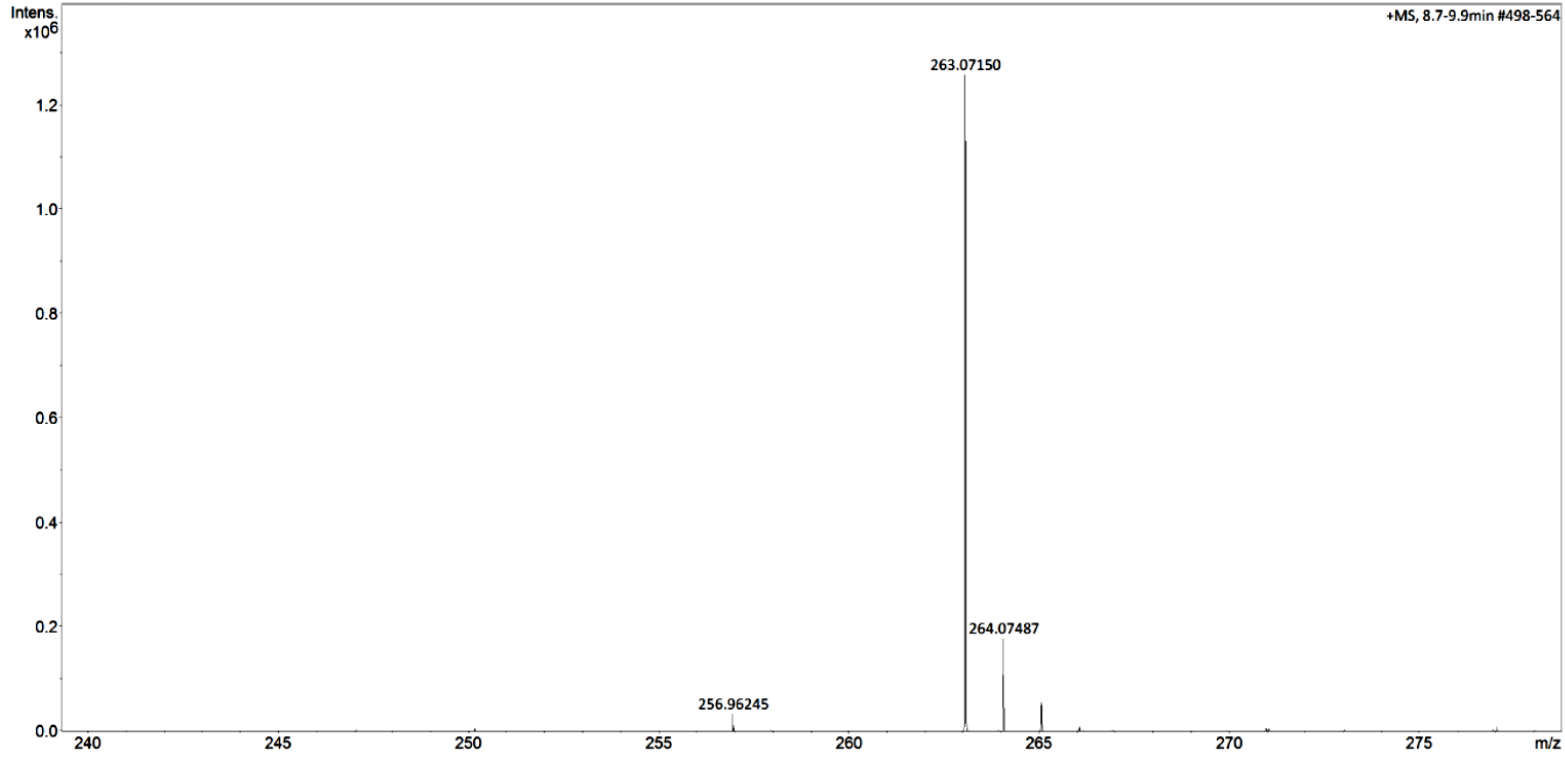

Figure S57: HRMS spectra of 1-(4-(methylsulfonyl)phenyl)pentan-1-one (7) 

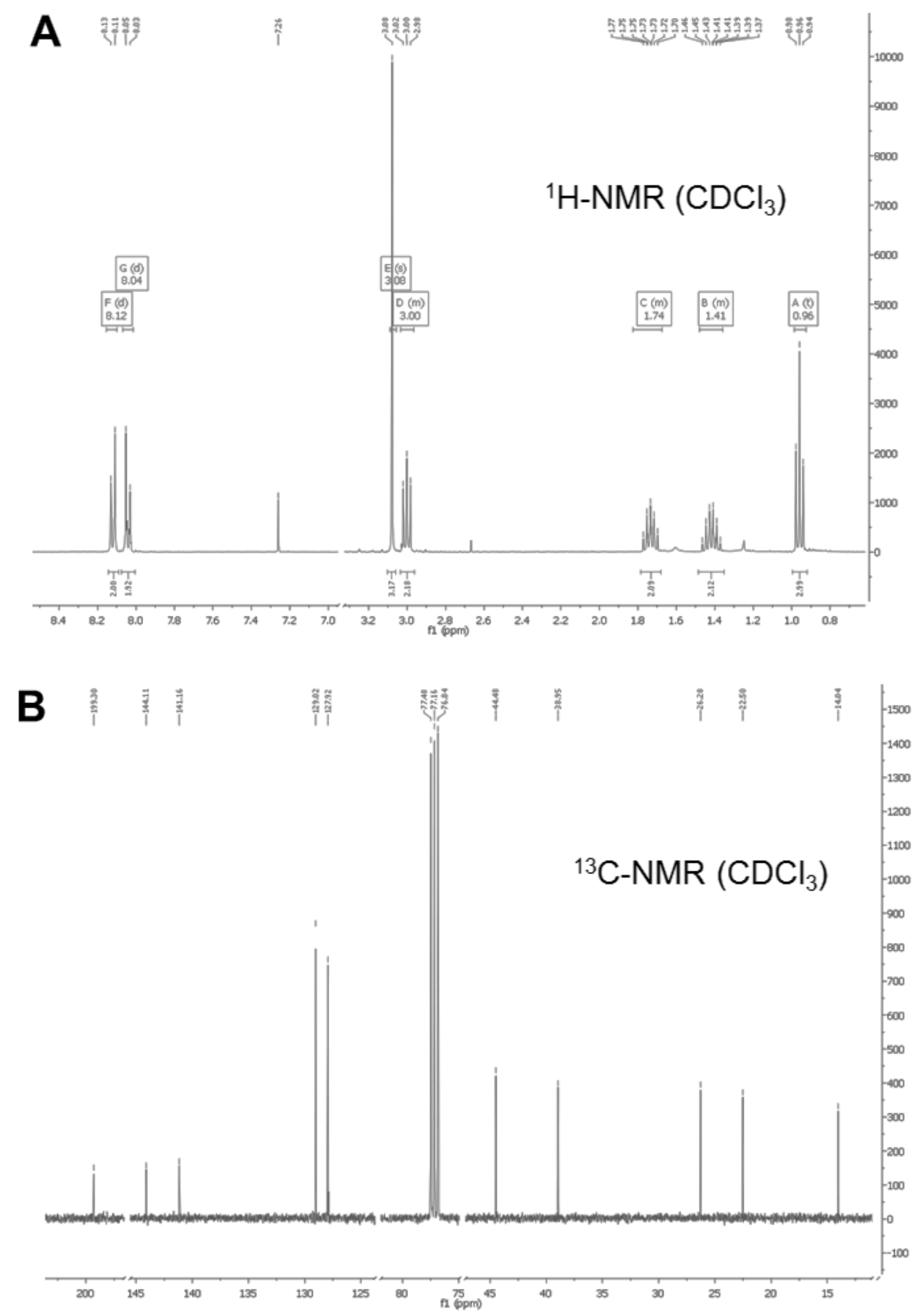

Figure S58: (A) ${ }^{1} \mathrm{H}$ - and (B) ${ }^{13} \mathrm{C}$-NMR-spectra of 1-(4-(methylsulfonyl)phenyl)pentan-1-one (7) 
4,4'-(2-(4-(methylsulfonyl)phenyl)hex-1-ene-1,1-diyl)bis(fluorobenzene) (8)

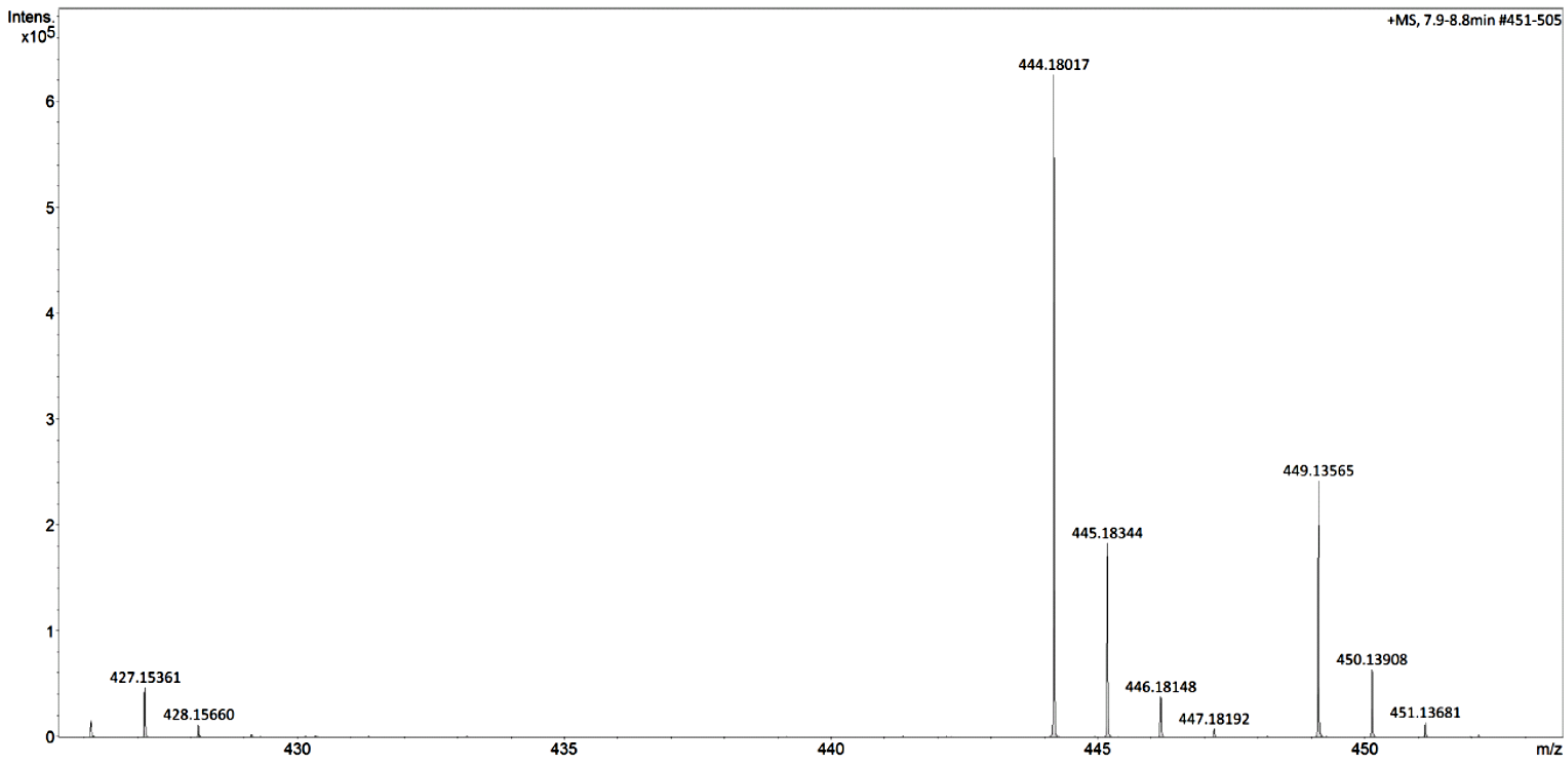

Figure S59: Section of the HRMS spectra of 4,4'-(2-(4-(methylsulfonyl)phenyl)hex-1-ene-1,1-diyl)bis(fluorobenzene) (8) 

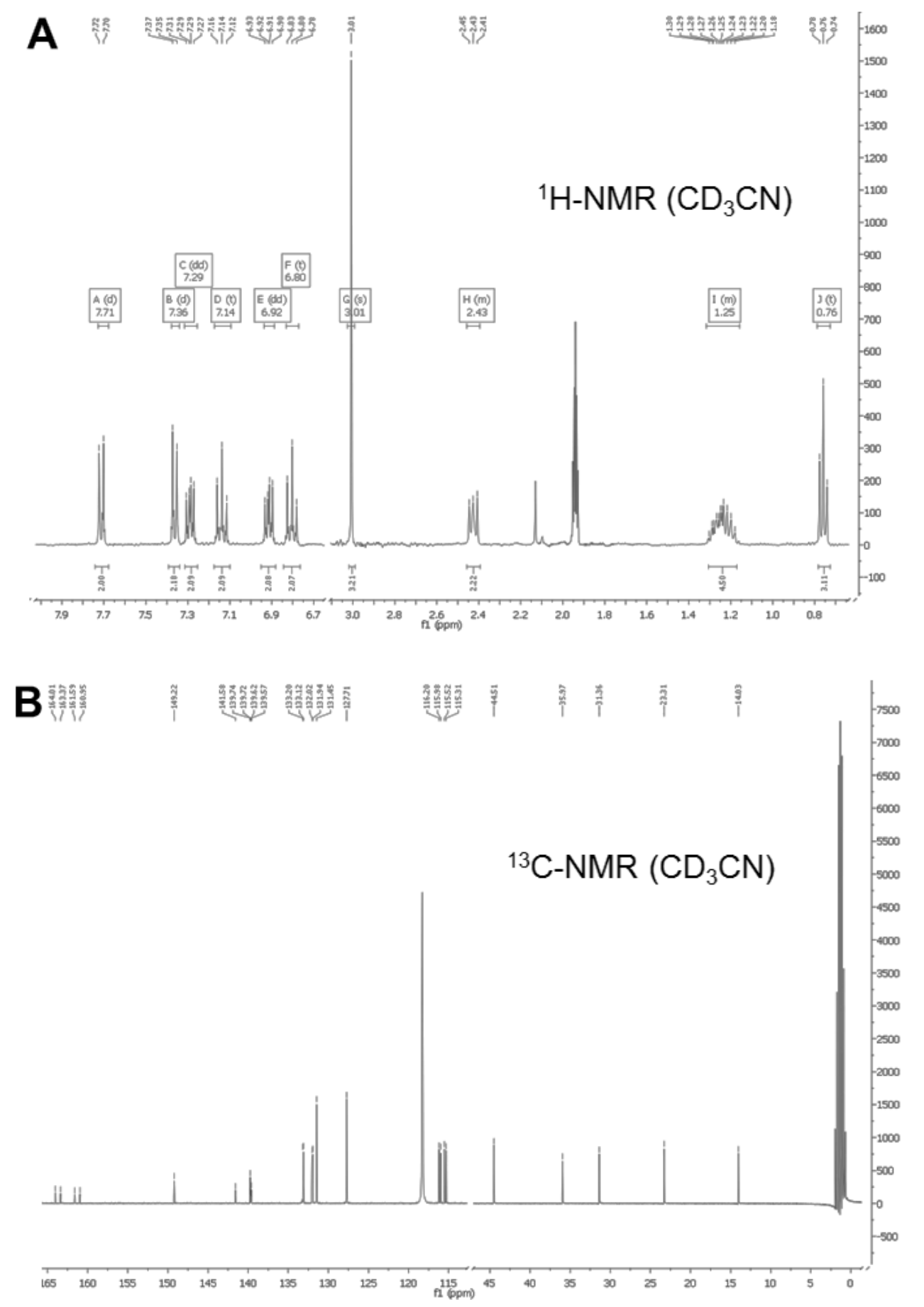

Figure S60: (A) ${ }^{1} \mathrm{H}$ - and (B) ${ }^{13} \mathrm{C}-\mathrm{NMR}$-spectra of 4,4 -(2-(4-(methylsulfonyl)phenyl)hex-1-ene-1,1diyl)bis(fluorobenzene) (8) 


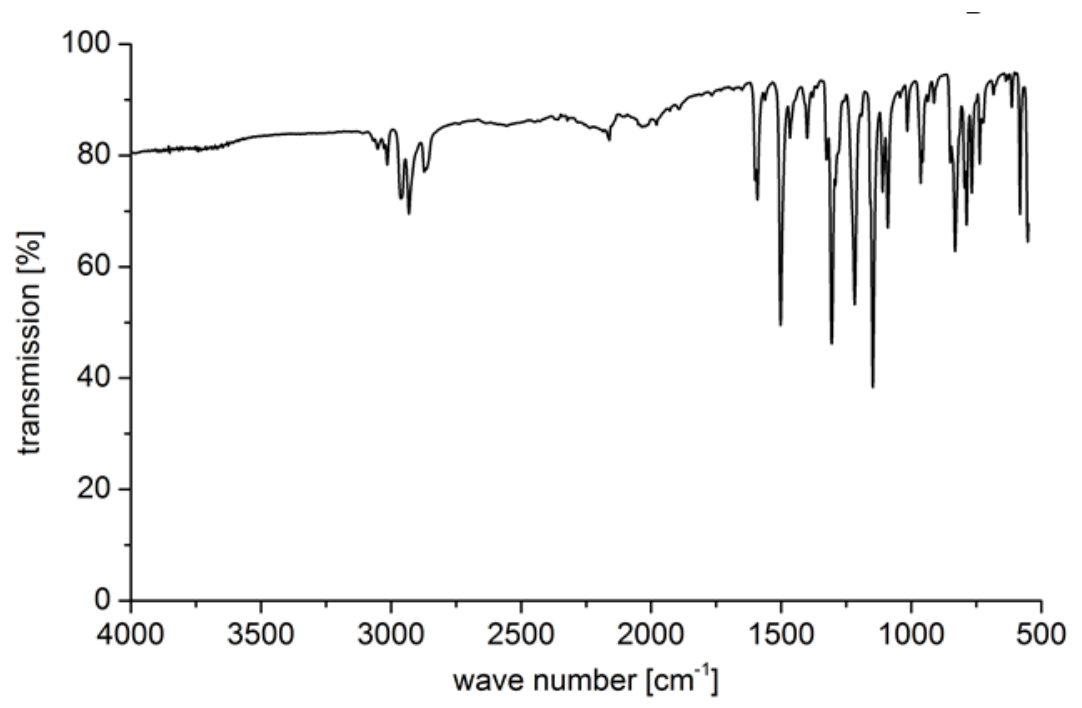

Figure S61: IR-spectra of 4,4'-(2-(4-(methylsulfonyl)phenyl)hex-1-ene-1,1-diyl)bis(fluorobenzene) (8)

\section{Reference}

1. Hydroxyarylketones via Ring-Opening of Lactones with Aryllithium Reagents: An Expedient Synthesis of ( \pm )-Anabasamine. Hydroxyarylketones via Ring-Opening of Lactones with Aryllithium Reagents: An Expedient Synthesis of (t)-Anabasamine. Synthesis, 2010, 91-97.

2. K. R. Abdellatif, C. A. Velázquez, Z. Huang, M. A. Chowdhury and E. E. Knaus. Triaryl Z-Olefins Suitable for Radiolabeling with Carbon-11 or Fluorine-18 Radionuclides for Positron Emission Tomography Imaging of Cyclooxygenase-2 Expression in Pathological Disease. Bioorg. Med. Chem. Lett, 2010, 20, 5245-5250.

3. K. R. Abdellatif, C. A. Velázquez, Z. Huang, M. A. Chowdhury and E. E. Knaus. Triaryl Z-Olefins Suitable for Radiolabeling with lodine-124 or Fluorine-18 Radionuclides for Positron Emission Tomgraphy Imaging of Estrogen Positive Breast Tumors. Bioorg. Med. Chem. Lett, 2011, 21, 1195-1198.

4. M. J. Uddin, P. N. Praveen Rao, R. McDonald and E. E. Knaus. A New Class of Acyclic 2-Alkyl1,1,2-Triaryl (Z)-Olefins as Selective Cyclooxygenase-2 Inhibitors. J. Med. Chem., 2004, 47, 6108-6111.

5. M. J. Uddin, P. N. P. Rao and E. E. Knaus. Design and Synthesis of Acyclic Triaryl (Z)-Olefins: a Novel Class of Cyclooxygenase-2 (COX-2) Inhibitors. Bioorg. Med. Chem., 2004, 12, 59295940.

6. M. J. Uddin, P. N. P. Rao and E. E. Knaus. Design of Acyclic Triaryl Olefins: a New Class of Potent and Selective Cyclooxygenase-2 (COX-2) Inhibitors. Bioorg. Med. Chem. Lett., 2004, 14, 1953-1956.

7. X. Y. Chen, S. J. Park, H. Buschmann, M. De Rosa and C. Bolm. Syntheses and Biological Activities of Sulfoximine-based Acyclic Triaryl Olefins. Bioorg. Med. Chem. Lett., 2012, 22, 4307-4309.

8. N. Bechmann, T. Kniess, M. Köckerling, A. Pigorsch, J. Steinbach and J. Pietzsch. Novel (Pyrazolyl)benzenesulfonamides with a Nitric Oxide-releasing Moiety as Selective Cyclooxygenase-2 Inhibitors. Bioorg. Med. Chem. Lett., 2015, 25, 3295-3300. 